\title{
Science Tools to Implement Ecosystem Based Management in Massachusetts
}

June 10, 2009

Prepared by:

MRAG Americas, Incorporated and The Massachusetts Ocean Partnership

With:

The Woods Hole Oceanographic Institute and UMass Boston

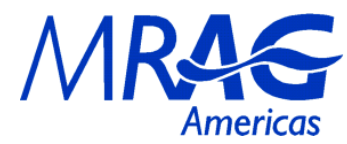


This report was developed by MRAG Americas, Inc. with primary contributions from Andrew Rosenberg, University of New Hampshire; Robert O'Boyle, Beta Scientific Consulting; Suzanne ludicello, Junkyard Dogfish Consulting; Jill Swasey and Jennie Harrington, MRAG Americas; and Karen McLeod, COMPASS.

Additional contributions regarding socioeconomic methods and decision support tools (in the primary report and Appendix D) were provided by Porter Hoagland, Di Jin, and Hauke L. Kite-Powell, Woods Hole Oceanographic Institute, and Jack Wiggin, John Duff, Dave Terkla, and Bob Bowen, University of Massachusetts at Boston. Bowen also developed the indicator framework provided in Appendix C. Hassan Moustahfid, Rutgers University, and Emily Klein, University of New Hampshire, provided contributions on natural scientific models, and Peter Bixby served as the technical editor to this report. Nicholas Napoli of the Massachusetts Ocean Partnership provided support and guidance throughout the development of the report. 


\section{Table of Contents}

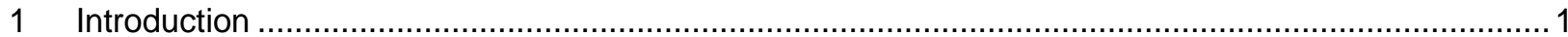

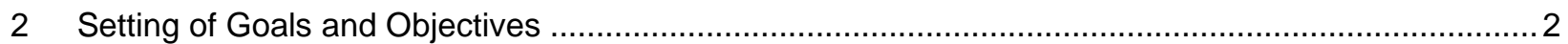

2.1 Using Science Tools to Advance Marine Ecosystem Based Management ................................ 4

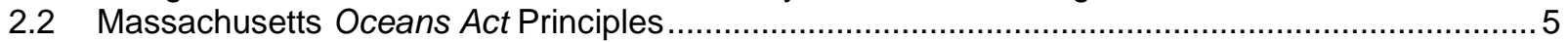

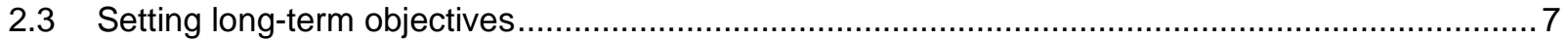

2.3.1 Identify ecosystem services and goals for conservation ................................................ 7

2.3.2 Identify key components of ecosystem and human activities .......................................... 9

2.3.3 Identify interactions among ecosystem components and activities ..................................10

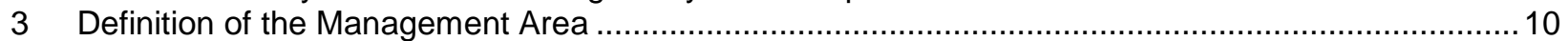

3.1 Identify potential connections to both smaller and larger scales ............................................. 11

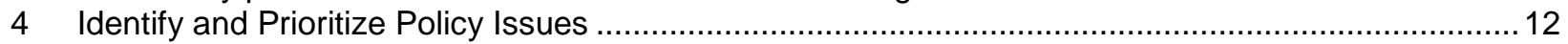

4.1 Undertake a description of the impacted ecosystem ............................................................ 13

4.2 Identification of priority ecosystem components for conservation ............................................ 15

4.3 Choose priority activities to be included in management plan .................................................16

4.4 Engage stakeholders to determine the scope of the array of issues that are of concern to the ocean community within management area................................................................................ 17

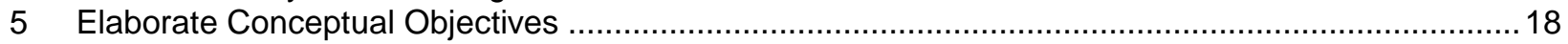

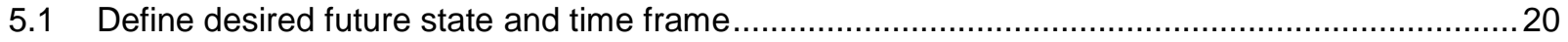

5.2 Link each Conceptual Objective to national, state and local policy ........................................23

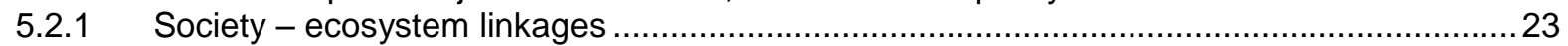

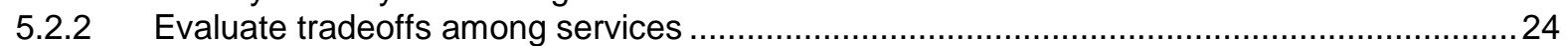

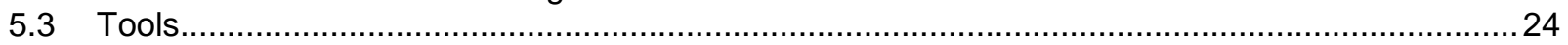

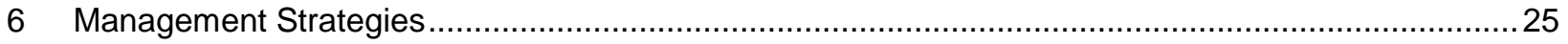

6.1 Identify Operational Objectives associated with each Conceptual Objective .............................26

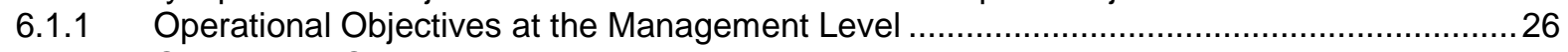

6.1.2 Operational Objectives at the Activity Level ................................................................26

6.1.3 Steps to Implement Operational Objectives ................................................................. 27

6.2 Identify Management Actions associated with Operational Objectives to address high priority

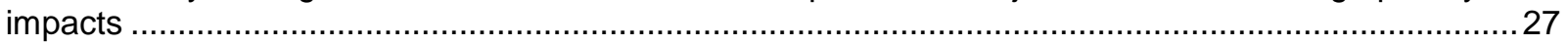

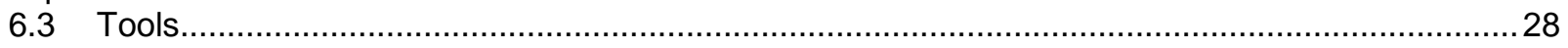

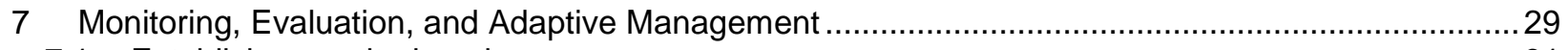

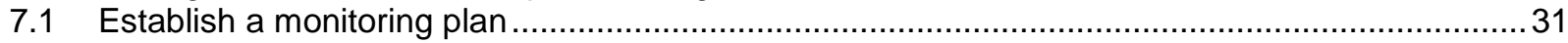

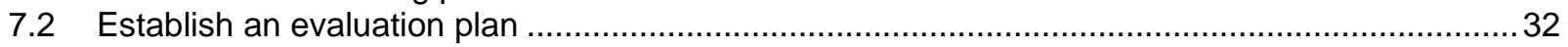

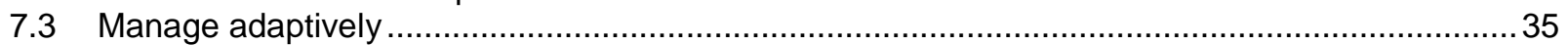

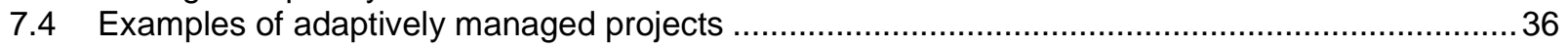

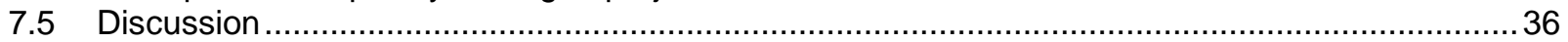

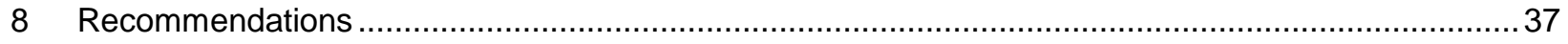

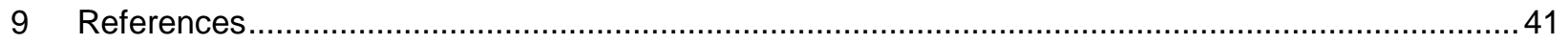




\section{Introduction}

Ecosystem based management (EBM) has developed in response to widespread declines in the state of marine ecosystems worldwide. Scientists have determined that $60 \%$ of ecosystem services globally have been degraded and that no part of the marine ecosystem remains unaffected by human impacts (Millennium Ecosystem Assessment, 2005; Halpern et al., 2008). In order to go beyond conventional policies that focus on a single sector or species in the ecosystem, coastal managers are increasingly adopting the EBM approach. EBM accounts for both ecological and socio-economic factors as well as their cumulative impacts on a management area. EBM provides for geographically specific, holistic resource management of habitats, species, and ecosystem level effects of resource use, such as food web impacts.

In accordance with the emergence of EBM, the state of Massachusetts (MA) signed the Oceans Act into law in May 2008 in order to develop a comprehensive integrated ocean management plan that will balance a full range of issues, including offshore renewable energy development, fishing, maritime shipping, recreation, and conservation. Principles of the plan require accounting for existing natural, social, cultural, historic, and economic characteristics of the planning areas; protecting the public trust; preserving the importance of coastal waters in citizen livelihoods; and valuing biodiversity and ecosystem health. The new law presents substantial opportunities and challenges for public policy and calls on public, private, and non-governmental organizations to collaborate and share resources. Concurrently, the Massachusetts Ocean Partnership is supporting the state's comprehensive ocean planning efforts, including the intent to integrate the best available science into management. The State of Massachusetts is making impressive strides by acknowledging that the status quo is not sufficient to conserve and manage vital marine ecosystem services that support human well-being and are at risk from a wide range of human activities. Other countries, including Australia, Canada, and the United Kingdom, have also recognized the insufficiency of sector-by-sector ocean management, and have begun implementing ecosystem based approaches (Rosenberg and Sandifer, 2009). EBM can be incorporated into existing management regimes as well as in newly developing management plans. Adopting a holistic approach to management in which the interactions and cumulative impacts across sectors of human activities are considered can fundamentally change how Massachusetts manages its resources and how the public values those resources.

Ecosystem based management addresses the full range of human use across sectors; its effectiveness and reliability require utilizing credible science, accounting for all user groups, and adapting to the changing needs of the environment and society (Leslie and McLeod, 2007), including current and proposed uses of the marine environment. However, managers must be careful to not go too far beyond the available data. If the physical or biological parameters for a particular model are not well defined, the results may be inaccurate (Mangel et al., 2001). The successful implementation of EBM will build upon the development of a common vision among stakeholders and require coordinated management at local, state, and federal levels. This will require that management be flexible and adaptive and acknowledge that trade-offs are unavoidable (Leslie and McLeod, 2007). Science will provide evidence to all users that healthy, productive, and resilient ecosystems are the key to providing the services people want and need.

Using the most current research and expertise in the field, we propose a framework of steps for the State and the Massachusetts Ocean Partnership to implement an EBM approach to Massachusetts ocean planning. The framework will facilitate decision making, enable thinking beyond issue boundaries, and recognize the breadth of issues and information types to be integrated. In brief, implementation involves the follow key steps: setting goals and objectives based on Massachusetts Oceans Act principles; defining the management area, identifying and prioritizing policy issues, elaborating the conceptual objectives that underlie stated policy principles, setting operational objectives for each conceptual objective, and instituting an evaluation and adaptive management process. For each step, we identify the types of scientific information needed for decision-making, summarize the goals and actions that should be included in ecosystem based management, and suggest natural- and social-scientific tools useful for informing decision making. While we discuss an array of decision support tools within the report, the tools 
discussed do not represent an exhaustive list. Appendices A, B, and C present a more detailed summary of available tools and applications. Because the choice and application of science tools (models, decision support tools and indicators) require appropriate benchmarks, EBM planning will involve rigorous scoping of the goals, objectives and activities of importance to the Commonwealth.

It is important to note that the provision of scientific advice for policy-making must be viewed as an ongoing, iterative and adaptive effort. That is, as new challenges, information, and issues come forward, the advice and tools employed must be updated or re-formulated in an ongoing manner. The application of scientific models or tools will depend on the available data, the managerial and public needs, and the changing set of issues confronting policy-makers.

In this report we provide a framework for implementing EBM and suggest a range of science information tools and their appropriate application to the decision making process. These tools can be broadly classified as modeling tools, decision analysis tools, and indicators. Modeling tools allow the user to organize data, communicate scientific findings to management and stakeholder audiences, and test alternative management scenarios. When used unwisely, however, models can preclude options, present unusable scenarios, generate results in scales that differ from management needs, and impose huge time, data, and technical requirements (Manno et al., 2008). Decision analysis tools can inform management decisions but should not be relied upon solely; they are valuable aids in the process and provide opportunities for all-stakeholder input, visualization, and scenario analysis. Indicators are scientific measurements of ecological or socio-economic phenomena that provide data for monitoring and evaluating the systems being managed. While indicators are by and large widely accepted, their selection is based on expert opinion and involves a level of subjectivity. Inappropriately selected indicators can misinform management decisions. By helping to identify and mitigate lack of information, these science tools can be of great value in the shift to ecosystem based management.

\section{Setting of Goals and Objectives}

Effective development of a framework for integrated ocean management must build on earlier successful approaches. Massachusetts stands apart through its landmark decision to enact statewide legislation for integrated management of the coasts and ocean for all users. The process to develop a framework for planning has begun and can be informed by similar efforts in other states, nationally and internationally.

In a report on available science and data gaps, Mooney-Seus points out that decision makers, scientists and interest groups in Massachusetts will need to agree on a definition and clearly define the goals of Ecosystem based management (EBM) (Mooney-Seus and Allen, 2007).

The following definition ${ }^{1}$ signed by more than 220 scientists and policy experts from academic institutions across the U.S., highlights current scientific understanding of marine ecosystems, explains how this knowledge shapes the call for a new management approach, and provides a definition for what the scientific community envisions when it recommends "ecosystem based management" for the oceans.

Ecosystem based management is an integrated approach to management that considers the entire ecosystem, including humans. The goal of ecosystem based management is to maintain an ecosystem in a healthy, productive and resilient condition so that it can provide the services humans want and need.

Ecosystem based management differs from current approaches that usually focus on a single species, sector, activity or concern; it considers the cumulative impacts of different sectors. Specifically, ecosystem based management:

\footnotetext{
${ }^{1}$ Scientific Consensus Statement on Marine Ecosystem based management developed by the Communication Partnership for Science and the Sea (COMPASS) in 2005. To see the full statement, go to: http://www.compassonline.org/pdf_files/EBM_Consensus Statement_v12.pdf.
} 
- emphasizes the protection of ecosystem structure, functioning, and key processes

- is place-based, focusing on a specific ecosystem and the range of activities affecting it

- explicitly accounts for the interconnectedness within systems, recognizing the importance of interactions between many target species or key services and other non-target species

- acknowledges interconnectedness among systems, such as between air, land and sea

- integrates ecological, social, economic, and institutional perspectives, recognizing their strong interdependences.

In the following discussion we adopt this definition and draw on lessons learned from the California Marine Life Protection Act (MLPA), Eastern Scotian Shelf Integrated Management (ESSIM) Initiative, and others. The MLPA is a comprehensive effort to manage California's marine and coastal resources through cooperation by all users and integration and coordination of multiple state agency programs and jurisdictions. The ESSIM is a prime example of the usefulness of stakeholder involvement in the development of a management plan.

A process for implementing EBM, based on a working group at the National Center for Ecological Analysis and Synthesis entitled "Science Frameworks for Ecosystem-Based Management", is given schematically in Figure 1. Each step in the process incorporates scientific data and information throughout. In this report we describe each step in greater detail and identify some of the tools and modeling approaches that can be used to inform the process.

Definition of the Management Area (Section 3)

- Based on ecological properties and jurisdictional boundaries

- Identify potential connections to smaller and larger scales

- MA Oceans Act Planning Area, MA Coastal Zone, Gulf of Maine, SNE, etc.

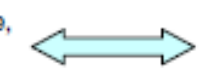

Setting of Goals and Objectives (Section 2)

- Massachusetts Ocean Act Principles

- Setting long-term Objectives

- Identify components of and interactions among ecosystem and human activities, ecosystem services and conservation goals

Identify and Prioritize Policy Issues (Section 4)

- As identified by Oceans Act and working groups

- Undertake a description of the impacted ecosystem

- i.e. Ecological Risk Assessment

- Identify priority ecosystem components for conservation

- i.e. Ecopath with Ecosim, EMAX, MIMES, Human Impacts Analysis, Ecoregional Assessments

- Choose priority activities to be included in management plan

- i.e. Multi-Criteria Decision Making

- Engage stakeholders to scope issues of concern to the ocean community within

Elaborate Conceptual Objectives (Section 5)

- For key ecosystem components and those associated with issue, define desired future state and time frame

- Link to each objective to national, state and local policy

- Use of ecosystem models: i.e. InVest, Mulino, Ecoregional Assessments, Marxan

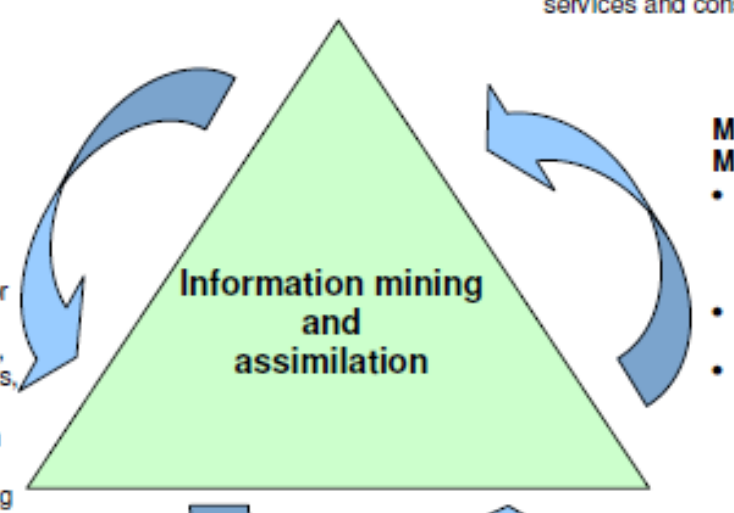

Monitoring, Evaluation and Adaptive Management (Section 7)

- Develop performance metrics to review and evaluate management actions - Measure metrics against goals

Revise and update management adaptively

Monitor indicators

Figure adapted from: NCEAS Working Group on Science Frameworks for EBM, F. Micheli and A.A. Rosenberg, co-chairs. 2007. 
Figure 1. Process of implementing ecosystem based management based on a working group at the National Center for Ecological Analysis and Synthesis and adapted for ocean management in Massachusetts.

\subsection{Using Science Tools to Advance Marine Ecosystem Based Management}

Within a single sector management context, fundamental ecological and socio-economic linkages are often ignored. Policymakers nationally and internationally are calling for a better understanding of the impact of human activities on the coastal ocean. Rather than managing one issue or resource in isolation, EBM considers the whole ecosystem, including humans (EBM Toolkit). Consequently, ecosystem based approaches to marine management (EBM) are at the forefront of progressive science and policy discussions.

However, according to a recent Gulf of Maine needs assessment, practitioners face major obstacles to implementing EBM, such as lack of money, time, understanding and information about the ecosystem or area in which they are managing (COMPASS, 2007). In addition, they lack techniques to engage stakeholders in decision-making. They continue to grapple with fundamental, big-picture issues regarding implementation despite a broad acceptance of the concept. Whether they are making decisions about coastal habitats, ocean zoning, or biodiversity conservation, they need the capacity to better understand how the ecosystem functions and how to visualize the impacts of management actions on the environment. Practitioners can gain the information and understanding necessary for EBM implementation by employing science tools such as decision-support tools and models. Decision-support tools can help practitioners by providing region-specific EBM methods, pre-calibrated, ready-to-use models, and information and data that enable practitioners to manage more holistically. They enable practitioners to better understand the ecosystem context of their management decisions.

Tools can take many forms:

- Forward-looking assessments of how the ecosystem and the economy are likely to change and the implications for management

- Spatially explicit information about human uses and economic values affecting a specific area or ecosystem

- Models of the structure, functioning, and key processes of an ecosystem and its associated human economy

- Simulations of management actions and their consequences for natural resources, and the ecosystem, and economy

- Techniques for engaging stakeholders and helping them understand human uses, non-uses, needs, and demands

These tools and others can be used to identify ecosystem services that are critical to an area. They can be used to assess how those key services affect the social and economic features of an area, and consequently show how socio-economics impact human use of the environment. They can be used to engage disparate stakeholders across management sectors to find common goals and objectives. Considering the many variables of marine ecosystem based management, decision-support tools are useful mechanisms for transparency, flexibility, and credibility (The Nature Conservancy).

In contemporary ecosystem science, the term "model" commonly refers to the use of mathematical or statistical approaches to characterize and often simulate complex systems seen in nature (Oreskes, 2003). Insightful models can be excellent tools for increasing understanding, conveying information, raising awareness among groups or individuals, and encouraging the origination of new ideas and theories (Root-Bernstein and Root-Bernstein, 1999). Models can also help identify where information is lacking and where pressing questions still exist (Root-Bernstein and Root-Bernstein, 1999; Canham et al., 2003). If a model works well, it can aid in the spread of ideas and the development of new concepts; if it does not, it can identify information needs and lack of understanding (Root-Bernstein and Root-Bernstein, 1999). 
Despite the above benefits of employing models in a general sense, models should be used carefully. They can never fully describe complex systems, and by definition are simplifications of the natural world, as is ALL science (Root-Bernstein and Root-Bernstein, 1999; Oreskes, 2003). As natural and social scientists attempt to represent as much of a system as possible using complex models with increasing numbers of parameters, the uncertainty of the models may increase as well. Even as confidence in the models is enhanced by incorporating more knowledge, the certainty of model predictions may actually decrease (Oreskes, 2003).

Because science can never fully describe the complex systems found in nature, all models incorporate inherent assumptions in order to make problems workable. Often, assumptions pertain to the form of the relationships between different ecological processes (e.g. water quality and fish recruitment, natural mortality rates, species interactions, or the relationship between habitat features and the productivity of certain resources). Although assumptions are necessary, they also increase the uncertainty of models. In any model application, it is useful to perform sensitivity analysis to evaluate the dependencies of particular results on the underlying assumptions.

The value of natural and social science models to the planning and management process is not that they provide exact predictions of what will happen in future, but that they serve as a guide to the likely effects of various management approaches. Models synthesize large amounts of information into products that can inform management, and they help clarify and make explicit what we know about a particular ecosystem.

\subsection{Massachusetts Oceans Act Principles}

"Underlying our principles of ocean resource management is our belief that our oceans embody extraordinarily dynamic and complex environments that are influenced by a combination of natural forces and human activities. Healthy ocean ecosystems are vital to human health and welfare. Human activities above, below and on the ocean surface, as well as on land, can and should be managed to allow both use and protection of ocean resources. Principles for managing those activities should embody an ethic of ocean stewardship that: (1) protects the public trust; (2) values biodiversity; (3) respects the interdependence of ecosystems; (4) fosters sustainable uses; (5) makes use of the best available information; and (6) encourages public participation in decision-making." (Waves of Change)

The passage of the Oceans Act reflects a consensus in Massachusetts about the importance of the ocean and the coast to the state's citizens. It signals the desire to move forward in a coordinated, integrated fashion to protect these natural assets and the benefits they provide. Built upon a multi-year public process conducted by the Task Force, the Act puts forth 15 principles. The bodies entrusted with managing ocean resources should

- "Set forth the commonwealth's goals, citing priorities and standards for ensuring effective stewardship of its ocean waters held in trust for the benefit of the public

- Adhere to sound management practices, taking into account the existing natural, social, cultural, historic and economic characteristics of the planning areas

- Preserve and protect the public trust

- Reflect the importance of the waters of the commonwealth to its citizens who derive livelihoods and recreational benefits from fishing

- Value biodiversity and ecosystem health

- identify and protect special, sensitive or unique estuarine and marine life and habitats;

- Address climate change and sea-level rise

- Respect the interdependence of ecosystems

- Coordinate uses that include international, federal, state and local jurisdictions 
- Foster sustainable uses that capitalize on economic opportunity without significant detriment to the ecology or natural beauty of the ocean

- Preserve and enhance public access

- Support the infrastructure necessary to sustain the economy and quality of life for the citizens of the commonwealth

- Encourage public participation in decision-making;

- Adapt to evolving knowledge and understanding of the ocean environment

- Identify appropriate locations and performance standards for activities, uses and facilities allowed under sections 15 and 16 of chapter 132A."

While these principles represent the policy agreement of the citizens and the legislature, and may inform management objectives, they will not suffice as management objectives. For example, the Oceans Act calls for "effective stewardship," "sound management practices," "protect special, sensitive or unique estuarine and marine life habitats," and other broadly stated resource conservation and protection goals. These relatively simple statements about protecting specific habitat areas or avoiding excessive economic impact are useful for designing goals and objectives, but they lack internal standards for evaluation, and are an inadequate basis for implementing an ecosystem based management plan.

Policy statements by government are "conceptual" objectives, and are a necessary part of a two-level set of management goals: conceptual and operational (Jamieson et al., 2001). Conceptual objectives are qualitative, general, and accepted by most stakeholders as desirable. In contrast, operational objectives are tied specifically to management measures and can be evaluated quantitatively as a measure of whether the plan is meeting its performance goals (O'Boyle and Jamieson, 2006). Specific objectives should be tied to some "desired future condition" of the ecosystem and its component parts (Sissenwine and Mace, 2002) and should be developed through an open and public process (Busch et al., 2003).

In 1999, the California Marine Life Protection Act directed the state to design and manage a network of marine protected areas to "protect marine life and habitats, marine ecosystems, and marine natural heritage, as well as improve recreational, educational and study opportunities provided by marine ecosystems that are subject to minimal human disturbance" (MLPA). The Act also had more specific goals about protecting diversity, rebuilding depleted populations and other targeted policies, including effective management measures, adequate enforcement, and sound scientific basis for decision-making.

In designing conceptual and operational objectives, process managers should not overlook or undervalue the central role that authorizing statutory or regulatory language plays in determining explicit goals and objectives. Iudicello and others (2004) describe pitfalls in a series of area protection case studies where vague or confusing expressions of goals led to ambiguous and conflicting expectations about roles and outcomes. In the case of areas to be designated under California's MLPA, the Department of Fish and Game tried twice between 1999 and 2004 to implement the law, but lack of public engagement and insufficient resources thwarted the process (Harty, 2006; Harty, 2008). Managers should therefore clearly articulate the underlying authority driving governmental action and then build on that authority to develop meaningful statements of goals and objectives. This will help participants know what is at stake for them and understand precisely how stakeholder advice, decisions, or recommendations will affect authorized decision making.

The relationship between policies, principles, and conceptual objectives is shown in Table 1, which arrays the principles of the Oceans Act in relation to conceptual objectives for ecosystem components (Heinz Center, 2008; O'Boyle and Jamieson, 2006). O'Boyle and others have found that linking conceptual objectives to operational objectives provides a clear path to choose indicators and evaluate performance (O'Boyle and Jamieson, 2006). Operational objectives would need to be developed with both scientific and ocean interest group participation, with the help of the Science Advisory Council and the EEA Working Groups. 
Table 1. Relationship between ecosystem elements, Oceans Act principles and conceptual objectives.

\begin{tabular}{|c|c|c|}
\hline Ecosystem Element & Oceans Act Principle & Conceptual Objective \\
\hline $\begin{array}{l}\text { Extent (Management } \\
\text { Area) }\end{array}$ & $\begin{array}{l}\text { ix) Coordinate uses that } \\
\text { include international, federal, } \\
\text { state and local jurisdictions }\end{array}$ & $\begin{array}{l}\text { Conservation of species and } \\
\text { habitat throughout their } \\
\text { range; sustainable use }\end{array}$ \\
\hline $\begin{array}{l}\text { Pattern (e.g. Bottom } \\
\text { features) }\end{array}$ & $\begin{array}{l}\text { vi) Identify and protect special, } \\
\text { sensitive or unique estuarine } \\
\text { and marine life and habitats }\end{array}$ & $\begin{array}{l}\text { Conserve physical and } \\
\text { biogenic properties }\end{array}$ \\
\hline Chemical (Water quality) & $\begin{array}{l}\text { v) Value biodiversity and } \\
\text { ecosystem health }\end{array}$ & Conserve water quality \\
\hline $\begin{array}{l}\text { Physical (water column, } \\
\text { bottom) }\end{array}$ & $\begin{array}{l}\text { vii) Address climate change } \\
\text { and sea level rise }\end{array}$ & Conserve physical properties \\
\hline $\begin{array}{l}\text { Biological } \\
\text { (community/species) }\end{array}$ & $\begin{array}{l}\text { v) Value biodiversity and } \\
\text { ecosystem health viii) Respect } \\
\text { the interdependence of } \\
\text { ecosystems; vii) Address } \\
\text { climate change and sea level } \\
\text { rise }\end{array}$ & $\begin{array}{l}\text { Maintain communities, } \\
\text { species and populations }\end{array}$ \\
\hline $\begin{array}{l}\text { Productivity (base of food } \\
\text { chain) }\end{array}$ & $\begin{array}{l}\text { v) Value biodiversity and } \\
\text { ecosystem health }\end{array}$ & $\begin{array}{l}\text { Maintain primary production } \\
\text { and trophic structure }\end{array}$ \\
\hline Ecosystem Services & $\begin{array}{l}\text { iv) Reflect the importance of } \\
\text { the waters of the } \\
\text { commonwealth to its citizens } \\
\text { who derive livelihoods and } \\
\text { recreational benefits from } \\
\text { fishing }\end{array}$ & $\begin{array}{l}\text { Conserve ecosystem } \\
\text { components and their role in } \\
\text { the system for production of } \\
\text { services; sustainable use; }\end{array}$ \\
\hline
\end{tabular}

\subsection{Setting long-term objectives}

Environmental management needs to strike a balance between short-term and long-term objectives. It is critical that long-term objectives be resolved early on in management planning in order to maintain perspective and ensure that short-term gain doesn't become the overwhelming management driver. In an ecosystem based management approach, the long-term objectives are to conserve and maintain the ability of the ecosystem to provide goods and services to support human well-being, and for a particular planning process, specific objectives with regard to those services should serve as a basis for policymaking.

The ability of the ecosystem to provide these goods and services is the link between the operational objective and the policy goals and interest group issues. One of the main purposes of integrated ocean and coastal management is the identification of common objectives among what were conventionally viewed as competing interests.

\subsubsection{Identify ecosystem services and goals for conservation}

An ecosystem is a dynamic complex of plant, animal, and microorganism communities and the nonliving environment, interacting as a functional unit. Humans are an integral part of ecosystems. Ecosystem services are the benefits people obtain from ecosystems and can be divided into four categories: (1) Provisioning services are products obtained from the ecosystem, such as food and water; (2) Regulating services are benefits obtained from regulation of ecosystem processes, such as flood and disease 
control; (3) Cultural services are nonmaterial benefits obtained from ecosystems, such as spiritual, recreational, and cultural benefits; and (4) Supporting services are those necessary for the production of all other ecosystem services, such as nutrient cycling, that maintain the conditions for life on Earth. Supporting services differ from the other three categories of ecosystem services in that their impacts on people are either indirect or occur over a very long time, whereas changes in the other categories have relatively direct and short-term impacts on people. People seek many services from ecosystems and thus perceive the condition of an ecosystem in relation to its ability to provide desired services (Millennium Ecosystem Assessment, 2005).

Examples of ecosystem services provided by the oceans include food and pharmaceutical supply, jobs, recreation, inspiration, coastal storm protection, nutrient cycling, climate regulation, carbon sequestration, human waste management, transportation, climate moderation, nutrient cycling, erosion buffering, tidal energy, national security, education, and research (Massachusetts Ocean Partnership). Table 2 provides a list of ecosystem services provided by the marine and coastal environment. This list is not exhaustive and some ecosystem services (i.e. biodiversity) fall under multiple categories.

Table 2. List of Services Provided by Coastal and Marine Ecosystems ( $X$ indicates that the habitat provides a significant amount of the service). Table adapted from UNEP, 2006.

\begin{tabular}{|c|c|c|c|c|c|c|c|c|}
\hline Ecosystem Service & 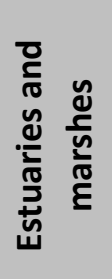 & 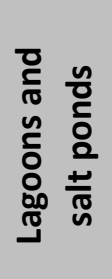 & 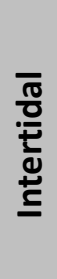 & 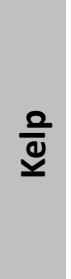 & 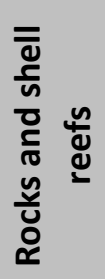 & 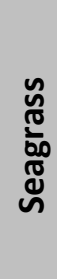 & 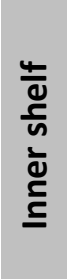 & 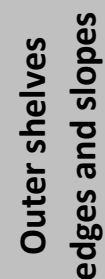 \\
\hline Biodiversity & $x$ & $\times$ & $x$ & $\times$ & $x$ & $x$ & $\times$ & $x$ \\
\hline \multicolumn{9}{|l|}{ Provisioning services } \\
\hline Food & $\times$ & $\times$ & $\times$ & $\times$ & $\times$ & $x$ & & $\times$ \\
\hline Fibre, timber, fuel & $\times$ & $\times$ & & & & & $\times$ & $\times$ \\
\hline Medicines, other resources & $\times$ & $\times$ & & $\times$ & & & $\times$ & \\
\hline \multicolumn{9}{|l|}{ Regulating services } \\
\hline Biological regulation & $\times$ & $\times$ & $\times$ & & $\times$ & & & \\
\hline Freshwater storage and retention & $\times$ & $\times$ & & & & & & \\
\hline Hydrological balance & $x$ & $\times$ & & & & & & \\
\hline Atmospheric and climate regulation & $\times$ & $\times$ & $\times$ & & $\times$ & $x$ & $\times$ & $\times$ \\
\hline Human disease control & $\times$ & $\times$ & $\times$ & & $\times$ & $\times$ & & \\
\hline Waste processing & $x$ & $\times$ & & & & $x$ & & \\
\hline Flood/storm protection & $x$ & $\times$ & $x$ & $x$ & $\times$ & $x$ & & \\
\hline Erosion control & $\times$ & $\times$ & & & & $x$ & & \\
\hline \multicolumn{9}{|l|}{ Cultural services } \\
\hline Cultural amenity & $\times$ & $\times$ & $\times$ & $\times$ & $\times$ & $\times$ & $x$ & \\
\hline Recreational & $x$ & $x$ & $x$ & $\times$ & & & & \\
\hline Aesthetics & $x$ & $\times$ & $x$ & & & & & \\
\hline Education and research & $\times$ & $\times$ & $\times$ & $\times$ & $\times$ & $\times$ & $\times$ & $\times$ \\
\hline \multicolumn{9}{|l|}{ Supporting services } \\
\hline Biochemical & $x$ & & & $x$ & & & & \\
\hline Nutrient cycling and fertility & $\times$ & $\times$ & $\times$ & $\times$ & $\times$ & & $\times$ & $\times$ \\
\hline
\end{tabular}


With the aid of resource managers and science advisors, key components of the ecosystem such as those posited above can be identified. The ability of the ecosystem to provide these goods and services is the link between the operational objective and the policy goals/interest group issues. Drawing on information from the EEA listening sessions, working group discussions, and stakeholder needs assessment, planners can describe key interests in a variety of ocean activities: fishing, transportation, recreation, energy development, and so forth. The ability of the ecosystem to provide these goods and services is the link between the operational objective and the policy goals/interest group issues. One of the main purposes of integrated ocean and coastal management is the identification of common objectives among what were conventionally viewed as competing interests.

"The demand for ecosystem services is now so great that trade-offs among services have become the rule. The problem posed by the growing demand for ecosystem services is compounded by increasingly serious degradation in the capability of ecosystems to provide these services. World fisheries are now declining due to overfishing, for instance, and some 40 percent of agricultural land has been degraded in the past half-century by erosion, salinization, compaction, nutrient depletion, pollution, and urbanization. Other human induced impacts on ecosystems include alteration of the nitrogen, phosphorous, sulfur, and carbon cycles, causing acid rain, algal blooms, and fish kills in rivers and coastal waters, along with contributions to climate change. In many parts of the world, this degradation of ecosystem services is exacerbated by the associated loss of the knowledge and understanding held by local communities-knowledge that sometimes could help to ensure the sustainable use of the ecosystem" (Millennium Ecosystem Assessment, 2003.).

Massachusetts has recognized that the quality of its marine ecosystem services is threatened, and a new planning and management authority has been authorized through the passage of the Oceans Act in 2008. This Act establishes the authority for the Commonwealth to move forward with developing an integrated multi-use ocean management plan. Considering the importance of coastal ecosystem services to human well-being, as well as the deteriorating nature of the services, it is important that ecosystem services are the basis for Massachusetts' integrated multi-use ocean management plan.

In an interesting exercise to inform decisions on long-term objectives, Walker and Salt (2006) outline a stakeholder engagement process used in the Northern Highlands Lake District of Wisconsin based upon an examination of potential futures under different possible paths of the social - ecological systems (i.e. scenarios). They point out that the traditional approach to exploring the future is to predict that future based upon the past and present. However, ecosystems and their associated social network are highly non-linear systems which mitigate against this approach. An alternative approach, which has been used in, amongst others, the Millennium Ecosystem Assessment project (Millennium Ecosystem Assessment, 2005), is to explore what might happen through structured narratives about possible future paths of a social - ecological system. Rather than trying to predict future possible states, the process of scenario development highlights the main issues and constraints facing the systems. This is similar in concept to Management Strategy Evaluation (MSE) which compares the utility of different management strategies rather than trying to identify the best one (Sainsbury et al., 2000).

\subsubsection{Identify key components of ecosystem and human activities}

There is fairly widespread agreement on key ecosystem components (Table 3), which are the combination of processes (energy flow, nutrient cycling) and patterns (biogeography, community structure) that comprise the system (See, e.g., Natural Resources Canada, 2000, The Atlas of Canada). This discussion uses components developed by the Heinz Center (2008) and listed in Table 1 above. Process managers may develop operational objectives based on the conceptual objectives that were extracted from the Oceans Act principles, or elicit objectives from existing management plans and policies and array them in an integrated management fashion such as the one described by O'Boyle and Jamieson (2006). 
One simple approach, described in Altman et al. (2008), uses a ranking system for ecosystem services and components and then weighting the average rankings to prioritize the key attributes for focus. Such an approach could be applied by the State or MOP to help develop objectives for management.

Table 3. Examples of what operational objectives might be for some ecosystem components.

\begin{tabular}{|l|l|l|}
\hline \multicolumn{1}{|c|}{$\begin{array}{c}\text { Ecosystem } \\
\text { Component }\end{array}$} & \multicolumn{1}{c|}{ Examples } & $\begin{array}{c}\text { Hypothetical } \\
\text { Operational Objective }\end{array}$ \\
\hline Management Area & $\begin{array}{l}\text { Definition of plan area, larger } \\
\text { ecosystem in which it lies, } \\
\text { federal/state jurisdiction }\end{array}$ & $\begin{array}{l}\text { By 2012, achieve integration } \\
\text { of CZ, MOP and federal } \\
\text { management through MOUs } \\
\text { with x,y,z agencies. }\end{array}$ \\
\hline Bottom features & Shoreline types, habitat types & $\begin{array}{l}\text { By 2011, complete fine scale } \\
\text { mapping of eel grass beds in } \\
\text { x sites. }\end{array}$ \\
\hline Chemical (Water quality) & $\begin{array}{l}\text { Nutrients, Carbon, Oxygen, } \\
\text { Presence of contaminants, } \\
\text { Contaminated sediments }\end{array}$ & $\begin{array}{l}\text { By 2012, reduce occurrence } \\
\text { of CSOs by x percent. }\end{array}$ \\
\hline
\end{tabular}

\subsubsection{Identify interactions among ecosystem components and activities}

The recognition that human activities affect the ocean informed passage of the Oceans Act and its call for integrated planning. During early discussions that led to passage of the Oceans Act, stakeholders, managers and interest groups came up with the term Integrated Multi-use Ocean Management (IMUOM) ${ }^{2}$ to capture two concepts the group felt were important for their discussions. "Integrated" reflects that impacts and tradeoffs should be considered across sectors. "Multi-use" reflects support for a full range of sustainable, thriving marine-based activities. IMUOM is comparable to the term Comprehensive Ocean Management used by MA Ocean Task Force (Massachusetts Ocean Partnership).

The framework requires participation by natural and social scientists, stakeholders, and the public to identify and understand how activities such as fishing, energy development, waste disposal practices, and coastal development affect the capacity of the coastal ocean to maintain the components of the ecosystem and their functions.

Another useful conceptual tool for identifying interactions among ecosystem components and activities is the Driver, Pressure, State, Impact, Response approach described in Appendix B. Utilizing this approach will lead to identification of principle drivers and threats for key ecosystem components and can help structure thinking about how to address impacts and evaluate ecosystem responses. This work has been well developed by Bowen et al. (2008) and others and has applicability to ocean planning.

\section{Definition of the Management Area}

"The Ocean Management Task Force focused its work on ocean areas within the Commonwealth's jurisdiction. Generally, this area extends from the low water mark to the seaward boundary of the Commonwealth. . . . Massachusetts should pursue ecosystem management of offshore waters through federal, regional, and state coordination and cooperation" (Waves of Change).

\footnotetext{
${ }^{2}$ IMUOM is comparable to the term Comprehensive Ocean Management used by MA Ocean Task Force (Massachusetts Ocean Partnership).
} 
The management area, or affected ecosystem, can be described in terms of both policy needs and the natural environment. According to the Massachusetts Oceans Act, the ocean waters and ocean-based development of the Commonwealth at issue are those within the Ocean Management Planning Area $^{3}$ (Figure 2).

Recommendations from the Ocean Management Task Force pertain to ocean areas within jurisdiction of the Commonwealth. State waters typically extend to three nautical miles offshore, as provided by the Submerged Lands Act. The Commonwealth's marine boundary comports with this, with the exception of areas within Massachusetts Bay, Cape Cod Bay, and Nantucket Sound that extend further due to bay closure lines established by the U.S. Supreme Court. Jurisdiction of the Coastal Zone Management Program goes further shoreward, encompassing coast and land areas from mean high water to the statutory 0.3 nautical mile line. The Oceans Act management planning area therefore applies to the ecosystems and associated economies from 0.3 to 3 nautical miles.

While the statute is explicit in describing the management area, there were political considerations that led to the language. It was pointed out to the Science Advisory Council that there are other state regulations for areas landward of the planning area, in particular (SAC 2008). Even though activities outside the plan area may affect, or be affected by, activities in the plan area, the plan itself will not address them. For example, establishing water quality standards could indirectly control shore activities that may be a source of discharge that will affect the plan area. In such a case, existing standards could be used to resolve such an issue, or planners may want to negotiate memoranda of understanding (MOUs) or similar agreements that better integrate management measures across jurisdictions.

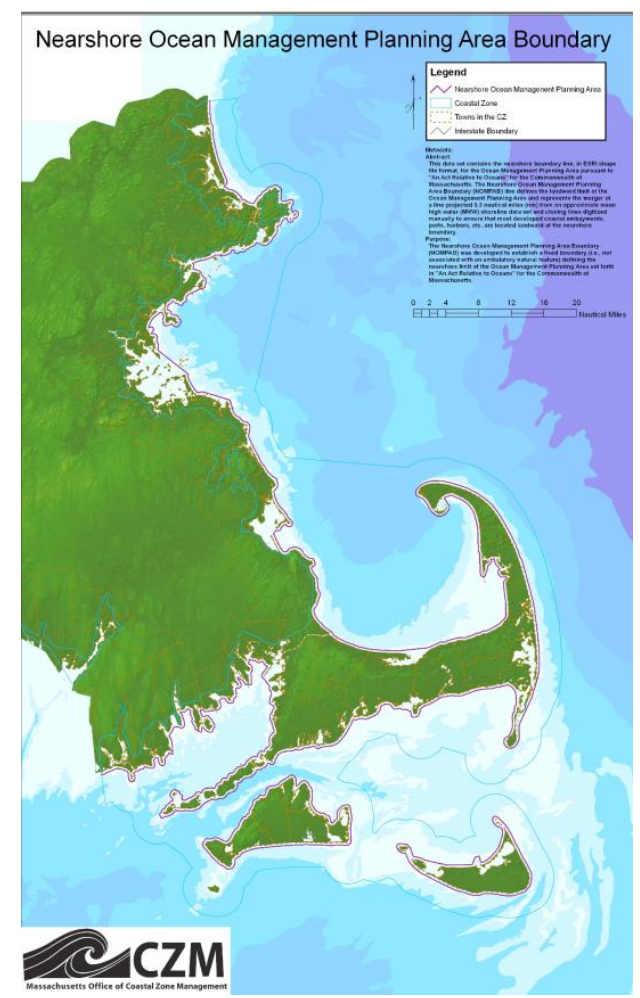

Figure 2. The line defines the landward limit of the Ocean Management Planning Area and represents the merger of a line projected 0.3 nautical miles from an approximate mean high water shoreline data set and closing lines digitized manually to ensure that most developed coastal embayments, ports, harbors, etc. are located landward of the nearshore boundary (MA Office of Coastal Zone Management).

\subsection{Identify potential connections to both smaller and larger scales}

Ecologically, the planning area sits within an ecosystem that crosses municipal, state, federal, and international jurisdictional boundaries. . At the greatest scale, the affected area could be described as the Georges Bank Ecosystem or the Northeast U.S. Continental Shelf Large Marine Ecosystem ${ }^{4}$. At a finer scale, the description could focus within a selected oceanographic boundary, such as depth, habitat type or physiographic zones (e.g. nearshore basin, rocky zone, shelf valley, nearshore ramp, bay-mouth shoal, outer basin). While the planning area is defined explicitly in the statute, an ecosystem based analysis

\footnotetext{
${ }^{3}$ This area includes "any waters and associated submerged lands of the ocean, including the seabed and subsoil, lying between the line designated as the 'Nearshore Boundary of the Ocean Management Planning Area,' which is depicted on a plan dated January 31, 2006, prepared by the office of coastal zone management and maintained at the executive office of energy and environmental affairs and with the clerks of the house and the senate, and the seaward boundary of the commonwealth, as defined in 43 U.S.C. § 1312" (Ch. $114 \S 4 \mathrm{C}(\mathrm{b})$ )).

${ }^{4}$ For description of Georges Bank Ecosystem, see, e.g., GLOBEC at http://www.usglobec.org/reports/nwaip/nwaip.chapter4.1.html or for the Northeast U.S. Continental Shelf Large Marine Ecosystem, see, e.g., http://na.nefsc.noaa.gov/lme/text/lme7.htm.
} 
would require incorporation of information from beyond the statutory boundaries in order to effectively assess impacts. Although the planning area is depicted within spatial boundaries, ecosystems are dynamic and interact with processes and activities beyond boundary lines. The rigidity of boundaries can be offset by collecting data from beyond borders, and using indicators and buffer zones to monitor trends in the state of the larger ecosystem in which the planning area lies (SAC, 2008).

In the Millennium Ecosystem Assessment (MEA) Toolkit authors emphasize the importance of scale and "getting it right." They recommend integration across jurisdictions, coordination that is neither too big to see local concerns nor too local to see the big picture. Further, the MEA Toolkit suggests management plan measures that protect the entire ecosystem, not just its components. In line with these recommendations, the Oceans Act calls for the coordination of uses that occur in multiple jurisdictions (Ch. $114 \S 4 C(a)(i x))$.

A synthesis of policy and scientific parameters for identifying the planning area might also include a cross check with priority issues, discussed below. For example, sediment management is an issue that has been identified as meriting its own working group, requiring examination of ecosystem parameters reaching both shoreward and seaward from the statutory planning area.

\section{Identify and Prioritize Policy Issues}

In the Oceans Act working groups and stakeholder comments identify the following priority issues:

- mitigation of loss and enhancement of habitat extent and value

- maintaining commercial and recreational fishing

- protection of biodiversity and ecosystem health

- recognition of climate change and sea level rise

- preservation and enhancement of public access

- understanding the ocean environment

- managing offshore renewable energy development

- acquisition and application of best scientific information

Several state agency working groups have been established to compile information about the following priority policy issues:

- Habitat

- Commercial and recreational fishing

- Renewable energy

- Navigation and infrastructure

- Sediment management

- Social, cultural and historic concerns

The Executive Office of Energy and Environmental Affairs (EEA) has compiled stakeholder views distilled from 18 public listening sessions, in addition to further stakeholder views elicited from targeted meetings and interviews being conducted by the Massachusetts Ocean Partnership. Priority issues identified include many of those listed above. Citizens also identified the importance of the ocean to the Massachusetts economy, the need to strive for balance among competing ocean uses, and the maintenance of public safety.

These issues are general and may conflict, creating difficulties in assigning priorities and making tradeoffs necessary. For example, maintaining commercial fishing may limit the extent to which the loss of ocean habitat can be mitigated. Clearly, tradeoffs among policy issues will need to be characterized. In assigning priorities to these policy issues, managers may find the economic tools discussed in Appendix $\mathrm{D}$, such as benefit-cost analysis, bio-economic modeling, non-market valuation, and "decision-making procedures under uncertainty" particularly helpful in articulating tradeoffs in a common unit (dollars). 


\subsection{Undertake a description of the impacted ecosystem}

Once the extent of the planning area has been identified, a description of the affected ecosystem can be developed from scientific information about ecological components, socio-economic information about human uses, and policy information on priority issues identified by the legislature, the Ocean Advisory Commission, the Science Advisory Council, state agency work groups, and stakeholder listening sessions. An "integrated assessment", comprises such a description, and involves steps such as identifying ecosystem services, undertaking risk assessments, assessing the current availability of data, and establishing procedures for ongoing information acquisition.

The combination of environmental data, policy priorities, legal boundaries, ecological areas, and human activities enables planners to produce a Draft Ecosystem Overview. This is comparable to what the Massachusetts Environmental Policy Act (MEPA) requires in an environmental impact report: the description of the "affected environment" called for by the National Environmental Policy Act (NEPA), or an integrated assessment applied by the NOAA Center for Coastal Monitoring and Assessment ${ }^{5}$. Integrated assessments describe the ecosystem, assess its current condition, forecast the future ecological health using current management strategies, and evaluate alternate strategies and their potential impacts. Integrated assessments provide a process to evaluate alternate management methods and information by identifying and relating to objectives and priorities. MEPA, for example, calls for the following elements in its description of the affected environment ${ }^{6}$ :

1. Topography, geology, and soils

2. Surface and groundwater hydrology and quality

3. Air quality and noise

4. Plant and animal species and habitat

5. Traffic, transit, and pedestrian and bicycle transportation

6. Scenic qualities, open space and recreational resources

7. Historic structures or districts, and archaeological sites

8. Built environment and human use of the Project site, its immediate surroundings and the region, including existing infrastructure (i.e., water supply, wastewater treatment and/or disposal, transportation, waste management, etc.), zoning districts and other relevant land-use designations or plans (i.e., local or regional capital improvement plans or infrastructure investments, economic development, growth planning and open space plans, etc.), business districts, industrial parks, housing stock, and vacancy rates

9. Rare or unique features (including environmental and social conditions) of the project site and its immediate surroundings such that any increase in environmental impacts, however small or gradual, may result in an unusual or disproportion.

Ecosystem Overview. The combination of environmental data, policy priorities, legal boundaries, ecological areas, and human activities enables planners to produce an Ecosystem Overview. Such an overview should describe the ecosystem, assess its current condition, forecast the future ecological health using current management strategies, and serve as a baseline against which to compare impacts of policy options or alternative decisions. It should include descriptions of biological resources, socioeconomic resources, habitat, cultural resources, and historical resources and estimate effects on environmental resources or quality of public health. We argue that economic models and tools, such as benefit-cost analysis and economic impact analysis (Appendix D), should be an integral part of the Ecosystem Overview. Such tools are particularly useful in evaluating alternative strategies.

To be effective, an ecosystem overview will be responsive to policy-relevant questions based on peer review and public participation, bring together information and data from many sources, be based on high-quality existing information, predict ecosystem health in response to consequences of various management actions and alternatives, and identify data gaps, uncertainties and priorities for additional

\footnotetext{
${ }^{5}$ Available online at http://ccma.nos.noaa.gov/about/ia/welcome.html.

${ }^{6} 301$ CMR 11.07(6)(g).
} 
data collection. Another critical aspect of the ecosystem overview, or integrated assessment, is the incorporation of commonly developed objectives that emerge from a multi-sector process. In other words, all ocean activities and interests have to have contributed to the definition of goals and objectives (O'Boyle and Jamieson, 2006).

Economic Analysis. Part of the ecosystem description is specifying both market and non-market values associated with the ocean ecosystem (see Appendix D for a more detailed description of non-market valuation). Goods and services that can be counted and have a monetary value placed upon them include fisheries, transportation corridors, recreation (e.g. whale watch tours), scientific research, wind or wave energy generation, and national security among others. But other less tangible services are more difficult to quantify or assign a value in economic terms. These include vital processes such as purification of air and water, detoxification and recycling of wastes and nutrients, regulation of climate through storage or use of carbon dioxide, and maintenance of ocean plants and animals. Natural ocean ecosystem processes reduce the severity of floods, disperse seeds and larvae, and protect coasts from erosion (Costanza, 1997; Dailey, 1997). Finally there are non-market values that do not involve any contemplated human uses, such as existence, option, and bequest values. These non-market uses and benefits should be evaluated using some of the tools discussed in Appendix D. The main purpose of estimating and compiling economic values is not descriptive, however; more importantly, these values should be used to characterize the opportunity costs of management actions, to make explicit the tradeoffs among uses, and to set the resource management priorities.

Ecological Risk Management. Another important element in the description of the impacted environment is an ecological risk assessment (see description in Appendix B). An evaluation of the vulnerability of an ecosystem component to human activity can be conducted using an ecological risk management (ERM) framework. An ERM is a process aids in identifying issues and prioritizing those issues by evaluating the vulnerability of habitats to a suite of activities. Scientists at the Australian's Commonwealth Scientific and Industrial Research Organisation (CSIRO) have developed an ERM approach, the Ecological Risk Assessment for the Effects of Fishing (ERAEF). While this approach is specific to fisheries activities, it has great potential for additional application. The process assesses the impacts that fisheries activities have on five aspects of the marine ecosystem (target species, bycatch and byproduct species, threatened, endangered and protected (TEP) species, habitats, and communities).

ERAEF is a hierarchal approach that proceeds from a comprehensive analysis of risk (Level 1, The Scale, Intensity, and Consequence Analysis) through a more focused semi-quantitative approach (Level 2, The Productivity-Susceptibility Analysis) to a fully quantitative model-based approach (Level 3). The value of the Productivity-Susceptibility Analysis as a method for conducting risk-based assessments of fisheries that could apply to all stocks, even those with deficient data, was noted by the 2007 Lenfest Working Group on Setting Annual Catch Limits (Rosenberg et al., 2007). This process has been endorsed through a Lenfest Ocean Program Research Series and analyses are underway by both MRAG Americas and NOAA Fisheries. This framework (see Appendix B) would serve as a valuable tool in identifying and prioritizing policy issues by recognizing impact activities and sensitive habitats and assigning levels of threat and vulnerability to those impacts and habitats. Once priority goals and objectives have been set, an ecological risk assessment should be conducted to assist in determining priority activities and their impacts.

An important step in developing the ecosystem description is assessing currently available information and establishing procedures for further data acquisition. One existing document central to this project is the report "Ecosystem-Based Coastal and Ocean Management in Massachusetts: Science Gap Analysis Final Report" which presents a review of current research (including data and monitoring activities) in Massachusetts coastal and marine waters, and the wider Gulf of Maine. (Mooney-Sues and Allen, 2007) The report identifies gaps in research, data, monitoring, infrastructure, and funding and makes recommendations for setting priorities. In addition to this information, which is specific to Massachusetts coastal waters, data are available from numerous sources and at varying scales. The management planning area lies within projects that have compiled or are compiling information on large marine 
ecosystems, conducting geologic mapping, producing data through coastal ocean observing systems, identifying essential fish habitat, and analyzing ocean ecosystems. .

Identifying data sources and acquiring information is an ongoing activity rather than a snapshot at a point in the planning schedule; therefore, it would be useful to have a web-based clearinghouse or similar network tool to enable researchers, monitoring programs and ecosystem projects to share information about ongoing or proposed information collection efforts (e.g. Mojave Desert Ecosystem GIS data clearing house, biodiversity clearing-house mechanism, USGS strategy for biodiversity and ecosystems information framework). Another proposal is to create maps of information on activities extracted from existing programs ${ }^{7}$; for example, there are several programs along the eastern coast, from the Bay of Fundy to North Carolina, especially regarding estuarine programs, ocean observing system, and surface currents (SAC, 2008).

Although EBM shares many planning and implementation steps with conventional management, some elements are not only unique to ecosystem based approaches, but also critical to their success. These elements include the consideration of multiple sectors; consideration of cross-scale interactions; integrated priorities, plans, and actions; ecosystem health indicators; and linkages between the ecosystem and society. Ideally, an EBM plan will contain elements of long-term sustainability, ecosystem health and resilience, recognition of ecosystem services, and human well-being (Heiman et al., in prep).

\subsection{Identification of priority ecosystem components for conservation}

The 15 principles of the Oceans Act provide some policy guidance for identifying ecosystem components for conservation. Table 4 sorts these principles into natural, socio-cultural and economic categories. While these broad statements of public policy give general direction, they need to be refined into measurable objectives for purposes of EBM. (See discussion of measurable objectives above in Section 1 and below in Section 6.)

Table 4. Categorization of Oceans Act Principles.

\begin{tabular}{|l|l|l|}
\hline \multicolumn{1}{|c|}{ Natural } & \multicolumn{1}{c|}{ Social-cultural } & \multicolumn{1}{c|}{ Economic } \\
\hline Climate change & Historic sites & Fishing \\
\hline $\begin{array}{l}\text { Interdependence of } \\
\text { ecosystems }\end{array}$ & $\begin{array}{l}\text { Underwater archaeological } \\
\text { sites }\end{array}$ & Sea level rise \\
\hline $\begin{array}{l}\text { Biodiversity \& ecosystem } \\
\text { health }\end{array}$ & Public trust, access & $\begin{array}{l}\text { Support necessary } \\
\text { infrastructure }\end{array}$ \\
\hline Natural beauty of ocean & Stewardship & $\begin{array}{l}\text { Sustainable use; economic } \\
\text { opportunity }\end{array}$ \\
\hline $\begin{array}{l}\text { Unique marine life \& } \\
\text { habitats }\end{array}$ & Knowledge \& understanding & Performance standards \\
\hline
\end{tabular}

For example, in order to achieve the objectives of the conservation of historic or archaeological sites, sites would need to be identified in the Ecosystem Overview. Later in the process, management actions would be considered in light of effects on historic sites. Economic models and value estimates can be helpful in developing ways of prioritizing these various ecosystem components, including human uses.

Because the Oceans Act calls for conservation and stewardship, scientists would define additional components because of their ecological significance or vulnerability. Some factors that might be considered include protecting diversity of species; protecting at least one example of key marine habitats

\footnotetext{
${ }^{7}$ As an example, see the distribution of economic valuation efforts along the coast and in the marine environment in the region near Massachusetts:

http://maps.google.com/maps/ms?ie=UTF8\&hl=en\&msa=0\&msid=114476102882294796535.00045c0de04db901ef3 96\&t=h\&z=7
} 
("Key" habitat types provide particular benefits by harboring a different set of species or life stages, having special physical characteristics, or being used in ways that differ from the use of other habitats); protecting adult populations; protecting biogeographic regions; protecting areas already identified as essential fish habitat or habitat areas of particular concern; protecting unique marine features; protecting rare marine features; and protecting critical habitat for endangered or threatened species. The principles of conservation and stewardship imply that it would be helpful to apply methods, such as those found in economics, to make explicit the net benefits of protecting ecologically significant features.

The overarching call for conservation can also be broken down in terms of broad conceptual objectives. For instance, Jamieson et al. (2001) suggest conservation of ecosystem components (biodiversity), conservation of the component's role (productivity) and conservation of physical/chemical properties of the system. Under these conceptual objectives, the authors describe specific actions related to the conservation and use of communities, species and populations; the maintenance or restoration of primary production and trophic structure; and the improvement of bottom and water column properties and water and biota quality.

The available information for describing the affected ecosystem can be synthesized using many of the ecosystem models described in Appendix A. For example, an aggregates system model like Ecopath with Ecosim or the EMAX model from the NEFSC in Woods Hole can be used to help understand the food web linkages in the ecosystem. More extensive models such as MIMES or GADGET can bring together large amounts of information on broader ecosystem components. Also, utilizing tools such as the Human Impacts Analysis or Ecoregional Assessment described in Appendix B can help inform the ecosystem description stage of the process. Finally, economic valuation and management techniques, such as costbenefit analysis, economic impact analysis, decision-making under uncertainty, and economic-ecological modeling are also useful in this context.

\subsection{Choose priority activities to be included in management plan}

Having described the components of an ecosystem and their inter-relationships, it is necessary to identify which ones require priority attention in a management plan. World-wide a number of approaches are being employed which have as their common element the evaluation of the risk of harm to the ecosystem components under consideration. In Canada, ecologically and biologically significant areas and species are identified by the scientific community (DFO, 2004) based upon a suite of criteria on characteristics such as uniqueness, aggregation, fitness, resilience, naturalness and so on. In Australia, a three-step Ecological Risk Assessment process for identifying priorities is being used with the evaluation progressing becoming more in-depth as one moves from one step to another (Smith et al., 2007). The second step in this process - the Productivity and Susceptibility Analysis (PSA) - uses criteria similar to those in DFO (2004) but casts them in a broader risk assessment framework.

Fletcher (2005) outlines another qualitative risk assessment methodology that provides a means to formally engage stakeholder input into priority setting particularly at the sector level. It should be pointed out that extant prioritization processes endeavor to identify the key ecosystem components at risk based on the best available science. While stakeholder engagement can lead to long-term buy-in to EBM, it is essential to do this within a formal risk assessment structure that is informed by natural and social scientific understanding.

Situations may arise in which every ecosystem component and issue appears to be a high priority to address. In addition to the economic tools previously mentioned, decision support tools such as MultiCriteria Decision Analysis (Appendix B), of which the Analytic Hierarchy Process (AHP) is an example, are being used to assist priority identification in these situations. MCDA depends upon pre-established objectives and criteria to prioritize a set of alternatives. It thus provides an objective basis for choosing amongst the seeming 'forest' of priorities. AHP is being used by assessment teams to inform ecolabeling of fisheries under the auspices of the Marine Stewardship Council (MSC). 


\subsection{Engage stakeholders to determine the scope of the array of issues that are of concern to the ocean community within management area}

Stakeholders played a significant role in the development phases that led to the passage of the Oceans Act, and the State, with its partner the Massachusetts Ocean Partnership, has mapped a path to planning that incorporates numerous and substantial opportunities for public participation. Through listening sessions sponsored by the Energy and Environment Agency (EEA), the State of Massachusetts has continued the process of education, eliciting views, and feedback. In addition to public events aimed at engaging citizens in general, the state foresees a process that brings interest groups and ocean resource stakeholders into its planning framework through an Ocean Advisory Commission, Science Advisory Council, work groups (Fisheries, Renewable Energy, Habitat, Sediment Management Navigation and Infrastructure, Social, Cultural and Historical) and a stakeholder needs assessment and framework.

Though details of this latter task are under development by another contractor, some general guidance about effective stakeholder input in ecosystem based management planning is offered here.

Design of a multi-stakeholder processes for ocean and coastal management requires the identification of factors including political considerations, presence or absence of effective leadership, conflict management techniques, and the availability of financial resources to fund a process. These elements affect how efficiently and effectively a process moves through any public resource decision that engages public and private sectors, preservation and development interests, resource users and managers, science, business, and politics. Stakeholder processes that appear to be straightforward applications of scientific information to resource questions may be significantly affected by their political settings and how user groups perceive the potential impacts of various proposals. Allocation, socioeconomic, and political considerations can dominate a process if stakeholder concerns are not carefully managed. Effective leadership at the political, agency, stakeholder, and process levels is a significant factor in the success or failure of a designation effort, as is the skillful application of interest-based conflict management tools.

Findings from assessments of other area-based, ecosystem management processes offer these guidelines:

- Early planning efforts must include a thorough assessment of past history and its potential effects on stakeholder perceptions, the goals to which they will agree, their willingness to participate, and the ground rules they will accept.

- Managers must have a grasp of the underlying authority for a zoning designation process, as well as the ability to explain both the authorities and the process to participants.

- Managers must have a vision of the process steps from beginning to end, not just the stakeholder participation stage.

- Managers should design and manage processes with an understanding of stakeholder motivation, an expectation that stakeholder goals will differ, and the preparation to handle disagreements and conflict.

- Processes should incorporate appropriate flexibility and adaptability. Conveners and process managers should look at the full array of decision tools that are available and not feel locked into a complex consensus model or a rigid fishery management or land use planning model.

- Managers need to remember that scientists have their own motivations and biases like other stakeholders. Scientists should not work separately from other stakeholders, even on seemingly non-controversial issues. Scientists should be selected to ensure that their skills match the areas of expertise defined by the objectives of the process, and their role should be made clear to stakeholders.

- Planners and managers should treat politics as the natural expression of human and interest group dynamics that reflect stakeholders' genuine interests and perceptions. They are part of the policy process and need to be recognized, accommodated, and planned for. Such interest group dynamics often lead to conflict, which should be seen as a natural part of such complex processes. 
- Leadership is needed at the political level that initiates and supports the process, at the upper levels of involved agencies that ensure consistent commitment and follow through on decisions, at the process level where facilitation, negotiation, and conflict management skills are crucial, and at the interest group level, where perceived stature, relationships with constituents, and the effective framing, control, and communication of a core message are important.

- Value-laden conflicts can and should be addressed through the use of skilled, experienced facilitators. Where possible, third-party process managers should guide the process from the outset. If this is not possible, neutral third-party professional facilitators should at a minimum be employed to run the meetings.

- Process planners should consider three important aspects to maps - the process by which they are made, the information they contain, and how, when, and by whom they are used. Maps help identify gaps and analyze the implications of proposed boundaries.

- Upper level managers and agency decision makers must ensure that key program staff are formally assigned to manage the process from start to finish. Staff should have the experience, stature, and core skills needed to understand and influence the evolution of a process. In addition, they should be able to successfully flag and negotiate emerging issues with the program leadership (Bernstein and ludicello, 2004).

Another key factor in process design is the evaluation of, and ultimate choice among, alternative designs during the planning and decision process. It is critical to present policy options or management alternatives in a clear and transparent way. Where feasible, estimates of the economic costs and benefits of options should be presented so that stakeholders are able to understand the relevant tradeoffs using a common unit. Among other state laws and policies that will apply to the work of the MOP is the MEPA, which requires decision makers to evaluate the alternatives and the potential environmental consequences of their actions. Whether any elements of the MOP process rise to the level of MEPA analysis, the practice and systematic evaluation of alternatives that arise from this type of environmental assessment contribute to more informed stakeholder discussion and better understanding of the potential outcomes of various planning choices.

\section{Elaborate Conceptual Objectives}

After setting long term goals and objectives (Section 2), defining the management area (Section 3), and identifying and prioritizing key policy issues (Section 4), decision makers must elaborate on the objectives. Conceptual objectives (defined in Section 2.2) must be set early in any management plan, ocean or otherwise (and definitely prior to the creation of specific policy), as they set the tone and give direction to the rest of the plan. Ideally, they express a desired future state for the marine ecosystem and give context for the development of strategy and policy decisions (Rosenberg et al., 2007). They also link the legislation and policy with the operational objectives.

In the past, management has defined objectives for specific activities and industries, generally without regard for a common set of overarching objectives. As a result, activities which affect the same ecosystem and often overlap in time and space may have radically different objectives, contributing to a disjointed and uncoordinated attempt at management of ocean resources and the activities that impact them (O'Boyle and Jamieson, 2006). However, ecosystems and the humans that impact them have a complex link and it is now clear that responses to management decisions and the corresponding changes in use cannot be predicted with an understanding of individual components alone (O'Boyle and Worcester, 2009). To avoid this pitfall, the conceptual objectives for coastal and ocean management should be developed with guidance from a wide variety of stakeholders (including industrial organizations, NGOs, government agencies, scientists and researchers, general public), and should account for sustainable social, economic and institutional development, as well as environmental management and use. In this manner, all activities and industries operating in the management planning area should be managed with the same overall goals and desires (O'Boyle et al., 2004). In particular, models that couple the ecological dynamics to socio-economic structure and processes can provide useful insights. 
Examples of such models are found in Appendix D, including bioeconomic models and Input-output (IO) models linked to food webs (Jin et al., 2003).

Typically, the process of writing conceptual objectives begins with identifying the ecosystem component involved. The conceptual objective should be defined as specifically as possible using a characteristic of the ecosystem component. A characteristic is a biological property of the ecosystem, separate from our ability to measure it (Jamieson et al., 2001). For example, O'Boyle et al. (2004) identify spatial distribution and recruitment as characteristics, but a related, measurable indicator would be something like age one numbers from a population model.

Conceptual objectives should be articulated with verbs such as maintain, conserve, restore or minimize that can be coupled with an ecosystem component. In an example given by O'Boyle et al. (2004), one possible conceptual objective could be to "restore benthic community biodiversity to condition present in the 1960s". The phrasing of the objective should indicate that it is to be attained over the long term. Conceptual objectives should not include measurable indicators or reference points. The conceptual objective will influence determination of the reference points (and indicators to monitor those reference points) in the operational objectives (O'Boyle et al., 2004). The process must also be adaptive, with periodic evaluations and revision built in, to account for changing interests and use over time (Rosenberg et al., 2007).

Table 5. Relationship between Massachusetts Oceans Act issues and Ecosystem Models considered in this report.

\begin{tabular}{|c|c|c|c|c|c|c|c|c|}
\hline \multirow{3}{*}{ Class of Issues } & \multicolumn{8}{|c|}{ Minimally Realistic Models } \\
\hline & \multicolumn{6}{|c|}{ Non Spatial } & \multicolumn{2}{|c|}{ Spatial } \\
\hline & ESAM & MRM & MSVPA & MSVPA-X & MS-PROD & MSM & GADGET & CCAMLR \\
\hline \multicolumn{9}{|l|}{ Community biodiversity } \\
\hline \multicolumn{9}{|l|}{ Species biodiversity } \\
\hline \multicolumn{9}{|l|}{ Population biodiversity } \\
\hline \multicolumn{9}{|l|}{ Base of Food Chain } \\
\hline \multicolumn{9}{|l|}{ Population Productivity } \\
\hline \multicolumn{9}{|l|}{ Food Chain Processes } \\
\hline \multicolumn{9}{|l|}{ Water Column } \\
\hline \multicolumn{9}{|l|}{ Bottom Habitat } \\
\hline \multicolumn{9}{|l|}{ Water Quality } \\
\hline \multicolumn{9}{|l|}{ Biota Quality } \\
\hline \multicolumn{9}{|l|}{ Economic } \\
\hline Social \& Cultural & & & & & & & & \\
\hline
\end{tabular}




\begin{tabular}{|c|c|c|c|c|c|c|c|c|c|c|c|}
\hline \multirow{3}{*}{ Class of Issues } & \multicolumn{11}{|c|}{ Whole Ecosystem Models } \\
\hline & \multicolumn{4}{|c|}{ Aggregate System Models } & \multicolumn{7}{|c|}{ Dynamic System Models } \\
\hline & EwE & SSEM & Agg-PROD & EMAX & ATLANTIS & ERSEM & SEAPODYM & OSMOSE & INVITRO & MIMES & SystMOD* \\
\hline \multicolumn{12}{|l|}{ Community biodiversity } \\
\hline \multicolumn{12}{|l|}{ Species biodiversity } \\
\hline \multicolumn{12}{|l|}{ Population biodiversity } \\
\hline \multicolumn{12}{|l|}{ Base of Food Chain } \\
\hline \multicolumn{12}{|l|}{ Population Productivity } \\
\hline \multicolumn{12}{|l|}{ Food Chain Processes } \\
\hline \multicolumn{12}{|l|}{ Water Column } \\
\hline \multicolumn{12}{|l|}{ Bottom Habitat } \\
\hline \multicolumn{12}{|l|}{ Water Quality } \\
\hline \multicolumn{12}{|l|}{ Biota Quality } \\
\hline \multicolumn{12}{|l|}{ Economic } \\
\hline Social \& Cultural & & & & & & & & & & & \\
\hline
\end{tabular}

Ecosystem models and tools can help inform the process of creating conceptual objectives (Appendix A; Table 5). While many of the modeling approaches are specific to objectives such as fisheries management, they can be useful in summarizing available information and elucidating interactions and linkages more broadly. For example, the mapping and evaluation of human uses and impacts (Appendix B) can focus attention on highly vulnerable impacted areas and might enable framing of conceptual objectives for conservation or continued development of those areas.

\subsection{Define desired future state and time frame}

In addition to overarching conceptual objectives, O'Boyle and Jamieson (2006) argue that there should be a continuum of conceptual objectives, defining increasingly greater detail as one 'unpacks' or reveals the specific outcomes that make up the conceptual objective (O'Boyle and Jamieson, 2006). Decision makers can organize the components into a 'tree', each branch becoming more specific. The tree structure was initially advocated in Australia by Chesson (1998) and referenced in Sainsbury and Sumaila (2003).

At the end of each branch of the conceptual objectives tree, decision makers will define an operational objective and assign indicators and reference point to monitor it (O'Boyle and Jamieson, 2006). An example Conceptual Objectives tree is below (Figure 3, from Jamieson et al., 2001). According to the authors, the overarching conceptual objective in this figure (Conservation of Species and Habitats) is one of two broad, overarching management goals, the other being the sustainability of human usage of environmental resources (Dimensions of Human Activity). The ecosystem components addressed by the conceptual objectives in this diagram are biodiversity, productivity and physical and chemical properties. The main strength of the objectives tree is the sorting and organizing of the policy issues (such as those identified in Section 4). The tree allows one to readily see how the collection of issues is being broken down into conceptual objectives. 


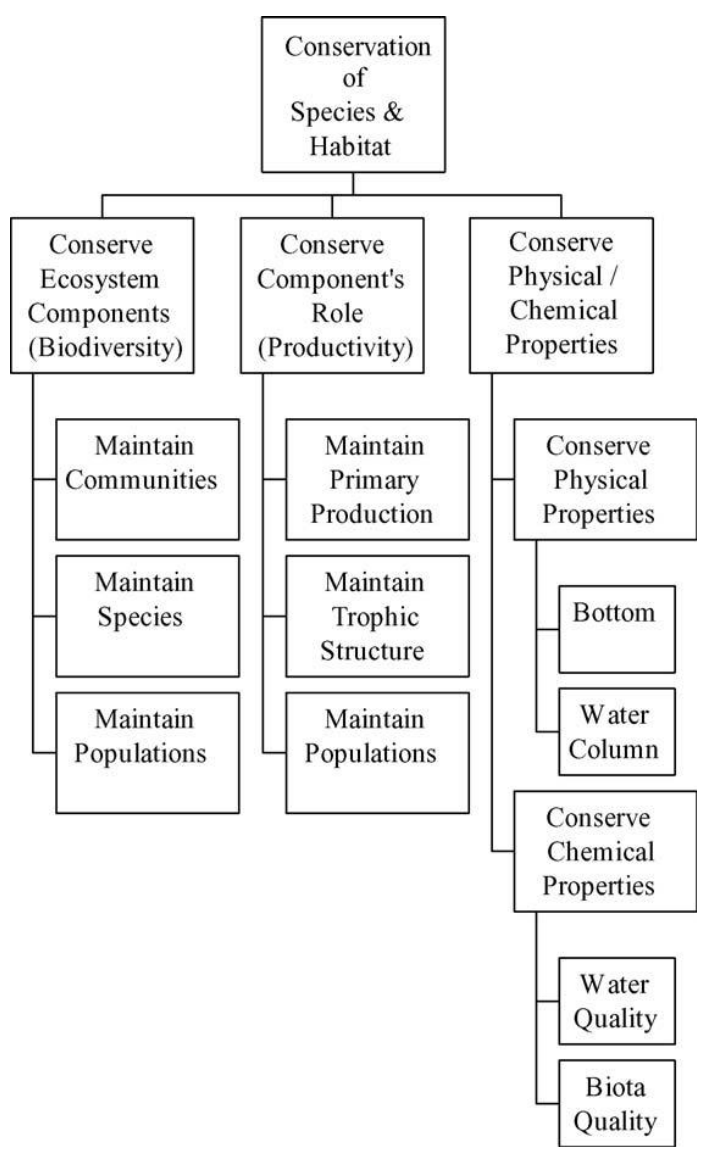

Figure 3. Conceptual objectives tree for the environmental dimension of integrated management in Canada (Jamieson et al., 2001).

Deliberations on the identification and characterization of policy issues at all levels for the Commonwealth of Massachusetts(identified in Section 4 of the EBM Implementation process) -from conceptual to operational-should incorporate the environmental and socio-economic concerns of all major stakeholders (O'Boyle et al., 2004). When determining all objectives, and particularly socio-economic ones, the process must be transparent and participatory so as to incorporate and reflect a broad set of community and industry interests. To the extent feasible, it is important to characterize in economic terms the opportunity costs of alternative policy options, so that stakeholders are able to perceive the relevant tradeoffs when one set of uses is given up or regulated in favor of another. The market and non-market valuation techniques discussed briefly in Appendix D will be useful for organizing thinking about tradeoffs.

An issue that will most likely emerge in Massachusetts is the role of stakeholder input into the biological conservation objectives. Process managers should note that there is no clear consensus on the role of stakeholder input into the setting of biological conservation objectives. The developing consensus is that the biological scientific community should develop these objectives as they are constraints on the socioeconomic objectives. Additionally, it is important to identify where issues are addressed within the conceptual objectives hierarchy. Knowing where individual issues fall in the tree will be especially important when calculating interactions and the cumulative effects of activities across various coastal and ocean activities (O'Boyle et al., 2004). On the other hand, the Massachusetts process highlights economic development in the statute as well as the engagement of stakeholders in the state process. One possibility is to have scientists, with their knowledge of ecosystem components and interactions, define priority conservation conceptual objectives. Experience in comparable processes that have designated objectives and priority uses for areas of ocean activity suggests that it is critical to make such scientific debate transparent. Controversy will arise around a decision to place such priority setting in the hands of scientists, but enabling stakeholders to observe-if not participate in-the debate, and to 
understand how priority setting is accomplished has proven useful in other settings (ludicello et al., 2004; Bernstein and ludicello, 2004).

Diagramming the objectives tree (Figure 3 ) and creating a visual link between the conceptual objectives and management can provide a rationale for the selection of particular indicators. In the past, management has stumbled when setting objectives, because they can sometimes be defined solely in response to previously collected data rather than the importance of the ecosystem component in the ecosystem. One indicator project labeled this tendency "finding data under the lamp post" (Heinz Center 2002; 2003). The authors point out that indicator selection should be goal driven, not measurement driven.

Managers need to determine what indicators will inform them of the state and trends of key ecosystem components for which they have objectives, even if indicators need to be developed, and even if no program is monitoring data to fill that indicator. A good example is the need for data on the specific geographic location of commercial finfish harvests for fishing vessels holding only state-permits that fish in Massachusetts waters. Without such data, it is difficult to estimate the opportunity costs of displacing commercial fishing in order to site permanent facilities, such as a deepwater port or a renewable energy facility.

To inform the State in their objective setting process, we refer you to Table 6 (O'Boyle and Jamieson, 2006) and Table 7 (Jamieson et al., 2001), which provide overviews of the components that objectives for the dimensions of human activities and the environment might address. Decision makers would develop conceptual objectives, in partnership with stakeholders, for every selected component.

Table 6. Components in the social and cultural, economic and institutional dimensions of sustainable development (from O'Boyle and Jamieson, 2006).

\begin{tabular}{|c|c|c|}
\hline $\begin{array}{l}\text { Social and cultural } \\
\text { dimension }\end{array}$ & $\begin{array}{l}\text { Economic } \\
\text { dimension }\end{array}$ & Institutional dimension \\
\hline $\begin{array}{l}\text { Community structure } \\
\text { 1. Ocean access } \\
\text { 2. Sharing } \\
\text { 3. Resource allocation }\end{array}$ & $\begin{array}{l}\text { Sector valuation } \\
\text { 1. Economic } \\
\text { costs/benefits }\end{array}$ & $\begin{array}{l}\text { Management approach } \\
\text { 1. Degree to which international, national, regional } \\
\text { and local requirements/ responsibilities met } \\
\text { 2. Decision-making (e.g. collaborative, inclusive, } \\
\text { transparent) } \\
\text { 3. Adaptability } \\
\text { 4. Responsiveness }\end{array}$ \\
\hline $\begin{array}{l}\text { Community behavior } \\
\text { (e.g. code of conduct) } \\
\text { 1. Best practices } \\
\text { 2. Responsible use }\end{array}$ & $\begin{array}{l}\text { Sector resilience } \\
\text { 1. Economic self- } \\
\text { reliance } \\
\text { 2. Pace of } \\
\text { develonment }\end{array}$ & $\begin{array}{l}\begin{array}{l}\text { Acceptability of management approach } \\
\text { (e.g. co-management) }\end{array} \\
\text { 1. Benefit for administrative cost }\end{array}$ \\
\hline $\begin{array}{l}\text { 3. Stewardship } \\
\text { 4. Compliance } \\
\text { 5. Safety and security }\end{array}$ & & $\begin{array}{l}\text { Achievement of management approach } \\
\text { 1. Sufficiency of institutional resources (eg. } \\
\text { commitment) } \\
\text { 2. Compliance with system }\end{array}$ \\
\hline
\end{tabular}

Table 7. Conceptual objectives of the environmental dimension (from Jamieson et al., 2001) 


\begin{tabular}{|l|c|c|}
\hline $\begin{array}{c}\text { To conserve enough } \\
\text { components (ecosystems, } \\
\text { species, populations, etc.) so } \\
\text { as to maintain the natural } \\
\text { resilience of the ecosystem }\end{array}$ & $\begin{array}{c}\text { To conserve each component of } \\
\text { the ecosystem so that it can play } \\
\text { its historic role in the foodweb } \\
\text { (i.e., not cause any component of the } \\
\text { ecosystem to be altered to such an extent that } \\
\text { it ceases to play its historical role in a higher } \\
\text { order component) }\end{array}$ & $\begin{array}{c}\text { To conserve the physical } \\
\text { and chemical properties of } \\
\text { the ecosystem }\end{array}$ \\
\hline $\begin{array}{l}\text { A. To maintain communities within } \\
\text { bounds of natural variability }\end{array}$ & $\begin{array}{l}\text { A. To maintain primary production within } \\
\text { historic bounds of natural variability }\end{array}$ & $\begin{array}{l}\text { A. Conservation of physical } \\
\text { properties of the ecosystem } \\
\text { 1. To conserve critical } \\
\text { landscape and bottomscape } \\
\text { features } \\
\text { 2. To conserve water column } \\
\text { properties }\end{array}$ \\
\hline $\begin{array}{l}\text { B. To maintain species within bounds } \\
\text { of natural variability }\end{array}$ & $\begin{array}{l}\text { B. To maintain trophic structure so that } \\
\text { individual species/stage can play their } \\
\text { historical role in the foodweb }\end{array}$ & $\begin{array}{l}\text { B. Conservation of chemical } \\
\text { properties of the ecosystem }\end{array}$ \\
\hline $\begin{array}{l}\text { C. To maintain populations within } \\
\text { bounds of natural variability }\end{array}$ & $\begin{array}{l}\text { C. To maintain mean generation times of } \\
\text { populations within bounds of natural } \\
\text { variability }\end{array}$ & 1. To conserve water quality \\
\hline
\end{tabular}

\subsection{Link each Conceptual Objective to national, state and local policy}

The point in the planning process at which conceptual objectives are determined will greatly influence the effectiveness of the management plan (i.e., the earlier the better). However, conceptual objectives must also be set within the boundaries of existing legislation (on the national, state and local levels). User group needs or desires cannot force compromise on this issue (Rosenberg et al., 2007). Ecosystem objectives from federal, state and even municipal policy (e.g. CZMA) are often broadly stated and may be difficult to incorporate directly into management plans (Sainsbury et al., 2000).

A few examples of binding policy statements from existing legislation are

- to promote efforts which will prevent or eliminate damage to the environment and biosphere and stimulate the health and welfare of man (NEPA)

- to enrich the understanding of the ecological systems and natural resources important to the Nation (NEPA); to protect marine mammals (MMPA)

- to preserve, protect, develop, and where possible, to restore or enhance, the resources of the Nation's coastal zone for this and succeeding generations (CZMA)

- to conserve endangered species and threatened species (ESA)

- to protect and promote tidelands as a workplace for commercial fishing, shipping, passenger transportation, boat building and repair, marinas and other activities for which proximity to the water is either essential or highly advantageous (Chapter 91)

These mandates must be incorporated into the development of conceptual objectives for an integrated plan and elaborated with respect to specific ecosystem components or services. For example, in applying Table 7 above, federal state and local requirements for conservation and management will build detail in one or more dimensions of objective setting.

\subsubsection{Society - ecosystem linkages}

While conservation of the ecosystems is critical when creating an Ocean Management Plan for Massachusetts, we must remember that we manage people and their actions, not ecosystems. Management areas are administrative tools that organize human impacts, and while human activity is not 
necessarily conveniently organized for ecosystem management, EBM requires that managers keep the ecosystem in sight and create zones for human activities that are compatible with the maintenance of ecosystem services. For example, the delineation of management plan areas may have to comply with jurisdictional boundaries, as opposed to ecosystem boundaries and the distribution of ecosystem components (O'Boyle and Worcester, 2009). O'Boyle and Worcester also suggest that in order to garner support for EBM among all stakeholders, initial efforts should build upon existing management processes and doctrines.

\subsubsection{Evaluate tradeoffs among services}

Rosenberg et al. (2007) cautions that decision makers can make tradeoffs between user-group desires, but they cannot forego primary policy restrictions or compromise on conservation and sustainability in order to alleviate conflict between use groups. In the face of uncertainty about environmental conditions and about the spatial distribution of human uses, it is not always easy to characterize the appropriate level of conservation or development. To help decision makers identify and evaluate trade-offs among objectives and to examine uncertainty, an iterative Management Strategy Evaluation (MSE) process may be implemented (Section 6). The information that MSE provides gives decision makers the necessary facts with which to evaluate the consequences of and alternatives to various proposed objectives. It is a somewhat subjective process, as decision makers can apply their own weightings and risk levels (Smith et al., 1999).

\subsection{Tools}

Given the decisions that are required when setting objectives, managers will need to conduct analyses of various impacts and scenarios. There are several decision support tools that will assist managers in this endeavor. Short descriptions for a selection of these tools are given here; longer summaries are provided in Appendix B and D to this report.

- Human Impact Mapping. Mapping the geographical distribution of human uses and impacts helps focus attention on vulnerable areas based on expert opinion and the available data on habitat types. This enables managers to consider how management objectives might be set for specific areas in coastal waters.

- Ecoregional Assessments (ERA). ERAs evaluate biodiversity in defined regions and are useful in informing the types, places and priorities for actions, and focusing large-scale conservation planning. As part of each assessment, The Nature Conservancy evaluates various decision support tools that managers and decision makers might employ when managing natural resources.

- Input-Output (IO) Modeling. 10 modeling comprises a system of linear equations that describe intersectoral flows in an economy. An input-output model answers the following question: given a specified shift in the level of final demands for economic goods and services, how do the levels of output from each of the industrial sectors of the economy change? The model is useful because it provides a map of the links between industrial sectors. The scale of these links can be summarized by one or more of a family of measures known as "multipliers."

- Ecological Risk Management. The ERM framework was designed to assess and address the impacts that fisheries activities have on five aspects of the marine ecosystem, including: target species; bycatch; threatened, endangered and protected species; habitats; and communities. The risk assessments are the foundation of the ERM framework and are designed to assist with prioritizing research, data collection, monitoring and future management decisions.

- Green Accounting. Green accounting involves two primary tasks: (1) measuring, in physical units, the changes in environmental quality, natural resource stocks, and other ecosystem services; and (2) estimating shadow prices for environmental quality, resource stocks, and ecosystem services. With estimates of both quantity and price, a green accounting framework can incorporate the consumption of resource endowments (e.g., depletion of exhaustible resources) and the depreciation of environmental quality stock into the state product accounts. Green accounting should be an important part of the monitoring program. 
- Multi-Criteria Assessment Modeling. Multi-Criteria Assessment Models assist decision makers in choosing a solution (or ranking ecosystem components) when multiple alternatives or courses of action are possible. These models are a quantitative way to evaluate often complex problems containing both quantitative and qualitative data, and the solutions are transparent and easy to understand.

- Mulino framework. The Mulino framework is a decision support system (DSS) that facilitates and structures productive discussion between decision makers and stakeholder groups regarding environmental problems. The methodology combines a DPSIR (Driving Forces - Pressure State - Impact - Response) approach with multi-criteria analysis methods using a decision support system (DSS) called mDSS.

- InVEST. InVEST is a tool that models and maps the delivery, distribution, and economic value of ecosystem services, or natural capital. There are three tiers available for use in the InVEST program, the first of which examines biophysical consequences of decision making. This tier does not require extensive input data, and provides a sense of the level of services provided in the ecosystem in question; Massachusetts will benefit from using this tier only in conjunction with Impact Mapping.

\section{Management Strategies}

The human uses and non-uses of the ocean involve potential overlaps in which some uses may conflict with others. Management of these multiple uses can lead to contention among stakeholders and is a necessary complication of the management process; as noted above in 5.2.2, one approach to addressing the issues arising from multiple uses is through Management Strategy Evaluation (MSE), as a system wide approach. MSE starts with setting conceptual objectives and then designing operational management strategies to meet the conceptual objectives. To explore the response of a system to different management strategies, the operational management strategies are evaluated iteratively by assessing the consequences of a range of management options and identifying the trade-offs in performance across a range of management objectives (Smith et al., 1999). Development and evaluation of management strategies is neither easy nor straightforward, though there has been considerable progress in the last two decades, particularly in fisheries management (Sainsbury et al., 2000). The complete evaluation of a management cycle relies on scientific input, and the resulting predictions for management actions will be uncertain to some degree as the ecosystem dynamics are complex (Smith et al., 2007; Sainsbury et al., 2000).

MSE can help identify scientific research priorities. Using MSE, the assumptions and uncertainties implicated in each component of the management system are explicitly stated and, through simulation, alternative management strategies are investigated. The simulation testing at the core of MSE methods uses performance measures derived from operational objectives to evaluate an entire management process (Smith et al., 2007). The goal is to determine which strategy both emphasizes the identification and modeling of uncertainties and leads to the robust achievement of the objectives (McAllister et al., 1999; Smith et al., 1999; 2007). The MSE approach considers not only the biological components of the management system, but also those related to monitoring and implementation. The concept of strategy evaluation or scenario analyses must be incorporated into the process at this stage, once operational objectives are identified, either with a formal MSE approach or a more qualitative analysis MSE has been applied for some fisheries outside the United States; most recently, at the level of a whole fishery with the southern and eastern scalefish and shark fisheries off Australia (Smith et al., 1999; 2007; Sainsbury et al., 2000). Scientists at Australia's Commonwealth Scientific and Industrial Research Organization (CSIRO) utilized a qualitative MSE (similar to the approach taken by Fletcher, 2005), which allowed the team to identify the low, medium, and high priority issues in a management system. This was followed by more detailed investigation of the medium and high priority issues through quantitative MSE as well as Ecological Risk Assessment (Smith et al., 2007). 


\subsection{Identify Operational Objectives associated with each Conceptual Objective}

The linkage between conceptual and operational objectives provides a clear path to choose indicators and evaluate performance (O'Boyle and Jamieson, 2006). As described in above in Section 5, conceptual objectives can be 'unpacked' into operational objectives which indicate specific actions, indicators, and reference points (Jamieson et al., 2001). Unlike conceptual objectives, which apply to all ocean activities in a management area, operational objectives are specific and guide the management of specific activities that are impacting the ecosystem. The operational objectives can address individual activities or cumulative impacts of a number of ocean activities. After setting operational objectives, managers then design and implement a monitoring program for each indicator and establish a framework for assessing the monitoring data (O'Boyle et al., 2004). We have chosen to examine operational objectives at both the management level and the specific activity level (or management action), which has the advantage of integrating both monitoring and control objectives into ecosystem based management (EBM). The monitoring objectives are generally discussed within the ocean science community without regard to management application, while control objectives are typically discussed within the ocean management community. By incorporating both into EBM, the monitoring gives context to the controls.

\subsubsection{Operational Objectives at the Management Level}

Process managers may develop operational objectives based on the conceptual objectives that were extracted from the Oceans Act principles, or elicit objectives from existing management plans and policies and array them in an integrated management fashion. Operational objectives at the management level have two purposes: 1) to control cumulative impacts on specific ecosystem components across activities; and 2) to monitor ecosystem health. Research on the operational objectives is targeted on the indicators and reference points required to measure progress towards the conceptual objectives. Numerous indicators can be considered when configuring operational objectives, For this reason, it is useful to use the DPSIR system ${ }^{8}$ to classify indicators. For instance, an operational objective might include indicators of the state of an ecosystem component, the pressure imposed by some human activity, and the management response.

If multiple activities have an impact on the same ecosystem feature (e.g., bottom trawling, mining, oil and gas pipelines all affect bottomscape), then we must manage the cumulative impacts of these activities. An operational objective to manage cumulative impacts would have to be included at the management level to inform operational objectives at the activity level. The second use for operational objectives at the management plan level relates to the determination of the overall health of the ecosystem in the management plan area. For ecosystem features where there is an operational objective to address cumulative impacts, this should suffice. For the features of the ecosystem where there are no cumulative impacts being assessed at the management plan level, operational objectives would need to be developed that, while having no direct management implication, would be used to monitor the overall effectiveness of integrated management and ecosystem health. In this case, the term 'operational' refers to the need to monitor the identified ecosystem features (O'Boyle et al., 2004).

\subsubsection{Operational Objectives at the Activity Level}

Associated with each operational objective is some management action to ensure achievement of the objective. For instance, imposition of a Marine Protected Area might be the action associated with an objective to conserve benthic habitat. While operational objectives for specific activities in light of other sectors are developed using the same format as for operational objectives at the management level, these objectives all have associated management actions; none are used purely for monitoring purposes.

${ }^{8}$ http://maps.grida.no/go/graphic/dpsir_framework_for_state_of_environment_reporting 
Research on the actions associated with management strategies is targeted at determining the technical merits of mitigation in the achievement of the objectives. While the operational objectives deal with the pressure on and state of an ecosystem component, the actions deal with the management response.

One way of organizing the objectives is to have an objectives tree that outlines the desired conceptual objectives and that formally links these to operational objectives used in everyday management. This forces consideration of why a particular indicator should be, or is being, measured. Jamieson et al. (2001) highlighted difficulties in developing a suite of operational objectives from the conceptual objectives tree and concluded that unpacking the conceptual objectives tree needs to occur as part of an overall management plan implementation process (O'Boyle and Jamieson, 2006).

It is essential to unpack all branches as completely possible, drawing on experts and stakeholders knowledgeable about the local ecosystem and available data. Unpacking is an iterative exercise and experts can fine-tune the initially proposed objectives at a later stage. Operational objectives considered under one conceptual objective may also be relevant to other conceptual objectives. As such, it is important to maintain an overall objectives-tree perspective in each unpacking exercise so as to recognize potential duplication and to ensure that all relevant conceptual objectives are adequately addressed (O'Boyle and Jamieson, 2006).

\subsubsection{Steps to Implement Operational Objectives}

For the purpose of being explicit, we have identified five steps that must occur for the implementation of operational objectives once managers and decision makers have identified conceptual objectives:

1. Examine, on a sector-by-sector basis, the management actions being taken and the indictors and reference points that inform them.

2. Formally link existing management activities to the conceptual objectives.

3. Identify gaps that need to be filled (the State would be responsible for this step.).

4. Develop, using a priority identification process, management strategies to fill operational objectives gaps in sectors (the State, in consultation with industries, would be responsible for this step).

5. Identify cumulative impacts and revise management area operational objectives, in consultation with stakeholders.

\subsection{Identify Management Actions associated with Operational Objectives to address high priority impacts}

Scenario analysis can be used to evaluate the results of alternative management approaches. The analysis should incorporate a broad range of information and consider likely changes that are expected from a particular action. In simplest form, a scenario analysis might use a simple model of a small number of ecosystem features to simulate likely changes under different management actions. For example, a simple fishery model of a single species, such as a surplus production model, might provide the basis for simulating the effects of changing fishing pressure on that species.

For ecosystem level effects with many different ecosystem features and human activities to consider, an approach to scenario analysis might begin with simple mapping of features and activities with as much spatial resolution as possible. Then, the ecological and socio-economic effects of area protection can be considered in terms of the spatial pattern of activities. It is important to model human behavioral changes in reaction to the change in specification of protected areas. Of course, a much more sophisticated approach would be to rate the vulnerability of ecosystem components to different activities (e.g. Halpern et al., 2008; Hobday et al., 2007).

More sophisticated scenario models analyze the dynamics of ecosystem features (e.g. including human uses, ecosystem responses, and human reactions) in the system, and then simulate what happens when management actions are taken. Model approaches such as MIMES, ATLANTIS, InVEST, bioeconomic models and others (Appendices B and D) take this approach. As more of the dynamics are simulated, 
more parameters and assumptions may be needed. Ecosystems have very high dimensionality, with many species, features and activities that vary over space and time. Because model systems for complex simulations can have hundreds or thousands of parameters, interpretation of results can rapidly become very difficult, especially if the sparseness of available data leads to highly uncertain results. Nevertheless, these models can synthesize a lot of information, and although labor intensive to develop, can be very informative if interpreted with care.

\subsection{Tools}

The decision support tools required to guide the setting of operational objectives and the selection of indicators are separate from those that aid with conceptual objectives, because operational objectives are very specific and are often used to guide management. Decision support tools for setting operational objectives include MARXAN, the OCEAN Framework, CAPS, MIMES, ATLANTIS, cost-benefit analysis, decision-making under uncertainty, bioeconomic models, and adaptive management. A separate tool may be necessary for creating the indicator framework with reference points and targets for performance evaluation. One option for this, the DSPIR framework, accounts for large-scale human drivers of forces, pressures, changes in state of coastal ecosystems, their consequences or impacts and management responses to them (Appendix C).

Short descriptions of the tools appropriate for setting operational objectives are given here, and longer summaries are provided in Appendices B and D:

- MARXAN with Zones. MARXAN can be employed to create alternative zoning configurations that minimize social, economic and ecological cost. It is a stand alone decision support tool for assisting planners with site selection and has been used extensively in marine and coastal planning and used to support multiple-use zoning plans that balance the varied interests of stakeholders. The Marxan approach, while data intensive, allows managers to analyze alternation zoning configurations based on solutions for a specific set of performance criteria. It has been used extensively to consider placement of protected areas within an ecosystem but has broader application once specific criteria are agreed upon.

- OCEAN Framework. The OCEAN Framework is a suite of tools developed by Ecotrust which allows for spatial analysis and interpretation of ecological and socioeconomic data.

- Conservation Assessment and Prioritization System (CAPS). CAPS is a decision support tool for conservation-and-restoration site selection. Researchers at the University of Massachusetts have developed this tool to assess the ecological integrity and biodiversity value of lands and waters (UMass 2007). Within the CAPS framework, assessments have been based upon natural community-specific models.

- Multiscale Integrated Model of the Earth System's Ecological Services (MIMES). MIMES is an interactive and dynamic interface developed for the spatial representation of various models describing an ecosystem(s). These models specifically address environmental resources and are geared towards ecosystem services. The premise is to represent an ecosystem via the true value of services provided for human welfare, and how various management scenarios might alter these services' function and value.

- $\quad \boldsymbol{A T L A N T I S . ~ A T L A N T I S ~ i s ~ a ~ m o d e l ~ w h i c h ~ s e e k s ~ t o ~ p r o v i d e ~ d e c i s i o n ~ m a k e r s ~ w i t h ~ t h e ~ i n f o r m a t i o n ~}$ with which to make rational decisions, given their own objectives, preferences, and attitudes toward risk. It is a deterministic biogeochemical whole-ecosystem model built specifically around the MSE approach, and includes modules for each of the major steps in the adaptive management cycle. It should be noted that the runtime for ATLANTIS, therefore the experiments performed with this model must be carefully chosen and designed.

- Benefit-cost Analysis (BCA). BCA comprises studies that compare the economic benefits and economic costs of the potential implementation of a policy to modify the allocation of resources. Economic benefits are measured in terms of consumer and producer surpluses; these surpluses may be observed in market settings or they may arise outside of markets, in the case of public goods or failed markets. Economic costs are opportunity costs, which are the potential surpluses that could obtain under alternative resource allocations. BCA involves identifying and estimating 
total economic value, comprising market values as well as non-market values, such as use and nonuse (existence, bequest, option) values.

- Decision-making under Uncertainty. Uncertainty about future effects is a common feature of management decisions about activities that affect natural resources. Decisions under uncertainty can be made systematically by trading off the expected benefits of the managed activity against the expected costs, including the risk of adverse consequences on natural resources and on other activities and uses. This requires an assessment of the potential risks (see "risk assessment and mitigation"), and a framework for trading off risks and benefits.

- Bioeconomic Models. Bioeconomic models have been used widely to examine fisheries management problems since the mid-1970s (Clark, 1976). These models couple biological growth models for one or more species (with biological interactions) with economic models of firm or fleet profits. The strength of bioeconomic modeling lies in revealing economically optimal levels of yield and the net benefits of the implementation of alternative management measures (cf., Edwards and Murawski, 1993). In some circumstances, the bioeconomic approach also can be used to determine the optimal dynamic path to a steady state. In these contexts, bioeconomic models can be viewed as a specific type of benefit-cost analysis. Because it often involves the use of nonlinear dynamic models of production and species growth and interactions, the bioeconomic approach is difficult to apply to a large number of species or markets.

- Adaptive Management. Adaptive management is a structured, iterative process of updating management decisions based on changes in observed outcomes or in factors that may be expected to change future outcomes. It is a useful approach for managing renewable resources, such as commercial fish stocks, that change in response to the combination of human exploitation/management and other exogenous factors, such as climate conditions. Adaptive management can also be a practical alternative to an outright ban on an economic activity that produces an uncertain risk of significant but reversible harm to marine resources. Under adaptive management, such an activity might be allowed to proceed at a limited scale, under guidelines that ensure monitoring and research to detect adverse effects early, and with provisions for the adjustment and revision of the activity in light of new information about its effects.

In general, the models provide means to identify the indicators in the DPSIR system, which comprises the cause and effect relationships necessary for management. They also allow identification of limit and precautionary reference points that could be linked to management actions.

Aside from models, the other main tool that is essential to developing operational objectives is an indicator framework which allows for the selection of a wide array of potential indicators of ecosystem state including socio-economic indicators and reference points (Appendix C). These indicators should convey the status of ecosystem and associated socioeconomic activities. When selecting indicators, some desired properties such as high signal strength, low noise, good data availability and a long time series should be considered. The State should aim to manage the ocean and coastal resources according to the precautionary approach, which implies the realization of limit reference points through operational objectives. Care should be taken to ensure that the selected indicators are relevant to actual management actions. An example DPSIR framework has been drafted and is included in Appendix C for initial consideration and review. This framework will have to be revised as information on data availability becomes available and objectives for the management plan area are solidified.

\section{Monitoring, Evaluation, and Adaptive Management}

As discussed above (Section 6) Management Strategy Evaluation (MSE) involves setting conceptual objectives and then designing operational management strategies to meet those conceptual objectives. The design of operational objectives includes indicators that allow on-going monitoring of the objective's effectiveness. Operational management strategies are then evaluated, and modified as needed. This cycle of monitoring, evaluation, and adjustment is sometimes termed adaptive management.

Monitoring results tell "what" is going on but not "why," so monitoring serves as the basis for evaluation. Evaluation is "the systematic collection of information about activities, characteristics, and outcomes of 
projects to make judgments about the project, improve effectiveness, and/or inform decisions about future planning" (Patton, 1997). Evaluation assesses management effectiveness, i.e. the degree to which management actions are achieving the stated goals and objectives of the site or system of protected areas. Adaptive management structures a decision and evaluation process to enable management to be highly responsive to information gathered from monitoring and evaluation (Millennium Ecosystem Assessment, 2005).

With regard to marine protected areas, adaptive management is defined by the California Marine Life Protection Act (MLPA) and the Marine Managed Areas Improvement Act (MMAIA) as "a management policy that seeks to improve management of biological resources, particularly in areas of scientific uncertainty, by viewing program actions as tools for learning. Actions shall be designed so that, even if they fail, they will provide useful information for future actions, and monitoring and evaluation shall be emphasized so that the interaction of different elements within marine systems may be better understood" (Section 2852(a) FGC). Agardy (1997) recommends that managers and conservation practitioners apply adaptive management principles to improve management effectiveness and to address the large uncertainties surrounding coastal and marine ecosystem management. Adaptive management allows managers to learn from their own and others' successes and failures.

Although monitoring, evaluation, and adaptive management programs are considered critical to EBM success, they sometimes face both operational and political obstacles. Day et al., (2002) note that monitoring and evaluation are often displaced or neglected in day-to-day management operations, leaving managers with little information to guide progress toward achieving objectives and adapting and improving management. Mooney-Seus and Allen (2007), in recommending that EBM needs to be supported by a science plan based on monitoring, caution that monitoring is one of the most difficult science activities to support fiscally and politically. Lee (1999) warns that the approach should only be applied to specific issues agreed upon by all stakeholders. Nevertheless, international initiatives, national policies, managing agencies, and other stakeholders now emphasize outcome-based performance measurements (rather than activity-based) to assess whether management effectiveness is proportional to the type and level of investment (Day et al., 2002; Pomeroy et al., 2004), and monitoring is essential to such performance measurement.

Thus, the process we recommend for implementing EBM involves continual reevaluation of goals, objectives, and associated management actions, as well as the scientific information available to inform those actions. A monitoring and evaluation plan should be designed to be both cost effective and thorough. The process of setting and assessing performance metrics requires that the management plan's ecological and socio-economic goals must be clearly stated up front for management actions to accurately reflect those goals.. To evaluate the management plan's effectiveness, a range of ecological, socioeconomic and institutional metrics or indicators need to be developed and monitored (Leslie and McLeod, 2007). Performance criteria should not only allow evaluators to judge whether particular policies and strategies are working, but also provide clues as to how they can be made more effective. The evaluation process needs to both identify shortcomings in management, and report progress being made towards management goals. Evaluation should give managers the information they need to adapt their management strategies and provide accountability by reporting results to all stakeholders.

Adaptive management requires that the evaluation process include more than simply identifying the outputs of the chosen set of indicators. Hockings and colleagues (2000) point out that effectiveness assessments typically fall into one or more of three broad categories:

- Design issues (i.e. context and planning);

- Appropriateness of management systems and processes (i.e. input and process);

- Delivery of protected area objectives (i.e. outputs and outcomes).

All of these categories need to be taken into account in adaptive management. The management cycle (Figure 4) presents six categories of ecosystem management subject to effectiveness evaluation. Indicators for monitoring effectiveness can be created for each category and should address issues within and beyond management control. The most comprehensive evaluation would address the entire cycle (Hockings et al., 2000; Day et al., 2002). 


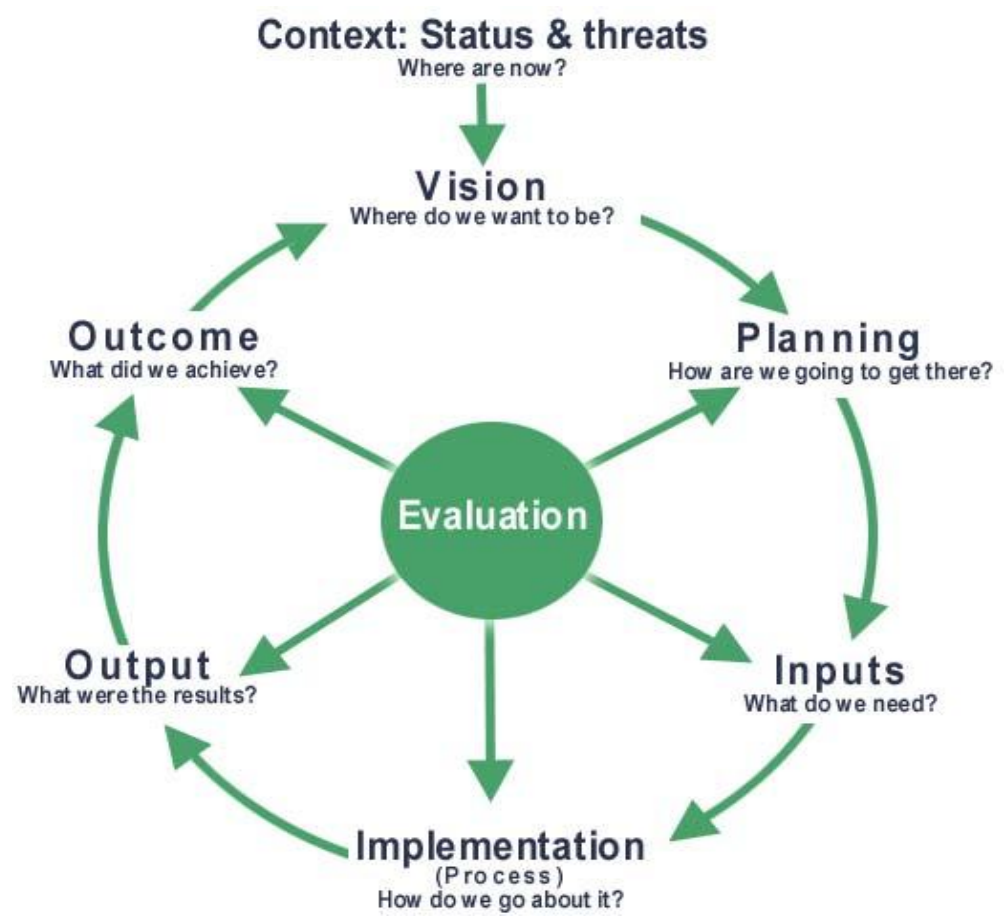

Figure 4. The management effectiveness framework (Hockings et al., 2000).

Evaluation methods at the site-level tend to be outcome-oriented, while evaluation methods designed at the system level, or site and system level, are geared toward management processes and inputs (Hockings et al., 2000). Assessing system effectiveness can identify issues that policy-makers can address with strategic, system-wide responses (Ervin, 2003). Because all six categories are subject to change over time, an adaptive management strategy demands iterative assessment of system elements, and the development of appropriate management responses.

\subsection{Establish a monitoring plan}

Designing an appropriate monitoring and evaluation plan depends on having a management plan with clear goals and objectives (Day et al., 2002), identifying ocean ecosystem elements that need to be monitored, choosing appropriate indicators, selecting data collection methods, and involving stakeholders. One common pitfall is viewing the monitoring and evaluation process too narrowly. In addition to helping achieve a particular project's goals, a good monitoring plan can lead to a better understanding of marine ecosystems, human impacts, and cost-effective management methods (NRC, 2001).

In order to support effective monitoring and evaluation, a management plan should provide answers to the following questions:

- What are threats/pressures on the system?

- What is the state of the system (e.g. dominant biota, special interest species, ecological processes, and ecological states)?

- What is the effect of the management response?

- Are management measures being implemented?

- Are people complying with management plan conditions?

- Is management meeting objectives? (Kelleher, 1999)

While the specific threats and goals of a marine management area determine the monitoring components, following categories of information belong in any ocean ecosystem monitoring program: 
- Structure of marine communities,

- Habitat maintenance or recovery,

- Environmental degradation, and

- Socioeconomic attributes/impacts. (NRC, 2001)

Operational objectives help determine the selection of indicators (units of measure that document changes in a specific condition), which, for a conservation and development project, should be

- Measurable: Able to be recorded or analyzed in quantitative or qualitative terms

- Precise: Defined the same by everyone

- Consistent: Always measures same thing

- Sensitive: Proportionately identifies changes in the item or condition measured

- Simple: Simple is preferred to complex (Margoluis and Salafsky, 1998)

The process of collecting indicator data should be accurate, reliable, cost effective, feasible, and appropriate (Margoluis and Salafsky, 1998).

One common pitfall in monitoring plans is an overly narrow understanding of what needs to be monitored. In general, monitoring plans fall short by only considering a few aspects of management or resource status and not providing a clear view of overall management effectiveness (Hockings et al., 2000). Kelleher (1999) suggests that socioeconomic and biological factors are equally important to include in monitoring plans. Economic indicators should attempt to quantify both market and non-market values and attempt to isolate benefits and costs to different users, e.g. displacement of effort; changes in fleet size, target species, and overall income. Ecological indicators must reflect both spatial and temporal changes in appropriate parameters, e.g. species and genetic diversity, abundance, biomass, and age structure. All indicators must be quantifiable and scientifically rigorous (Pomeroy et al., 2004). Given how much remains unknown about ecosystem processes, effectiveness criteria need to take uncertainties into account. The best plans include monitoring of temporal (before and after comparisons) and spatial (inside and outside the management area) factors at multiple locations. In addition to providing biophysical data, this establishes public perception and governance baselines for comparison (NRC, 2001).

Involving stakeholders and local institutions in the monitoring plans has several advantages. Stakeholders can help with data collection where high resolution, spatially-oriented information is important to monitoring. When stakeholders are engaged in the monitoring process, it helps build acceptance and compliance with rules. Kelleher (1999) recommends involving local scientific institutions to contribute to local historical and social expertise, improving community capacity for research and monitoring whenever possible, and reporting results and analysis back to the community before project evaluation (Wells and White, 1995; Margoluis and Salafsky, 1998).

\subsection{Establish an evaluation plan}

Agardy (1997) suggests that monitoring and evaluation should aim to reveal three things:

- Current environmental condition or status of the ecosystem or its components,

- Trends in condition or predictions for the short-term future of ecosystem components, and

- Management effectiveness and appropriateness of conservation measures.

A well designed monitoring plan will provide some of the data to assess these, but the data need to be evaluated in light of established operational and conceptual objects as well as data mined from the broader body of scientific knowledge to accurately characterize current conditions, trends, and management effectiveness.

Management effectiveness is the degree to which management actions are achieving EBM goals and objectives. There are many reasons to evaluate management effectiveness, and there are multiple ways to use evaluation results. First, as a normal part of the management process, evaluation aids in adaptive management. Adaptive management is the ongoing process of testing assumptions, learning from the results, and applying that learning to improve management practices (Salafsky et al., 2001). Marine 
ecosystem plans in particular, require an adaptive approach because of the dynamics of marine systems, use patterns, political support, available technology, and societal views (Day et al., 2002). Second, evaluation that incorporates the current state of scientific knowledge is important in program planning. Because management tools in marine areas may solve problems in different ways, reviewing another program's design and methods can focus policy and limited resources on effective and efficient actions (Hockings et al., 2000). Third, management effectiveness evaluation supports accountability and reporting (Hockings, 2003). Performance indicators designed to evaluate MPA sites or marine ecosystems can support the growing demand from stakeholders, governments, and donors for evidence that achievements match effort and resources. Finally, evaluation reveals knowledge gaps and guides resource requirements and allocations (Day et al., 2002).

Evaluation in a marine environment poses particular challenges, because dynamic marine ecosystems make monitoring more difficult, the marine environment is extraordinarily 'interconnected' in all dimensions, and many species exhibit wide geographic dispersal and migration ranges. A further impediment is lack of knowledge of marine systems (Day et al., 2002). In order to address these challenges, as well as the socio-economic dimensions of designing marine management plans, Hockings et al., (2000) suggest that evaluation systems should be:

- Participatory in development and implementation

- Easily understood by all

- Focused on the most important issues affecting the protected area

- Developed to examine social, biological, and management issues

- Adaptive and able to show change over time

An important consideration during design of an evaluation program is the question of who will participate, and whether the evaluators will be internal or external. Table 8 compares the relative benefits and drawbacks of each. Pomeroy and colleagues (2004) recommend assigning an individual to lead the evaluation process and the evaluation team.

Table 8. Considerations for internal versus external evaluators (information taken from Pomeroy et al., 2004).

\begin{tabular}{|c|c|}
\hline Internal Evaluators & External Evaluators \\
\hline $\begin{array}{l}\text { May have a bias or complex } \\
\text { relationships with a community }\end{array}$ & $\begin{array}{l}\text { Often provide impartiality, a fresh } \\
\text { perspective, and credibility }\end{array}$ \\
\hline $\begin{array}{l}\text { Have an understanding of the history, } \\
\text { experiences, and details of the site }\end{array}$ & $\begin{array}{l}\text { May have limited local knowledge, } \\
\text { learning is a cost in time and money }\end{array}$ \\
\hline Often live in or near the site & Usually stay for short visits to the site \\
\hline $\begin{array}{l}\text { Tend to focus on issues of relevance } \\
\text { to the managers }\end{array}$ & $\begin{array}{l}\text { Tend to focus on questions relevant to } \\
\text { external groups }\end{array}$ \\
\hline $\begin{array}{l}\text { May not have all the skills necessary } \\
\text { and need technical assistance }\end{array}$ & $\begin{array}{l}\text { Bring technical expertise and } \\
\text { perspectives from other sites }\end{array}$ \\
\hline Are more likely to apply results & $\begin{array}{l}\text { Take away valuable information, } \\
\text { knowledge, perspectives, and skills }\end{array}$ \\
\hline
\end{tabular}

Like monitoring plans, evaluation results should be easy to understand and available to stakeholders, so that management and other decision makers can apply results in order to adapt and improve goals, objectives and overall management (Day et al., 2002). To make the monitoring and evaluation worthwhile, it is necessary to share the results with target audiences and identify ways to adapt management practices (O'Boyle and Jamieson, 2006; Pomeroy et al., 2004). 
As noted by Day et al. (2002), a significant challenge to evaluating marine systems is lack of knowledge. Because scientific understanding of marine ecosystems is continually expanding, a critical part of effective implementation of EBM is continual information mining and assimilation. This will necessarily include an assessment of the available information and identification of information gaps. A thorough review of existing information will allow managers to assess the types of questions they can ask and the types of tools that can inform those questions. Information mining and assimilation includes the following steps: identify information needed, collect existing data, assign mechanisms to collect additional data, and identify available tools to translate the data into information readily usable by managers.

The Massachusetts Ocean Partnership (MOP) has organized data gaps into three major types: baseline assessment/synoptic survey gaps; monitoring and data gaps; infrastructure gaps and then described research, monitoring and model development priorities for topics within each (Mooney-Seus and Allen, 2007). More broadly, California's Ocean Protection Council, in making recommendations about implementation of its statewide ocean management plan, suggests that managers find a cross-cut between types of research and research tools, and information and research topics. They call out ecosystem based management, integrated ocean observing systems, seafloor mapping, social and economic data collection, technology and engineering, and data accessibility, synthesis and dissemination as types of research that apply to numerous topics such as fisheries, aquaculture, coastal hazards, shoreline processes and so forth (California Ocean Protection Council, 2005). Syms and Carr (2001) have pointed out that not only are monitoring and evaluation programs important for judging whether a particular ecosystem plan has been effective in meeting its goals, they add to the information base. They have proposed a web-based clearinghouse of information on effectiveness of existing marine protected areas, which aims to assimilate information from published studies, grey literature, and webbased information sources into a relational database.

One pitfall in establishing an evaluation plan is using an approach that is too closely tied to operational objectives. In a review of evaluation systems, Hockings (2000) observes some of the criticisms of objectives-based evaluation. First, these systems may not discover unintended results of management actions, such as restoration of one location affecting another location. Second, objectives-based evaluation may lead to goal displacement - managers adjusting actions to produce the desired short-term outcome but losing focus of the ultimate goal. Finally, critics argue that these systems are not equipped to handle multiple and competing objectives.

The most common means of addressing these concerns is to place emphasis on prioritizing objectives and monitoring and evaluating outside the sometimes narrow scope of management objectives. There are also problems with applying evaluation results. Some assessments may be criticized as too subjective (i.e. rapid assessment methods), but these assessments are often a good starting point that provides useful insights, while requiring fewer resources. Generally, evaluation methods that balance objective and subjective components are most useful in adaptive management. Finally, a more generic and consistent evaluation system makes it easier to compare between sites and systems, but the results are less useful to site-level adaptive management (Hockings et al., 2000).

NRC (1990) provides a conceptual model for designing evaluation systems. Despite the complexity of ecological and institutional systems, a simple conceptual model can help determine if a monitoring/evaluation system is adequately designed. This model has three levels of design and three levels of measurement (Table 9) and is based on the core assumption that any evaluation must be based on an understanding of the system being measured. This understanding can range from completely qualitative to specifically quantitative. 
Table 9. Design levels and correlated measurements.

\begin{tabular}{|l|l|}
\hline \multicolumn{1}{|c|}{ Design Level } & \multicolumn{1}{c|}{ Correlated Measurement } \\
\hline Clearly define the goals. & $\begin{array}{l}\text { Measure of ultimate success } \\
\text { (O'Boyle \& Jamieson, 2006, recommend operational } \\
\text { objectives made up of a verb, an indicator, and a } \\
\text { reference point, e.g. "maintain age3+ herring population } \\
\text { biomass above 50,000t") }\end{array}$ \\
\hline $\begin{array}{l}\text { Describe how the system } \\
\text { (ecological or institutional) is } \\
\text { thought to work. }\end{array}$ & $\begin{array}{l}\text { Perform periodic assessments, as new knowledge } \\
\text { is gained, of the adequacy of the underlying } \\
\text { conceptual model(s) }\end{array}$ \\
\hline $\begin{array}{l}\text { Define the mechanisms or actions } \\
\text { that will be taken to achieve the } \\
\text { goals. }\end{array}$ & $\begin{array}{l}\text { Monitor interim milestones or benchmarks to } \\
\text { determine whether the system is moving as } \\
\text { expected in response to the management plan. }\end{array}$ \\
\hline
\end{tabular}

\subsection{Manage adaptively}

Evaluation of monitoring data produces results that can then be used and applied towards adaptive management strategies. Because many decisions taken in the course of EBM involve high levels of uncertainty, lack of data, or new frameworks, the process is well suited for adaptive management, a responsive mechanism recommended by MOP in its strategic plan. Adaptive management structures a decision and evaluation process to enable management to be highly responsive to information gathered from monitoring and evaluation (Millennium Ecosystem Assessment, 2005).

Nyberg (1999) summarizes the aims of adaptive management:

- $\quad$ Finding better ways of meeting goals

- Identifying key gaps in understanding

- Improving understanding of ecosystem responses, thresholds and dynamics, in order to adapt practices to fit changing social values and ecological conditions

- Gaining reliable feedback about effectiveness of alternative policies/practice,

- Encouraging innovation and learning

- Passing on information and knowledge gained through experience

- Fostering an organizational culture that emphasizes learning and responsiveness

- Helping detect cumulative, long-term, large-scale, and emergent effects of actions

Nyberg (1999) organizes adaptive management into six main steps: problem assessment, design, implementation, monitoring, evaluation, and adjustment. However, the three main steps (testing assumptions, adapting, and learning) proposed by Margoluis and Salafsky (1998) effectively condense Nyberg's six into a more flexible management structure. First, managers and other stakeholders experimentally test the assumptions that specific actions will achieve the desired outcome. Systematic testing of assumptions should address three main areas: the initial conceptual model; the linkages between goals, objectives, threats, and activities; and the appropriateness of monitoring strategies and indicators. Adapting management is the second step. In evaluating project status, process managers or planners use monitoring results as guidance for adapting and improving management. If monitoring results reveal that management is not achieving desired results, assumptions will change (Salafsky et al., 2001). The third step is learning from successes and failures and documenting the process. Documentation will ensure avoiding the same mistakes in the future and aid managers and stakeholders who may face similar circumstances.

One objection to adaptive management is that may be costly and slow in many situations. Lee (1999) suggests that decision makers must decide whether the systematic adaptive approach is ultimately 
worthwhile - it is worthwhile when laboratories are not practical and trial and error is too risky. Nyberg (1999) points out the following potential obstacles to adaptive management learning programs:

- Additional costs

- Designing powerful experiments

- Experimenting with delicate ecosystems

- Maintaining long-term funding and staffing support

- Regulatory and institutional inflexibility

- Unclear and inconsistent definitions of adaptive management

Despite these pitfalls, an adaptive approach is a means to deal with imperfect ecosystem knowledge that results in learning while doing.

\subsection{Examples of adaptively managed projects}

Adaptive management was applied in the declining groundfish fishery in northwest Australia through a series of management experiments (Peterman and Peters, 1998). The program took ten years to realize significant benefits to fishery management and legislation. Recent evaluation results at the Galapagos Marine Reserve revealed that the local community lacked critical knowledge about the value of the reserve (Guerrero et al., 2003). Based on the results, reserve management intends to adapt and continue to monitor communication and education programs. Likewise, Miramare Natural Marine Reserve recently undertook management effectiveness evaluation, and learned that adapting patrolling and biological monitoring efforts may improve overall reserve effectiveness (Constantini et al., 2003). The Channel Islands National Marine Sanctuary, in conjunction with the California Department of Fish \& Game, also has a detailed monitoring plan for its marine reserves covering both biological and socio-economic information (California DFG, 2004).

The Florida Keys National Marine Sanctuary (FKNMS) included a detailed monitoring and evaluation program in its management plan. The plan set out what would be monitored, the agencies responsible for various aspects of the program, use of volunteers, geographic focus, monitoring priorities, funding information, and a schedule for evaluation based on the monitoring data (NOAA, 1996). The sanctuary manager reports that the multi-agency approach, combined with independent scientific reviews, has had good results (FKNMS, 2003). The Florida Keys Ecosystem Monitoring Integration project has recently been implemented within the FKNMS. This includes a database and GIS for South Florida, Florida Bay, and the Florida Keys, which will be used to help develop a Florida Keys marine ecosystem monitoring plan. The primary goal of the Research and Monitoring Program is to provide the knowledge necessary to make informed decisions about protecting the biological diversity and natural ecosystem processes of the Sanctuary and its resources.

\subsection{Discussion}

The Oceans Act calls for "effective stewardship," "sound management practices," "protect ...habitats," and other broadly stated resource conservation and protection goals. Relatively simple statements about protecting specific habitat areas or avoiding excessive economic impact are useful for designing goals and objectives, but inadequate as the basis for monitoring. Similarly, routine general ecosystem monitoring does not track success or assess progress toward specific goals such as rebuilding fish populations or restoring damaged habitats. In order to support a monitoring and evaluation plan, the management plan must have in place formalized conceptual objectives (Section 5) and operational objectives (Section 6) that correlate indicators with both the legislated goals of the Oceans Act and with the specific management activities designed to carry out the Act.

A monitoring program should be based on clearly measurable and verifiable performance criteria that reflect marine management goals and consider both socioeconomic and ecological aspects. Conceptual objectives need to be broken out into operational objectives with reference points and indicators to monitor those reference points. Indicators should reflect not only the operational objective, but also the associated conceptual objective. Stakeholders should be involved in the selection of the performance 
indicators, as well as in the design and implementation of the monitoring program. The designers of the marine management plan must agree on the characteristics and timeframe of "success," as reflected by measurable performance indicators. Performance indicators must embody the objectives of the marine management plan and should evaluate short- and long-term socioeconomic and ecological effects and report both positive and negative outcomes.

Evaluation focuses on the degree to which the plan is meeting its stated goals. Cooperation and participation among stakeholders and managers are necessary for the evaluation plan to succeed. The evaluation process should include the following activities:

- Compiling and cross correlating data from monitoring

- Assessing whether the indicators being monitored provide the necessary information

- Determining the current environmental condition or status of the ecosystem or its components

- Comparing monitoring results to program goals

- Revealing trends in condition or predictions for the short-term future of ecosystem components

- Using data mining techniques to gather marine science and management information related to program goals and activities

- Assessing management effectiveness and appropriateness of conservation measures

- Proposing potential changes to management actions

- Providing interim reports to stakeholders

Effective evaluation and appropriate reporting of results can help secure public support for continuing management measures, help gain necessary funding, and guide adaptive management.

Adaptive management is particularly well suited for managing complex systems with many unknowns, as is the case with marine ecosystems. Operating within a framework of conceptual and operational objectives, adaptive management entails an ongoing cycle of monitoring, evaluation, and adjustment. Adaptive management allows managers to find better ways to meet goals, identify gaps, adapt practices to ecosystem responses and socio-economic factors, gain feedback about alternative practices, encourage innovation, responsiveness and learning, and better understand the cumulative, long-term, large scale and emergent effects of actions. Successful application of adaptive management requires establishing an initial conceptual model with clear goals, objectives, monitoring regimens, and evaluation strategies. In so far as possible, all assumptions going into the conceptual model should be made explicit. Managers use evaluation results to revise assumptions and guide adaptations of management strategies. Documentation of all successes and failures provides data for further iterations of the evaluation and adaptation cycle. Adaptive management, when performed well, is a continual learning process. The results should both improve management of resources and expand the body scientific knowledge.

\section{Recommendations}

Massachusetts ocean planning and management will be best served by developing a process that can

- characterize conceptual objectives

- $\quad$ prioritize policy issues

- identify ecosystem components and human uses

- assess human impacts to ecosystem components and responses to regulation

- explore management scenarios in the short and long-term

- adapt to environmental changes and shifts in human behavior

The State has amassed an enormous amount of information to support integrated coastal management. Both new and existing efforts support the integration of scientific information into the management activities for Massachusetts coastal waters. Implementing EBM will take time, and involve a number of recommendations that will complement and enhance the ocean management plan by furthering the State's understanding of the ecosystem components and services. 
While it is necessary that stakeholders be engaged in issues they see as priorities, the priority conservation conceptual objectives should be defined by natural and social scientists, who are equipped with in-depth knowledge of ecosystem components, human activities, and the interactions between them. It is critical that scientific approaches can not only provide clear information rapidly, but also be updated and expanded over time as new data become available.

While our recommendations are based on general knowledge of available information, building a more specific inventory of available data and information will be necessary. Instrumental to building a robust store of information will be information mapping approaches; modeling tools; decision support tools, such as InVEST and benefit-cost analysis, that can be used to evaluate trade-offs; and ongoing research by scientists in the region.

We recommend the following steps in the implementation of the Oceans Act:

Map Human Impacts and Vulnerable Areas. For near-term information needs, the mapping approaches described in Appendix B will be valuable. In particular, the Human Impacts Mapping approach could be applied in conjunction with the TNC Eco-Regional Assessment. In the longer term, a more comprehensive approach such as OCEAN, which depends on the state of the integrated data system, may be useful.

Catalogue Ecosystem Services. A follow-on approach would build upon the mapping efforts and go beyond simply identifying impacts and vulnerable areas by providing a fuller catalog of ecosystem services. This approach, to work with the Natural Capital Project on InVEST, would build on activity from the impacts analysis and may be a step towards the OCEAN model. It should, however, be noted that the InVEST approach is not a full dynamic simulation such as ATLANTIS or MIMES and is not a "model" of the ecosystem but a decision support tool.

Develop an Indicator Framework. Indicators will inform the models used by managers to make decisions. We have suggested a broad array of ecological and socio-economic indicators (Appendix C), but the selection of indicators will be depend greatly on available information and the objectives chosen by the State. An indicator framework for the operational objectives would provide both program and ecological indicators and is an inherent part of an EBM approach to management. Limit reference points and precautionary reference points need to be linked to management actions. These reference points are important in setting boundaries for management actions. To measure management performance, there will need to be indicators of system state that concisely express progress toward achieving management goals and objectives.

Employ Ecosystem Models. Whole ecosystem models attempt to model processes that operate across trophic levels, both bottom-up (physical forcing) and top-down (biological forcing), as opposed to models that don't incorporate environmental and lower trophic level processes (termed Minimum Realistic Models, MRMs). The most useful of these modeling approaches are spatially explicit food web models such as Ecopath with Ecosim or EMAX, and more sophisticated dynamical approaches such as MIMES.The MIMES approach has some advantages over ATLANTIS for the application considered here because it is more interactive and flexible and can be directly linked to the economic analysis in a several ways. While ATLANTIS is comprehensive, it is neither accessible nor transparent to most users. MIMES, on the other hand, is more accessible, can synthesize a very large amount of information, and allows scenario exploration of "what-if" type questions.

Employ Ecological models and scenario analysis. These approaches are valuable to evaluate trade-offs and will identify the consequences of actions. A number of additional models types would enhance the Ocean Management Plan's Science Strategy. More sophisticated scenario models include the dynamics of ecosystem features, e.g. including humans in the system, and then simulate what happens when management actions are taken. For the implementation of 
EBM, there is an overall need for scenario analysis or integrated assessments. Scenario analysis is an important approach to evaluating the results of alternative management approaches. The analysis should incorporate a broad range of information and consider likely changes that are expected from a particular action. In simplest form, a scenario analysis might use a simple model of a small number ecosystem features to simulate likely changes under different management actions.

Utilize Integrated Assessments. Integrated assessments are a valuable process used in describing the impacted environment. Integrated assessments describe the ecosystem, assess its current condition, forecast future ecological health using current management strategies, and evaluate alternate strategies and their potential impacts. Integrated assessments provide a process to evaluate alternative management methods and information by identifying and relating them to objectives and priorities. To be effective, an ecosystem overview will be responsive to policy-relevant questions based on peer review and public participation, bring together information and data from many sources, be based on high-quality existing information, predict ecosystem health in response to various management actions and alternatives, and identify data gaps, uncertainties, and collection priorities. Another critical aspect of an integrated assessment is the incorporation of commonly developed objectives that emerge from a multi-sector process. In other words, all ocean activities and interests have to have contributed to the definition of goals and objectives. Development of an ongoing dynamic ecosystem assessment can serve as the basis for management decisions within the Oceans Act planning area. It would serve as the common framework for each of the sectoral analyses of permit issues, management actions, etc., fulfilling MEPA and NEPA requirements.

Employ Economic Decision Support Tools. The trade-offs among alternative management strategies should be made explicit using economic methods. Market and non-market valuation techniques can be used to assign economic values to uses and non-market ecosystem services. Bio-economic modeling and benefit-cost analysis can be used to characterize tradeoffs among alternative strategies and suggest those that are economically optimal. Input-Output modeling can be used to characterize the economic impacts of alternative strategies on industry sectors, employment, and government tax revenues. Participation of stakeholders and the public will help reveal the distributional aspects of potential alternative management strategies. Stakeholder and public participation in developing and interpreting the results of economic analyses may help uncover management strategies that are both fair and efficient.

Perform Vulnerability Assessments. Habitat Risk Assessments are semi-qualitative analyses of the most productive and vulnerable areas to impacts. These assessments provide a description of the impacted environment and help determine how cautious management should be. The first step to this work, identifying cumulative impacts, is currently underway, though not explicitly listed as a part of the Science Strategy (Halpern and others for the Massachusetts Ocean Partnership). The information collected from vulnerability assessments complements the Ecological Valuation Index analysis and helps interpret scenario analyses.

Expand on Existing Work. In addition to selecting specific science tools, it will be very important to capitalize on current work in the region in order to support ongoing management planning. In this regard, ensuring that area natural and social scientists are involved in the development and implementation of the approaches will be critical. It is worth noting that many of the models and tools described in the appendices are similar in approach and application. For example, CAPS program at UMass Amherst can be applied along with TNC Ecoregional Assessment and the Human Impacts Analysis as a planning tool and provide information similar to that provided by InVEST. Likewise, several food web models that can be used to inform management are now under development (e.g. Link et al., 2006). While it will always be important to employ new ideas and methods developed by researchers from outside the region, much of the ongoing work in New England, from Eco-Regional Assessment to EMAX and MIMES, should be brought to bear on the issues and problems of ocean planning for Massachusetts. 
Evaluate and monitor invasive species. Invasive and exotic species may play an increasing role in coastal ocean ecosystems, especially in light of climate change. Monitoring and analysis of invasive species and their impacts should be part of the Ocean Science Strategy and be integrated into broader ecosystem analyses.

Develop and maintain an interoperable data system. Data on different aspects of ocean ecosystems and the human activities that impact them must be interoperable, coherent and upto-date. In an interoperable data system, different pieces of data must be related to one another in a coherent manner, as opposed to merely being stored. The data system should underpin EBM decision making, and will require substantial and sustained effort. Ready and flexible access to a wide range of data is critical for successful management of the Ocean Plan.

Finally, the implementation of ocean management will require efforts at monitoring and assessment of management strategies. Adaptive management, in which feedback on the effectiveness of management strategies can be used to revise those same strategies should be employed. 


\section{References}

Agardy, T. 1997. Marine Protected Areas and Ocean Conservation. San Diego, Calif., U.S.A.: Academic Press; Austin: R.G. Landes. 244p.

Alexander, R.B., P.J. Johnes, E.W. Boyer, and R.A. Smith. 2002. A comparison of models for estimating the riverine export of nitrogen from large watersheds. Biogeochemistry. 57/58: 296-339.

Altman, I., A.M.H. Blakeslee, G.C. Osio, C. Rillahan, S.J. Teck, J.J. Meyer, J.E. Byers, and A.A. Rosenberg. 2008. A practical approach to guide the implementation of ecosystem based management using the Gulf of Maine marine ecosystem as a case study. Submitted to Frontiers in Ecology and the Environment.

Bernstein, B.B., and S. ludicello (eds). 2004. Consensus Statement: Integrating Marine Reserve Science and U.S. Fisheries Management. National Fisheries Conservation Center.

Bowen, Robert E., J-S Kim, and J. Wiggin. 2008. Linking Socio-Economics and Coastal Environmental Change: Outcome Indicators to Assess Coastal Management Success (English): 242-290 in J.-Y. Choi, H.J. Choi, J.D. Kim, J.H. Jeong, and C.O. Shin, Development of Coastal Indicators and Survey Guideline (in Korean). Seoul, Republic of Korea, Korea Maritime Institute, 348 pp.

Brown, W.S. 2006. Massachusetts and Rhode Island Bays \& Shelf (MARIBS) Coastal Ocean Observing System Design Workshop(s). 16 March 2006.

Busch, W-D.N., B.L. Brown, and G.F. Mayer (Eds). 2003. Strategic Guidance for Implementing an Ecosystem based Approach to Fisheries Management. United States Department of Commerce, National Oceanic and Atmospheric Administration, NMFS, Silver Spring, MD 62p.

California Department of Fish \& Game. 2004. Channel Islands Marine Protected Areas Monitoring Plan. 60 pp. February.

California Marine Life Protection Act (MLPA) of 1999 (as Amended): California Fish \& Game Code Sections 2850-2863.

California Ocean Protection Council. 2005. California ocean and coastal information, research, and outreach strategy. $20 \mathrm{pp}$. Available online at http://resources.ca.gov/copc/

Canham, C.D., J.J. Cole, and W.K. Lauenroth. 2003. Models in Ecosystem Science. In: C. D. Canham, J. J. Cole, and W. K. Laurenroth eds. Models in ecosystem science. Princeton University Press (Princeton, NJ): pp 1-10.

Chesson, J. and H. Clayton. 1998. A Framework for Assessing Fisheries with respect to ecologically sustainable development. Bureau of Resource Sciences, Fisheries Resource Branch, Canberra, Australia. $60 \mathrm{pp}$.

Clark, C.W. and G.R. Munro. 1975. The economics of fishing and modern capital theory: a simplified approach. Journal of Environmental Economics and Management 2:92-106.

Coastal Zone Management Act of 1972, 16 USC 1451-1464, Chapter 33; P.L. 92-583, October 27, 1972; 86 Stat. 1280.

Commonwealth of Massachusetts. 2008. An Act Relative to Oceans. Chapter 114 of the Acts of 2008. available at: http://www.mass.gov/legis/laws/seslaw08/sl080114.htm

COMPASS. 2007. Gulf of Maine EBM Toolkit Survey Report. Waterview Consulting.

Constantini M., M. Spoto, and C.G. Miramare. 2003. A demonstration case report. September 2003. (Accessed 13 January 2005). http://effectivempa.noaa.gov/cases.html

Costanza R., R. d'Arge, R. de Groot, et al. 1997. The value of the world's ecosystem services and natural capital. Nature 387: 253-60; Daily GC. (Ed). 1997.

Cury, P.M., Y-J. Shin, B. Planque, J.M. Durant, J-M. Fromentin, S. Kramer-Schadt, N.C. Stenseth, M. Travers, and V. Grimm. 2008. Ecosystem oceanography for global change in fisheries. Trends in Ecology and Evolution. 23(6): 338-346.

Daily, G.C. 1997. (Ed) Nature's services. Societal dependence on natural ecosystems. Washington DC: Island Press.

Day J., M. Hockings, and G. Jones. 2002. Measuring effectiveness in marine protected areas-principles and practices. Keynote presentation in Aquatic Protected Areas. What works best and how do we know? World Congress on Aquatic Protected Areas; August 2002. Cairns, Australia.

Department of Fisheries and Oceans Canada (DFO). 2004. Identification of Ecologically and Biologically Significant Areas. DFO Can. Sci. Advis. Sec. Ecosystem Status Rep. 2004/06. 
Department of Fisheries and Oceans Canada (DFO). 2005. Guidelines on Evaluating Ecosystem Overviews and Assessments: Necessary Documentation. DFO Canadian Science Advisory Secretariat Science Advisory Report 2005/026.

EBM Toolkit. 2008. www.ebmtools.org

Edwards, S.E., and S.A. Murawski. 1993. Potential economic benefits from efficient harvest of New England groundfish. North American Journal of Fisheries Management 13:437-449.

Ellner, S., and P. Turchin. 1995. "Chaos in a noisy world: New methods and evidence from time-series analysis." The American Naturalist, 145(3): 343-375.

Ervin J. 2003. Protected area assessments in perspective. BioScience 53:9 819-822.

Fletcher, W.J. 2005. The application of qualitative risk assessment methodology to prioritize issues for fisheries management. ICES Journal of Marine Science, 62: 1576e1587.

Florida Keys National Marine Sanctuary (FKNMS). 2003. Science Report. Available online at http://floridakeys.noaa.gov/research_monitoring/2003_sci_report.html (Accessed 12 November 2008).

Garcia, S.P., L.B. DeLancey, J.S. Almeida, and R.W. Chapman. 2007. Ecoforecasting in real time for commercial fisheries: the Atlantic white shrimp as a case study. Marine Biology. 152: 155-24.

Gavaris, S., J.M. Porter, R.L. Stephenson, G. Robert, and D.S. Pezzack. 2005. Review of Management Plan Conservation Strategies for Canadian Fisheries on Georges Bank: A test of a practical ecosystem - based framework. ICES CM.

Guerrero P., M. Velasquez, E. Cruz, and M. Jorge. 2003. Galapagos: A demonstration case. September 2003. (Accessed 12 November 2008). http://effectivempa.noaa.gov/cases/galapagoslslands.pdf

Halpern, B.S., A. Walbridge, K.A. Selkoe, C.V. Kappel, F. Micheli, C. D’Agrosa, J.F. Bruno, K.S. Casey, C. Ebert, H.E. Fox, R. Fujita, D. Heinemann, H.S. Lenihan, E.M.P. Madin, M.T. Perry, E.R. Selig, M. Spalding, R. Steneck, and R. Watson. 2008. A Global Map of Human Impact on Marine Ecosystems. Science, 319, 948-952. http://www.sciencemag.org/cgi/content/abstract/sci;319/5865/948

Harty, M., and D. John. 2006. Report on Lessons Learned from the Marine Life Protection act Initiative. Aug. 17, 2006.

Harty, M. 2008. Report on Lessons Learned from the Marine Life Protection act Initiative. North Central Coast Study. October 31, 2008.

Heiman, K.W., C. Bason, T. Cowan, F. de Jong, B.S. Halpern, B. Keller, B. Jago, K. McLeod, and D. Wendt. In preparation. Practical framework for implementing marine ecosystem-based management. Ocean \& Coastal Management.

Heinz Center for Science Economics and the Environment. 2002. State of the Nation's Ecosystems; measuring the lands, waters and living resources of the United States. www.heinzctr.org/ecosystems

Heinz Center for Science Economics and the Environment. 2003. The State of The Nation's Ecosystems: Annual Update 2003. www.heinzctr.org/ecosystems

Heinz Center for Science Economics and the Environment. 2008. The State of the Nation's Ecosystems. Washington, D.C. Island Press. www.heinzctr.org/ecosystems

Hobday, A.J., A. Smith, H. Webb, R. Daley, S. Wayte, C. Bulman, J. Dowdney, A. Williams, M. Sporcic, J. Dambacher, M. Fuller, and T. Walker. 2007. Ecological Risk Assessment for the Effects of Fishing: Methodology. Report R04/1072 for the Australian Fisheries Management Authority, Canberra.

Hockings M. 2000. Evaluating protected area management. A review of systems for Assessing management effectiveness of protected areas. School of Natural and Rural Systems, University of Queensland Occasional Paper 2000 (7)4:1-58.

Hockings M., S. Stolton, and N. Dudley. 2000. Evaluating Effectiveness: A Method for Assessing the Management of Protected Areas. Gland (Switzerland): IUCN.

Hockings M. 2003. Systems for assessing the effectiveness of management in protected areas. BioScience 53:9 823-832.

ludicello, S., B. Bernstein, C. Stringer, and H. Lovett. 2004. Lessons Learned from Recent Marine Protected Area Designations in the United States. A Report to The National Marine Protected Areas Center NOAA. Available online.

ludicello, S., B. Bernstein, I. Tetrault, M. Keene, and M. Shoemaker. 2005. Report to California MLPA Task Force summarizing literature reviews on approaches to design of marine protected areas 
and evaluation of MPAs and MPA networks.

Jamieson, G., R. O'Boyle, J. Arbour, D. Cobb, S. Courtenay, R. Gregory, C. Levings, J. Munro, I. Perry, and $\mathrm{H}$. Vandermeulen. 2001. Proceedings of the National Workshop on Objectives and Indicators For Ecosystem based Management, Sidney, British Columbia, 27 February-2 March 2001. CSAS Proc. Ser. 2001/09.

Jin, D., P. Hoagland and T.M. Dalton. 2003. Linking economic and ecological models for a marine ecosystem. Ecological Economics 46(3):367-385.

Kelleher G., C. Bleakley, and S. Wells. (Eds.) 1995. A Global Representative System of Marine Protected Areas: Volume One. Washington, D.C.: The World Bank.

Kelleher G. 1999. Guidelines for Marine Protected Areas. Gland, Switzerland: IUCN. Island Press. 2007. Millennium Assessment Toolkit.

Kinzig, A.P. 2003. On the benefits and limitations of prediction. In: C. D. Canham, J. J. Cole, and W. K. Laurenroth eds. Models in ecosystem science. Princeton University Press (Princeton, NJ): pp 461-465.

Kostylev, V.E., and C.G. Hannah. 2007, Process-driven characterization and mapping of seabed habitats, in Todd, B.J.and Greene, H.G., eds., Mapping the Seafloor for Habitat Characterization: Geological Association of Canada, Special Paper 47, p. 171-184.

Lee K.N. 1999. Appraising adaptive management. Conservation Ecology 3(2): 3. [online] URL:http://www.consecol.org/vol3/iss2/art3

Legates, D.R., and G.J. McCabe Jr. 1999. Evaluating the use of 'goodness-of-fit' measures in hydrologic and hydroclimatic model validation. Water Resources Research. 35(1): 233-241.

Lenfest Ocean Program Research Series. 2007. Setting Annual Catch Limits for US Fisheries. Summary of An Expert Working Group Report: Rosenberg, A., Agnew, D., Babcock, E., Cooper, A., Mogensen, C., O’Boyle, R., Powers, J., Stefánsson, G., and Swasey, J. 2007. Setting annual catch limits for U.S. fisheries. September 2007.

Leslie, H.M., and K.L. McLeod. 2007. Confronting the challenges of implementing marine ecosystem based management. Frontiers in Ecology and the Environment. 5(10):540-548.

Link, J.S., C.A. Griswold, E.M. Methratta, and J. Gunnard (eds). 2006. Documentation for the Energy Modeling and Analysis eXercise (EMAX). Northeast Fisheries Science Center Reference Document, 06-15, 166 p. http://www.nefsc.noaa.gov/nefsc/publications/crd/crd0615/crd0615.pdf

Mangel, M., $\varnothing$. Fiksen, and J. Giske. 2001.Theoretical and statistical models in natural resource management and research. Pg 57-71 in Modeling in Natural Resource Management. Development, interpretation and application. T.M. Shenk and A.B. Franklin, editors. Island Press, Washington, DC.

Manno, J.P., R. Smardon, J.V. DePinto, E.T. Cloyd, and S.M. Del Granado. 2008 The use of models in Great Lakes decision making: an interdisciplinary synthesis. Randolph G. Pack Environmental Institute: Syracuse, NY. Occasional Paper 16. 95 pp. www.esf.edu/es/documents/GreatLakesRpt.pdf.

Marine EBM. 2008. www.marineebm.org

Massachusetts Environmental Policy Act (MEPA), M.G.L. c. 30 §1-62h (1977).

MEPA Regulations, 301 CMR 11.00 et seq. (1998).

Massachusetts Executive Office of Energy and Environmental Affairs (EEA). http://www.mass.gov/?pagelD=eoeeahomepage \&L=1\&L0=Home\&sid=Eoeea

Massachusetts Ocean Management Task Force. 2004. Waves of Change: The Massachusetts Ocean Management Task Force Report and Recommendations, March 2004.

Massachusetts Ocean Partnership Website: http://www.massoceanpartnership.org/

Massachusetts Office of Coastal Zone Management Website: http://www.mass.gov/czm/

Massachusetts Public Waterfront Act (Chapter 91), M.G.L. c. $91 \S 1-63$ (1866).

McAllister, M.K., P.J. Starr, V.R. Restrepo, and G.P. Kirkwood. 1999. Formulating quantitative methods to evaluate fishery - management systems: what fishery process should be modeled and what tradeoffs should be made? ICES J. Mar. Sci. 56: 900 - 916.

Millennium Ecosystem Assessment. 2003. Ecosystems and Human Well-Being: A Framework for Assessment. 212p. http://www.millenniumassessment.org/en/Framework.aspx

Millennium Ecosystem Assessment. 2005. Ecosystems and Human Well-being: A Framework for Assessment. 2005. Available online at http://www.millenniumassessment.org/en/Framework.aspx 
Millennium Ecosystem Assessment. 2005. Millennium Ecosystem Assessment synthesis report. Washington, DC: Millennium Ecosystem Assessment.

Millennium Ecosystem Assessment. 2008. Available online at http://www.millenniumassessment.org/en/index.aspx. Last accessed November 14, 2008.

Margoluis R., and N. Salafsky. 1998. Measures of Success: Designing, Managing, and Monitoring Conservation and Development Projects. Washington, D.C.: Island Press.

Mooney-Seus, M.L., and L.K. Allen. 2007. Ecosystem-Based Coastal and Ocean Management in Massachusetts: Science Gap Analysis Final Report. Massachusetts Ocean Partnership Fund. May 2007.

National Environmental Policy Act (NEPA) of 1969 § 102, 42 U.S.C. § 4332 (1994).

National Oceanic and Atmospheric Administration (NOAA). 1996. Florida Keys National Marine Sanctuary Final Management Plan/Environmental Impact Statement (FMP/EIS) Volume I, The Management Plan. $27 \mathrm{p}$.

National Research Council (NRC). 1990. Managing Troubled Waters: The Role of Marine Environmental Monitoring. Washington, D.C.: National Academy Press. 125p.

National Research Council (NRC). 2001. Marine Protected Areas: Tools for Sustaining Ocean Ecosystems. Washington, D.C.: National Academy Press. 272p.

Natural Resources Canada (NRC). 2000. The Atlas of Canada: mapping natural hazards. http://atlas.nrcan.gc.ca/site/english/index.html; http://atlas.nrcan.gc.ca/site/english/maps/environment/ecology/components

Nyberg B. 1999. An introductory guide to adaptive management for project leaders and participants. Victoria, British Columbia: BC Forest Service. 22p.

O'Boyle, R., M. Sinclair, P. Keizer, K. Lee, d. Ricard, and P. Yeats. 2004. An integrated management framework for the eastern Scotian Shelf. DFO Canadian Science Advisory Secretariat Research Document Series, 2004/076.

O'Boyle, R., V. Kostylev, H. Breeze, T. Hall, G. Herbert, T. Worcester, D. Ricard, and M. Sinclair. 2005. Developing an Ecosystem-Based Management Framework for Benthic Communities: A Case Study of the Scotian Shelf. ICES CM 2005 / BB:18.

O'Boyle, R., and G. Jamieson. 2006. Observations on the implementation of ecosystem-based management: experiences on Canada's east and west coasts. Fisheries Research 79(2006) 1 12.

O'Boyle, R., and T. Worcester. 2009. Eastern Scotian Shelf, Canada. In K. O. McLeod and H. Leslie (eds.) Ecosystem-Based Management for the Oceans. Island Press. http://www.islandpress.com/bookstore/list.php?cat_id=27

O'Malley, R., K. Cavender-Bares, and W.C. Clark. 2003. Providing 'Better' Data: Not as simple as it might seem. Environment 45(4): 8-18.

O'Malley, R., and W.C. Clark. 2000. Ecosystem assessment. Issues In Science and Technology 16(4): 55.

Oreskes, N. 2003. The role of quantitative models in science. In: C.D. Canham, J.J. Cole, and W.K. Laurenroth eds. Models in ecosystem science. Princeton University Press (Princeton, NJ): pp 13 -31 .

Park, H.H. 1998. Analysis and prediction of walleye pollock (Theragra chalcogramma) landings in Korea by time series analysis. Fish.Res.38: 1-7.

Patton M.Q. 1997. Utilization-Focused Evaluation. Thousand Oaks, CA: Sage Publications.

Peterman RM, Peters CM. 1998. Decision analysis: Taking uncertainties into account in forest resource management. Pages 105-27 in V. Sit and B. Taylor, editors. Statistical Methods for Adaptive Management Studies. Lands Management Handbook no. 42. Ministry of Forests, Research Branch, Victoria, British Columbia, Canada.

Pomeroy, R.S., J.E. Parks, and L.M. Watson. 2004. How is Your MPA doing: A Guidebook of Natural and Social Indicators for Evaluating Marine Protected Area Management Effectiveness. Gland, Switzerland and Cambridge, UK: IUCN.

Rochet, M.J., and V.M. Trenkel. 2003. Which Community Indicators can Measure the Impact of Fishing? A Review and Proposals. Can J. FAS. 60:86-99

Root-Bernstein, R., and M. Root-Bernstein. 1999. Modeling. In: Root-Bernstein, R. and M. RootBernstein. Sparks of Genius: The Thirteen Tools of the World's Most Creative People. Mariner Book (Boston): 226-245. 
Rosenberg, A., D. Agnew, E. Babcock, A. Cooper, C. Mogensen, R. O’Boyle, J. Powers, G. Stefánsson, and J. Swasey. 2007. Annual Catch Limits Report from the Lenfest Working Group. Lenfest Ocean Program.

Rosenberg, A.A., D. Agnew, K. Garrison, C.B. Mogensen, E. Pikitch, J. Powers, M. Powell, R. O’Boyle, S.E. Roady and J.H. Swasey. 2007. Best Practices in US Fishery Management. A Report of the Lenfest Best Practices Working Group.

Rosenberg, A. A., and P. A. Sandifer. 2009. Manager's perspective: the scientific and technical basis for implementing marine ecosystem-based management. In K. O. McLeod and H. Leslie (eds.) Ecosystem-Based Management for the Oceans. Island Press. http://www.islandpress.com/bookstore/list.php?cat_id=27

Rosenberg, A. A., M. Mooney-Seus, I. Kiessling, C.B. Mogensen, R. O’Boyle, J. Peacey, In press. Lessons from national level implementation in North America and beyond. In: K. O. McLeod and $H$. Leslie (eds.) Ecosystem-based management of the ocean. Island Press.

Sainsbury, K.J., A.E. Punt, and A.D.M. Smith. 2000. Design of operational management strategies for achieving fishery ecosystem objectives. ICES Journal of Marine Science, 57: 731-741.

Sainsbury, K., and U.R. Sumaila. 2003. Incorporating Ecosystem Objectives into Management of Sustainable Marine Fisheries, Including 'Best Practice' Reference Points and Use of Marine Protected Areas. In: Responsible Fisheries in the Marine Ecosystem. Edited by M. Sinclair and G. Vladimarsson. FAO and CABI Publishing: 343-361pp.

Salafsky N., R. Margolius, and K. Redford. 2001. Adaptive Management: a Tool for Conservation Practitioners. Washington, D.C.: Biodiversity Support Program.

Salm R.V., J.R. Clark, and E. Siirila. 2000. Marine and Coastal Protected Areas: A Guide for Planners and Managers, 3rd ed. Gland, Switzerland: IUCN. 370p.

Science Advisory Council (2008). First Meeting of the Science Advisory Council, Meeting Summary. September 15, 2008. http://www.mass.gov/Eoeea/docs/eea/oceans/sac_minutes_m1.pdf

Selkoe, K.A., C.V. Kappel, F. Micheli, C. D’Agrosa, J.F. Bruno, K.S. Casey, C. Ebert, H.E. Fox, R. Fujita, D. Heinemann, H.S. Lenihan, E.M.P. Madin, M.T. Perry, E.R. Selig, M. Spalding, R. Steneck, and R. Watson. 2008. A Global Map of Human Impact on Marine Ecosystems. Science, 319, 948-952.

Shertzer, K.W., M.H. Prager, D.S. Vaughan, and E.H. Williams. 2008. Fishery Models. In: S.E. Jorgensen and B.D. Fath eds. Encyclopedia of Ecology: Vol. 2, Population Dynamics. Oxford: Elsevier: 1582-1593.

Sissenwine, M.P. \& Mace, P. 2003. Governance for responsible fisheries: an ecosystem approach. In M. Sinclair \& G. Valdimarsson, eds. Responsible fisheries in the marine ecosystem, pp. 364-391. Rome, Italy and Wallingform, UK. FAO and CABI Publishing

Smith, A.D.M., K.J. Sainsbury, and R.A. Stevens. 1999. Implementing effective fisheries-management systems - management strategy evaluation and the Australian partnership approach. ICES Journal of Marine Science, 56: 967-979.

Smith, A.D.M., E.J. Fulton, A.J. Hobday, D.C. Smith, and P. Shoulder. 2007. Scientific tools to support the practical implementation of ecosystem based fisheries management. ICES Journal of Marine Science, 64: 633-639.

Syms C., and M.H. Carr. 2001. International Clearinghouse for MPA Effectiveness Measures: A Conceptual Design Institute of Marine Sciences and Department of Ecology and Evolutionary Biology, University of California, 100 Shaffer Rd, Santa Cruz CA95060, USA

The Nature Conservancy. www.nature.org

Turner, R.K., R. Brouwer, S. Georgiou, and I.J. Batement. 2000. Ecosystem Functions and Services: An Integrated Framework and Case Study for Environmental Evaluation. The Centre for Social and Economic Research on the Global Environment (CSERGE). ISSN 0967-8875.

UNEP. 2006. Marine and Coastal Ecosystems and Human Well-Being: A synthesis report based on the findings of the Millennium Ecosystems Assessment. http://www.unep.org/pdf/Completev6 LR.pdf

University of Massachusetts at Amherst. 2007. CAPS: Conservation Assessment and Prioritization System. http://www.umass.edu/landeco/research/caps/caps.html, http://www.umass.edu/landeco/research/caps/data/caps data.html,http://www.umass.edu/landec o/research/caps/reports/caps reports.html

Walker, B., and D. Salt. 2006. Resilience Thinking: sustaining ecosystems and people in a changing world. Island Press. Washington, DC, USA. 174 pp. 
Wells S., and A.T. White. 1995. Involving the community. In: Marine Protected Areas: Principles and Techniques for Management, edited by Susan Gubbay. London: Chapman \& Hall. 


\section{Appendix A: Ecosystem Models}

\section{Introduction to models}

Ecosystem models will be important in the development of the MA Oceans Act Plan and to the Massachusetts Ocean Partnership (MOP, the Partnership), specifically, in a number of different ways. First, they represent a synthesis of understanding of the relationships and interactions within the ecosystem. The mere process of evaluating and constructing these models will lead to better understanding of the structure and function of the ecosystem and the limits to this knowledge. Knowing the uncertainties is critical to the second benefit - they can inform decision - making on the mitigation of human impacts on stressed ecosystem components. By understanding how ecosystem components interact and their resilience to impacts, decisions can be made to ensure that the ecosystem is not stressed beyond its breaking point. Thus, the models are a critical part of the development of an ecosystem-based management approach (as described in this report). A third benefit of ecosystem models is that they allow identification of suites of indicators of the state of ecosystem components to allow determination of overall ecosystem health. It will be important for the state of Massachusetts and the Partnership to determine how it will use the products of ecosystem models to inform their varying objectives.

A wide array of ecosystem models is available; and here we highlight the main model classes and their potential relevance to the Oceans Act and the Partnership's initiative, rather than providing an exhaustive review of all possible models. The summaries of the models provided herein will also indicate some of the main issues to consider in using these models, such as their strengths and weaknesses and identify uses in particular situations. Generally ecosystem models are developed to inform on different issues and different ecosystem components; for example, models which serve to inform decisions on fisheries impacts understandably focus on different ecosystem components than those that serve to inform decisions on marine environmental quality. Therefore it is important to both have a clear definition of the priority interests and the value and limitations of various modeling tools. The scale at which the management area is defined with relation to impacts must match the scale of the data and be in concert with the scale of the management decisions; many ecosystem components cross over from the coastal to the offshore environment, while others may be isolated to the coast. These are essential factors in model decision and are particularly important when considering the defined area of the Oceans Act and the extended area of interest to the Partnership. It is worth noting that there has been considerable progress in fisheries-specific modeling approaches for ecosystem management of fisheries. These models, such as SEASTAR are valuable aids to inform decision makers. The approaches in these models deal with aspects of fisheries issues, such as relationships between forage species and target species; these models will not be discussed at length in this report as they are not pertinent to the issues of the Oceans Act.

Most of the approaches considered in this appendix are explanatory models, that is, they seek to explain patterns in the data, often by "fitting" data statistically to model equations. In a few cases (ECOSIM, MIMES) the models simulate the consequences of particular assumptions about the structure of the ecosystem based on the data available. However, no predictive models are presented because few have been explicitly applied to marine ecosystems. A predictive model is intended to predict future outcomes and its performance is based on those predictions rather than on how well it fits existing data. For example, statistical time series models might be used to predict one two or more years ahead the value of the time series (e.g. water quality or fish catch). Such approaches may be useful to managers once a management system is in place. However, for planning, understanding structure and interactions between system components is likely more useful.

Appendix $B$ will provide summaries on the decision support tools referenced in the main report in addition to others that have been utilized in coastal planning decision making that the state and the Partnership may choose to consider; Appendix $C$ provides an indicator framework; Appendix D and $E$ provide summaries on available economic and social analysis approaches, respectively. As mentioned, the tools 
provided as recommendations in the main report are those that the authors are most familiar with. This does not mean to imply that there aren't other appropriate models for decision analysis in Massachusetts. While decision support tools are also models, they do not fit within the described ecosystem model classifications given below, and are therefore addressed in a separate appendix.

\section{A Classification of Ecosystem Models}

Given the wide array of potential ecosystem models available, it is helpful to have a classification system that categorize their main features. Plaganyi (2007) provides such as classification system based upon that of Hollowed et al. (2000). We extend their classification system (

Figure 1) beyond fisheries-related models to include the other models considered in this report.

The first level of the hierarchy splits models that incorporate environmental and lower trophic level processes (termed Whole Ecosystem Models, WEMs) from those that don't (termed Minimum Realistic Models, MRMs). WEMs attempt to model processes that operate across trophic levels, both bottom-up (physical forcing) and top-down (biological forcing). Within this group, there are two subcategories: 1) Aggregate models which do not incorporate the age/size processes of ecosystem components under consideration; and 2) Dynamic System Models which do incorporate age/size processes. This distinction is important for many issues as it allows investigation of mitigation of human impacts that are related to the life stage of the ecosystem component under consideration. The next level of the hierarchy is whether the models incorporate spatial processes. This distinction dramatically increases model complexity and allows investigation of a wide range of issues pertinent to EBM, for instance the efficacy of Marine Protected Areas (MPA) to conserve sensitive habitat.

It should be noted that this report, while recognizing the wide array of physical and biological oceanographic models available, did not undertake a formal review of those, but rather provides brief summaries of the models approach and applicability to the objectives of the Oceans Act. The obvious linkages between the physical oceanography of the Gulf of Maine area (GOM) and the North Atlantic will be important to understand for evaluation of the impacts of many different drivers including climate change on coastal Massachusetts. Whichever modeling efforts the state and Partnership decide to pursue, it will be valuable to maintain communication with US and Canadian oceanographers conducting research along the western Atlantic coast. 


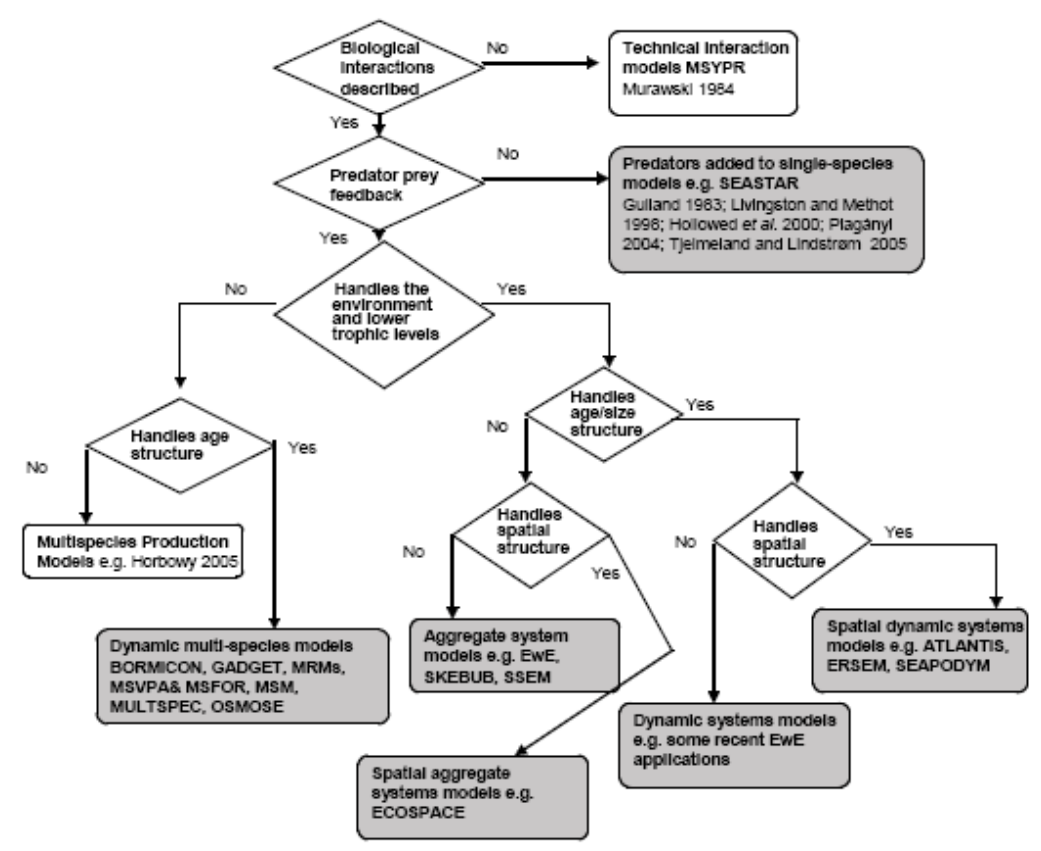

Figure 1. A flowchart summarizing the classification of the various models. The flowchart has been modified and updated from that presented in Hollowed et al. (2000) (Plaganyi, 2007).

As with WEMs, MRMs can be either incorporate age and size structure or not. Multispecies production models such as MS-PROD and Agg-PROD (see Townsend et al., 2008) have recently been used to derive ecosystem - level estimates of production of the fisheries communities in the New England area (GARM III, NEFSC, 2008). Most MRMs which have been developed to support fisheries management decision-making are age/size structured. On the other hand, as with WEMs, the incorporation of spatial processes into MRMs is not a trivial task and thus most are not spatially explicit. As with WEMs, having spatially explicit models is an important consideration for evaluating human impacts on habitat.

In contrast to WEMs, MRMs seek to include only those ecosystem components considered likely to have important interactions with the species of primary interest. Thus, only a small selected component of the ecosystem is modeled to address a relatively small number of questions. MRMs tend to be multi-species extensions of single species approaches. When developing a MRM it is critical to decide how many ecosystem components to include in the model, and the optimal level of complexity. Plaganyi (2007) points out that reducing the number of species or components considered, or aggregating similar species into groups, reduces the number of inter-species or component links which need to be modeled, but consequently also reduces the number of weak links included in the model. Yodzis (1998) used a food web model of the Benguela ecosystem to demonstrate that the exclusion of weaker feeding links (representing less than 10 percent of consumption both by and of any species) had minimal effect on model predictions, but above this threshold for linkage strength the model predictions started to become unreliable. Simplified model outcomes varied drastically from those based on detailed foodweb structure, this was likely due to the presence of potentially strong diffuse effects in complex food webs (Yodzis, 2000).

While there are constraints in the utility of MRMs, they can also be valuable tools. These models focus on a small set of species and issues, which generally implies that there is less need to make the assumptions required by the larger WEMs. On the other hand, MRMs are typically configured to address specific issues and are generally not easily extended to examine broader ecosystem issues. Plaganyi (2007) notes that in contrast to WEMs, recent MRMs have focused on parameter estimation (maximum likelihood and Bayesian) and representation of uncertainty. They can be used to both support tactical management decisions (e.g. TAC advice) and in Management Strategy Evaluation (Smith et al., 1999). 
Although several MRMs have been developed and published, they have seldom been used as basis of tactical fisheries management advice (Bundy et al., 2007).

The models summarized in this appendix are listed in Table 1 ; in the table the complexity of these models generally increases from left to right. 
Table 2 provides a list of the model's acronyms and associated key references. Many of these models are fishery-based, but they can provide a basis for extension to address impacts from other ocean industries. Indeed, it is best to consider these models as exemplary of types of models rather than specific applications. Following the summaries of the models we provide a brief discussion of the appropriateness of the various models to the objectives of the Oceans Act and the Partnership.

Table 1. Ecosystem Models considered in this report.

\begin{tabular}{|c|c|c|c|c|c|}
\hline \multirow{2}{*}{\multicolumn{2}{|c|}{ Minimally Realistic Models }} & \multicolumn{4}{|c|}{ Whole Ecosystem Models } \\
\hline & & \multicolumn{2}{|c|}{$\begin{array}{l}\text { Aggregate Ecosystem Models } \\
\text { No age / size Structure }\end{array}$} & \multicolumn{2}{|c|}{$\begin{array}{l}\text { Dynamic System Models } \\
\text { Age / size Structure }\end{array}$} \\
\hline Non spatial & Spatial & Non spatial & Spatial & Non spatial & Spatial \\
\hline ESAM & GADGET & EwE & \multirow{7}{*}{ Ecospace } & \multirow{7}{*}{$\begin{array}{c}\text { EwE } \\
\text { (recent devel) }\end{array}$} & ATLANTIS \\
\hline MRM (original) & KPFM & SSEM & & & ERSEM \\
\hline MSVPA/MSFOR & EPOC & Agg-PROD & & & SEAPODYM \\
\hline MSVPA-X & \multirow{4}{*}{ SMOM } & EMAX & & & OSMOSE \\
\hline MS-PROD & & & & & INVITRO \\
\hline MSM & & & & & MIMES \\
\hline & & & & & SystMod \\
\hline
\end{tabular}


Table 2. Acronyms and Key References of Ecosystem Models

\begin{tabular}{|c|c|c|}
\hline Abbreviation & Model Approach & References \\
\hline Agg-PROD & Aggregate production models & Link (2003) \\
\hline ATLANTIS & Dynamic system model & Fulton et al. (2004) \\
\hline BORMICON & BOReal Migration and CONsumption Model & Stefansson and Palsson (1998) \\
\hline Ecopath & Food web and mass balance model & Christiansen and Pauly (1992) \\
\hline Ecosim & Food web simulation & Walters et al. (1997) \\
\hline EMAX & The Energy Modeling and Analysis eXercise & Link et al. (2006) \\
\hline EPOC & Ecosystem Productivity Ocean Climate Model & Constable (2005) \\
\hline ERSEM & European Regional Sea Ecosystem Model & Baretta-Bekker and Baretta (1997) \\
\hline ESAM & Extended Single-Species Assessment Model & $\begin{array}{l}\text { e.g. Hollowed et al. (2000); Tjelmeland } \\
\text { and Lindstrom (2005); Moustahfid et al. } \\
(2008)\end{array}$ \\
\hline EwE & ECOPATH with ECOSIM and ECOSPACE & $\begin{array}{l}\text { Christensen and Pauly (1992); Walters } \\
\text { et al. (1999) }\end{array}$ \\
\hline GADGET & $\begin{array}{l}\text { Globally applicable Area-Disaggregated General } \\
\text { Ecosystem Toolbox }\end{array}$ & Begley and Howell (2004) \\
\hline IGBEM & Integrated Generic Bay Ecosystem Model & Fulton (2001) \\
\hline INVITRO & None & Gray et al. (2006) \\
\hline KPFM & Krill-Predator-Fisheries Model & Watters et al (2005) \\
\hline MIMES & $\begin{array}{l}\text { Multiscale Integrated Model of the Earth System's } \\
\text { Ecological Services }\end{array}$ & $\begin{array}{l}\text { Boumans et al. (2002); Boumans and } \\
\text { Costanza (2007) }\end{array}$ \\
\hline MRM & Minimally Realistic Model & Punt and Butterworth (1995) \\
\hline MSM & Multispecies Statistical Model & Jurado-Molina et al. (2005) \\
\hline MS-PROD & Multispecies Production & $\begin{array}{l}\text { Sullivan et al. (1991); Collie and DeLong } \\
\text { (1999); Link (2003) }\end{array}$ \\
\hline MSVPA and MSFOR & $\begin{array}{l}\text { Multi-Species Virtual Population Analysis and Multi- } \\
\text { Species FORcasting model }\end{array}$ & Gislason and Helgason (1985) \\
\hline MSVPA-X & Multispecies Virtual Population Analysis Extension & Garrison and Link (2004) \\
\hline MULTSPEC & MULTi-SPECies model for the Barents Sea & Bogstad et al. (1997) \\
\hline OSMOSE & $\begin{array}{l}\text { Object-oriented Simulator of Marine ecOSystems } \\
\text { Exploitation }\end{array}$ & Shin and Cury (2001) \\
\hline SEAPODYM & Spatial Ecosystem And POpulation DYnamics Model & Lehodey et al. (2003) \\
\hline SMOM & Spatial Multi-species Operating Model & Plaganyi and Butterworth (2006) \\
\hline SSEM & Shallow Seas Ecological Model & Sekine et al. (1991) \\
\hline SystMod & System Model for the Norwegian and Barents Sea & Hamre and Hatlebakk (1998) \\
\hline
\end{tabular}

\section{Non-Spatial Minimum Realistic Models}

\section{ESAM}

This model type is likely the simplest MRM considered. It incorporates either environmental covariates and/or interactions with one or two other species into single species fishery assessments (e.g. Virtual Population Analysis). Extended single-species assessment models (ESAM) approach is based on traditional single-species fishery assessment models which are extended to account for some basic interactions (e.g. predation). Other ESAM models have been developed by adding density-dependent growth and climate effects on recruitment. These approaches are increasingly being encouraged as a first step towards accounting for some of the ecosystem effects of fishing (Plagányi, 2007).

The ESAM models that account for biological interactions (e.g. predation) have been both age structured and biomass production models (e.g. Livingston and Methot, 1998; Hollowed et al., 2000; Overholtz et al., 
2008; Moustahfid et al., 2008). These have ranged from providing context of stock biomass, tuning indices, sources of other mortality, to explicit estimates of predation mortality.

Mostly the way predation is added into these models is to treat it as an additional fleet, explicitly as another source of removals. The data required are usual survey and fisheries catch data, abundance of predators, stomach contents, consumption estimates, and diet composition estimates. It was recognized that the major challenge in constructing ESAM models lies in the choice of a suitable interaction term. These interactions range from a simple Lotka Voltera linear interaction to more complicated functional response formulations (such as the various Holling functional response formulations or ECOSIM's foraging arena formulation). Tjelmeland and Lindstrom (2005) provide a good example of an ESAM to investigate the interaction between Norwegian herring and minke whale; Chouinard et al. (2005) investigated the hypothesis that increased predation by a growing number of Grey seals resulted in increases in the natural mortality of Atlantic cod.

The other ESAM model that incorporate environmental considerations are been developed by including changes in carrying capacity $(\mathrm{K})$, growth rates (r), stock-recruitment relationships (e.g. Sinclair and Crawford, 2005). In addition to the standard stock assessment data needs, these approaches require appropriately (spatio-temporal) scaled environmental data such as temperature, depth, salinity from various monitoring sources.

In general these approaches are relatively simple conceptually and operationally, they use standard fishery stock assessment data, they are implemented in a familiar assessment and management context, they provide familiar model outputs and they improve the biological realism of assessment models. However, these approaches run the risk common to all minimum-realistic models, namely that they may be missing a suite of complex interactions and non-linear responses from not including the full suite of interactions in an ecosystem.

\section{MRM (original)}

This is termed the MRM (original) as the concept was pioneered D. Butterworth and colleagues working on marine mammal - hake interactions off the South African west coast. The fur seal population (Arctocephalus pusillus pusillus) there is estimated to consume about as much hake as is landed by fishers. The issue was whether the hake fishery would benefit in response to a seal cull. The hake fishery exploits two species - a shallow-water (Merluccius capensis) and a deep-water species (M. paradoxus), with the larger of the shallow-water species eating the smaller individuals of the deep-water species. The Punt and Butterworth (1995) model was restricted to the two species comprising the hake resource, seals, a grouped category of large predatory fish and the hake fishery. Together these were estimated to account for more than 90 percent of all mortality of hake. The level of detail taken into account for each component depended on that considered necessary to capture the key aspects of its dynamics. Fully age-structured models were used for the two hake species (to capture cannibalism and interspecies predation effects), but the "other" predatory fish components were lumped into either a small or large fish category.

The approach of Punt and Butterworth (1995) involved taking explicit account of uncertainty and management issues through the use of a simulation framework that incorporated the feedback control rules actually in place for setting TACs for the hake fishery; this framework has provided useful for further work in the field of fisheries management. There are currently an increasing number of multispecies management strategy evaluation (MSE) studies taking this approach beyond single and limited multispecies applications to consider the broader aspects of ecosystems or assemblages. The data required are fairly standard fishery stock assessment data.

\section{MSVPA / MSFOR and MSVPA-X}

MSVPA and its projection component MSFOR are deterministic age - based fish stock models based upon the early North Sea model of Andersen and Ursin (1977). Multispecies Virtual Population Analysis (MSVPA) is an extension of traditional fisheries stock assessment models (cohort analysis or virtual population analysis (VPA) (Gulland, 1965)) that includes a simple feeding model to estimate mortality due to predator-prey interactions in exploited fish communities. The MSVPA approach was initially developed 
by the International Council for the Exploitation of the seas (ICES) multispecies working group (e.g. Gislason and Helgason, 1985), and it has been applied to the North Sea, the Georges Bank, the Baltic Sea and the eastern Bering Sea fish communities. The primary feature of the MSVPA is that the natural mortality rate $(\mathrm{M})$ is split into two components: predation due to predators explicitly included in the model (M2) which is determined by suitability parameters that reflect the preference of a prey species to a predator and residual mortality (M1) due to all other factors, including minor predators, disease, and senescence which is not explicitly included in the model.

The MSVPA approach can be viewed essentially as a series of single-species virtual population analysis models that are linked by a simple feeding model to calculate natural mortality rates. The system of linked single-species models is run iteratively until the predation mortality (M2) rates converge. The basic model is therefore performed in two primary iteration loops. First, all single-species VPAs are run to calculate population size at all ages for predators and prey, then predation mortality rates are calculated for all age classes of each species based upon the simple feeding model. The single-species VPAs are run again using the calculated M2 rates, and this iteration is repeated until convergence. Forward projections are made by a separate module, MSFOR, based on the same assumptions as MSVPA.

MSVPA has recently been expanded to incorporate additional features and to address several recognized weaknesses of the original ICES approach. The expanded version of the MSVPA approach (described as MSVPA-X; Garrison and Link, 2004) has a more user friendly interface than some previous implementations of the model. MSVPA-X modifies the predator consumption equations to incorporate the effects of changing food availability and temperature on predators' consumption rates. It also includes a choice of four "tuned" single species virtual population analysis models (e.g. Extended Survival Analysis (XSA)) which allow for greater flexibility to account for differing data availability. The MSVPA-X feeding selectivity model more explicitly formulates spatial overlap, prey type and size selectivity than the original MSVPA. MSVPA-X implements an improved functional feeding response (weak Holling type III) and includes also provisions for "biomass predators"; predation by these species affects the mortality of explicitly modeled prey species. The model also includes a forecasting component to allow exploration of multispecies population trajectories under a range of management scenarios and assumptions about future recruitment.

MSVPA-X has been applied to two-subsystems in US Northwest Atlantic. One is for the coastal mid Atlantic region and emphasizes Atlantic menhaden as prey and its three main predators (bluefish, weakfish and striped bass). The other is for the whole Northeast US ecosystem, has 19 species, and emphasizes herring and mackerel as the major prey. The mid-Atlantic MSVPA-X has gone through extensive peer review in the Atlantic States Marine Fisheries Commission (ASMFC) and the NEFSC Stock Assessment Review Committee (NEFSC, 2006) context. Outputs from that model have informed the single species assessments, particularly by providing time-series of M2s for the assessment of menhaden. The Northeast US MSVPA-X is now been accepted for publication in ICES journal (Tyrrell et al., 2008), and the results are expected to inform single species assessments for herring and mackerel.

MSVPA approaches outputs include population sizes, quantification of predator-prey interactions and variation in mortality rates. Each of these variables is age specific and includes both seasonal and interannual variation. The data requirements for MSVPA approaches include age-structured catch and assessment data along with information on predator diets, consumption rates, and growth. In addition, biomass estimates for lower trophic level prey are important inputs to adequately model predator diets. Thus, the data demands for implementing these approaches are significant. However, the MSVPA approach uses similar catch and biological data to single-species assessments and results in directly comparable measures of mortality rates, population size, and benchmarks. The MSVPA approach is therefore relatively easily incorporated into fisheries management and provides additional information to evaluate potential tradeoffs between ecological processes and commercial fishery yields.

\section{MS-PROD}

Multispecies production (MS-PROD) models are simple extensions of traditional single species production models. They are constructed by adding terms to Schaefer production model (Schaefer, 1954) to 
characterize ecological interactions with other species- primarily competition and predation- resulting in a system of linked difference equations (Sullivan et al., 1991; Collie and DeLong, 1999, Link, 2003).

As with single species production models, both equilibrium and non-equilibrium methods can be used to derive estimates of the coefficients; however, non-equilibrium methods are generally recommended since the assumption that a stock is at equilibrium is rarely valid. MS-PROD models have been applied in the Baltic Sea (Horbowy, 2005), the Eastern Bering Sea/Aleutian Islands region and in the Gulf of Alaska (e.g. Mueter and Megrey, 2006).

The recent advance in this type model is the development of a simulator model that seeks to simulate the relative importance of predation, intra-guild competition, between guild competition, and fisheries removals (Townsend et al., 2008). The model has been parameterized for US Northeast continental shelf ecosystem (NEUS) with empirically based values that can then explore sensitivities and scenarios for different considerations. The data required are initial biomass estimates, carrying capacities, predation and competition interaction terms, growth rates, and fishery removals.

One advantage of this approach is that it requires relatively few data (only data on catch and total biomass are needed) compared to other multispecies approaches. The other advantages are that it explicitly accounts for ecological processes in addition to fisheries effects and that lower trophic level processes can be directly linked to estimates of carrying capacity. The disadvantages are that some of the parameters are difficult to estimate and that it does not currently fit to time series data.

\section{MSM}

A related formulation to MSVPA is MSM (Multi-species Statistical Model) (Jurado-Molina et al., 2005) which is forward fitting using the same general approach as other Minimally Realistic Models (MRM) but assuming error in the catch at age. It is the model analogy between the single species Statistical Catch at Age and Virtual Population Analysis that are common fishery stock assessment models used for management advice.

MSM approach estimates fish stock size and predation mortality based on catch-at-age data, relative indexes of abundance, predator annual ration and predator stomach contents using estimation procedures for the statistical part and the predation mortality. The MSM statistically estimates parameters using either an optimization algorithm or Bayesian methods. In both cases, for a given set of parameter values, MSM projects population trajectories over the specified time frame. These trajectories are computed based on catch-at-age and on predation mortality. The predation mortality requires an iterative solution since its value in each year is confounded with the abundance of other species in that year. Given fixed values for the parameters (initial age structure, recruitment, fishing mortality and selectivity coefficients) and an initial guess for $M 2$, the population trajectories are computed. These population estimates together with given values of the suitability coefficients allows the estimation of the predation mortality. The predation algorithm then adjusts the $M 2$ values and updates population estimates until two consecutive iterations converge to marginally different $M 2$ and suitability coefficients values according to established criteria (Sparre, 1991). Once the criteria are reached and the estimates of predation mortality, suitability coefficients and population have converged, the likelihood is used in the criteria of the main data fitting routine. This procedure (the main part and the internal estimation for M2) is repeated until the negative log-likelihood is minimized (by adjusting main parameters) or in the Bayesian methods until the posterior distribution is adequately represented.

The MSM has being applied for three important species in the Eastern Bering Sea (walleye pollock, pacific cod and arrowtooth flounder) and results were compared with past approaches (e.g., multispecies VPA) (Jurado-Molina et al., 2005). MSM is an important advancement in providing advice to fisheries managers because it incorporates the standard tools such as Bayesian methods and decision analysis into a multispecies context, helping to establish useful scenarios for management.

Data requirements include common stock assessment data: catch-at-age data, maturity-at-age, and weight-stage. Also include stomach content data, prey weight-at-age in the predator stomach contents, predator annual ration, and residual natural mortality. 
The advantages of MSM approach include providing the means to evaluate the information content of data in a statistically defensible manner. Key players in the ecosystem are included and the relative impact of alternative fishing mortalities can be extended. The structure of these types of models lends themselves to simulation testing. The disadvantages of these models are the common weaknesses to all minimum-realistic models that they includes only a segment of the ecosystem and may miss processes that are important controlling factors.

\section{Spatial Minimum Realistic Models}

\section{GADGET}

MULTSPEC, BORMICON and GADGET are all of Northern Hemisphere origin and have variously incorporated predation by marine mammals. A common feature is that they are area-disaggregated which is a definite advantage given the migratory behavior of many marine mammals and the consequent importance of considering spatial-temporal overlaps between fisheries, marine mammals and shared prey species. MULTSPEC (see Bogstad et al., 1997) is a length-, age- and area-structured simulator for the Barents Sea that includes cod, capelin, herring, polar cod, harp seal and minke whales. Predation interactions are modeled only as one-way in the case of marine mammals i.e. marine mammal abundance do not react to changes in prey availability. BORMICON (A BOReal Migration and CONsumption model) is another area-structured approach for the multi-species modeling of Arcto-boreal ecosystems (Stefánsson and Palsson, 1998). Plaganyi (2007) notes that work on MULTSPEC is not continuing while BORMICON is being incorporated as a special implementation of GADGET.

In GADGET, populations can be split by species, size class, age group, area and time step. The model platform permits the easy addition/substitution of alternative model components of biological processes such as growth, maturation and predator-prey interactions. It is extremely flexible in terms of methods for fitting to data, being comprehensive and incorporating state-of-the-art features. GADGET on the other hand, like all ecosystem models, should only be used by those that understand its assumptions. Also, although the GADGET manual (Begley and Howell, 2004) is fairly comprehensive, it doesn't always include the underlying equations for some components. As with the other modeling approaches, a major impediment to applying this approach in many cases is the lack of data to describe feeding relationships, especially when considering situations where resource abundances and their ratios differ greatly from those of the recent periods for which data are available. A strong advantage however is that GADGET incorporates a data warehouse that provides the flexibility for ready use of data at the different levels of aggregation that may be required across a number of investigations.

\section{CCAMLR Models (KPFM, EPOC and SMOM)}

Predator-prey modeling procedures have been developed through CCAMLR (Convention of Antarctic Marine Living Resources) to assess the impact of Antarctic krill harvesting on krill predator populations and to explore means of incorporating the needs of these predators into the models that are used to recommend annual krill catch levels. Models such as KPFM, EPOC and SMOM have been developed to consider these krill predation issues. In general, initiatives pursued under CCAMLR recognize the need to balance the needs of predators with the socio-economic pressures underlying fishery harvests.

KPFM is being developed to address options for subdivision of the precautionary krill catch limit in the Antarctic Peninsula region (Statistical Area 48) amongst Small Scale Management Units (SSMUs) with areas in the range 104 to $93 \times 104 \mathrm{~km}^{2}$. The model is like a WEM in that it can be used to investigate the roles of transport, production, predation and harvesting, but it also resembles a MRM as it focuses on aspects considered to be most important rather than fully specifying the entire spectrum of ecosystem processes and species. The model is spatially resolved to the level of SSMUs and surrounding oceanic areas and it uses a transition matrix approach to model the transport of krill between areas.

EPOC, initially applied only to krill, is being developed using an object-oriented framework built around the following modules: (i) biota; (ii) environment; (iii) human activities; (iv) management; (v) outputs; and (vi) presentation, statistics and visualization. Each element within a module is an object carrying all its 
own functions and data. It is thus designed to be a fully flexible plug-and-play modeling framework in response to a need to easily explore the consequences of uncertainty in model structures as well as widely varying knowledge on different parts of the ecosystem. The model is being set up to easily examine the sensitivity of outcomes to changes in model structures, not only in terms of the magnitudes of parameters but also in the spatial, temporal and functional structure of the system. An added advantage is that within the same simulation, different species can be modeled at different spatial and temporal scales as well as with different biological and ecological levels of complexity.

SMOM includes 15 SSMUs and uses an annual timestep to update the numbers of krill in each of the SSMUs, as well as the numbers of predator species in each of these areas. The model currently includes four predator groups (penguins and seals, fish and whales) but is configured so that there is essentially no upper limit on the number of predator species which can be included. Stochastic replicates are produced to explore different hypotheses such as those related to the transport of krill. SMOM is intended for use in an MSE. CCAMLR has encouraged the further development of spatially explicit management frameworks and the development and evaluation of operating models and decision rules for adjusting fishing activities (e.g. catch limits) based on field data in the future.

\section{Aggregate Ecosystem Models}

\section{EwE and ECOSPACE}

ECOPATH with ECOSIM (EwE), developed at the Fisheries Centre of the University of British Columbia, is arguably the predominant ecosystem model worldwide. The EwE software suite (including ECOSPACE) is a tool for constructing a model of trophic flows between compartments in an ecosystem (Christensen and Pauly, 1992). While ECOPATH can be considered an analytic tool, ECOSIM can be used to simulate changes in abundance of system components over time. At the core of ECOPATH are mass balance equations describing production gains and losses to estimate flows for species in the model. Each group is represented by one balanced equation and requires six input parameters: biomass, production, consumption, ecotrophic efficiency (the fraction of the production that is either passed up the food web or exported), diet composition, and catch of each group. The linear equations are solved via matrix algebra to produce estimates of the flows that balance inputs and outputs; any missing parameters are estimated (ecotrophic efficiency is estimated if all parameters have been entered). Export and diet composition must always be entered while of the four remaining basic input parameters (biomass, production, consumption, and ecotrophic efficiency), three must be entered. In most cases, when all the information to run an ECOPATH model is assembled, the model will not balance due to the inconsistencies in the information. In this case, the values of one or more of the terms can be changed iteratively until a balance is obtained.

Ecosystem changes can be simulated over time using ECOSIM, which is a dynamic ecosystem model. ECOSIM converts 'steady state' trophic flows of ECOPATH into dynamic, time dependent predictions. ECOSIM was originated by Walters et al. (1997) with its key feature being a flexible "foraging arena" model of predator-prey functional response (Walters and Martell, 2004), which assumes that the percapita consumption of prey by predators decreases as predator abundance increases. This is different from the more traditional assumption used in, say MSVPA, which assumes that the per-capita consumption of prey by predators is equal to the predator's required daily ration. ECOSIM can be used to explore the dynamics of the system as well as the responses of the system to various fishing patterns and environmental disturbances. The basics of ECOSIM are derived from the ECOPATH equation and consist of biomass dynamics expressed in the form of coupled differential equations. It takes into account the trade-off between searching for prey and being exposed to predators. This can be manipulated through changing the vulnerability parameter of prey. The vulnerability parameter ranges from 0 (prey not vulnerable, implying bottom-up control) to 1 (prey vulnerable, implying top-down control). ECOSIM requires input of life history parameters and allows for linking of juvenile and adult groups to better represent ontogenetic shifts. ECOSIM models can be replicated over a spatial map grid (ECOSPACE) to allow exploration of policies such as marine protected areas (MPA), while accounting for spatial dispersal/advection effects. 
Plaganyi (2007) considers that EwE provides a good balance in model structure between simplicity and complexity. It can include either a small number (MRM) or large number of ecosystem components and has a number of other strengths, including:

- $\quad$ structured parameterization framework

- inclusion of a well-balanced level of conceptual realism

- novel representation of predator-prey interaction terms

- use of a common framework for making comparisons between systems studied by different researchers

- $\quad$ rigorous analytical framework provided by ECOPATH (in contrast to an ad hoc type model);

- Inclusion of a Bayes-like approach (ECORANGER) to take account of the uncertainty associated with values for model inputs

- large user base and good input / output options

Past implementations of EwE have been criticized for a number of shortcomings although Plaganyi (2007) considers that many of these are not due to the model itself but rather to use misuse. This might have been facilitated by the efforts to make EwE accessible and user-friendly. As noted above, ecosystem models are by their nature very complex and without a solid understanding of their workings, it is easy to go dramatically wrong.

Recent versions of EwE include a facility to model fully age - structured population dynamics with multiple life history stanzas which dramatically extends its utility to a wider range of issues. The new model version can handle age-structure, include improved capabilities to balance models based on uncertainty, ability to plug in any functional response desired by user, and examine the impact of uncertainty as part of the management process and to quantify input parameter uncertainty to run ECOSIM using a Monte Carlo approach to fit to time series.

ECOSIM and ECOSPACE are being used in NOAA NMFS Science Centers in a variety of applications (Townsend et al., 2008). In general, the model is used for describing ecosystems and for improving understanding of how simultaneous physical, ecological, and fisheries interactions affect commercial and bycatch species in those systems. Specific applications have included examining apex predator (and/or protected species) carrying capacity and predicting their responses to changing fishing and primary production; examining effects of changing water quality on key species; examining the ecosystem effects of changing fishing gear; examining the ecosystem effects of different MPA scenarios; and evaluating tradeoffs at the ecosystem level between alternative management strategies. In several Centers, the model has been useful in providing a foundation for developing proposals to integrate ecosystem-based management approaches into the current management regime.

It is important to note that EwE has undergone an overhaul with support from the Lenfest Ocean Program. The outcome is a new release (EwE6) restructured to modularize the individual components and completely separating the user interface from the computational core to allow different interfaces, not just the standard scientific but also for instance gaming interfaces. The Lenfest Ocean Futures Project is designed to address how current fisheries management approaches can be modified to become more responsible from social, economical as well as ecological perspectives. The project is developing a new approach to fisheries management through a EwE-based ecosystem modeling and visualization methodology aimed at exploring scenarios management in policy and management workshops. The project relies on development of three technical components: optimization of EwE, development of interactive gaming software, and visualization of the impact humans have through fishing activities on the ecosystems. The product of the project will thus serve in support of ecosystem-based management of fisheries, while offering a possibility for a group of managers to quickly explore alternative scenarios and evaluate the potential outcome.

\section{SSEM}

The Shallow Sea Ecological Model (SSEM) (Sekine et al., 1991), like ERSEM (see below), includes detailed representation of processes such as swimming, advection and diffusion and requires inputs in the form of water temperature, currents and nutrient loads from surrounding land masses. While neither 
age/size based nor spatially explicit, it has specifically been developed to predict the impact on fisheries of coastal development activities. It is thus it can be a useful approach combined with one of the fishery specific models, but would not be suitable for broader questions related to the ecosystem impacts of fisheries.

\section{Agg-Prod}

Aggregate production models (Agg-PROD) are based in the same approach as MS-PROD model, except that they are parameterized for aggregate groups of species as opposed to a particular stock. The intended purposes of this approach as described in recent workshop (DFO, 2008) are to 1) assess the status of living marine resources (LMR) as major groups or clusters (e.g. guilds, taxa, etc.), not as individual stocks, particularly in instances when doing so is data-limited; and 2) estimate total systemic or group level biological reference points (BRP) that account for species interactions and precaution.

There are two example applications of this approach from the northeast U.S. (NEFSC, 2008). One is a traditional surplus production model (ASPIC) for the full suite of groundfish, all finfish, and all targeted species. The second is using a MS simulation production model (MS-PROD) parameterized for the entire fish community as a whole and in component groups to estimate total carrying capacities under various scenarios and parameter sensitivities.

\section{EMAX}

The Energy Modeling and Analysis eXercise (EMAX) is a focused ecosystem study being conducted by the NEFSC (Link et al., 2006). It is a network analysis model (a more nuanced energy budget) of the entire food web. It includes the entire northeast US continental shelf, broken into 4 sub-regions with 36 network "nodes" or biomass state variables across a broad range of biology. The emphasis is on the role of small pelagic species with some pseudo-dynamic scenarios executed. Interactions among targeted and protected species are explicitly included. This work is highly interdisciplinary and involves personnel from most of the Center's Divisions.

The primary work has been to calculate a balanced energy budget for the four regions: mid-Atlantic, Southern New England, Georges Bank, and the Gulf of Maine. Once these networks were balanced, a suite of network analyses and outputs were executed. This work has not gone through a formal model review process; however there has been an interdisciplinary team meeting regularly in workshops to review and revise the work as it has progressed. The rigor and degree of quantitative data used to input and balance these networks has been atypical in comparison to much of the published literature on the subject. This modeling approach was designed to compile and catalog information, identify data gaps, and serve as the basis for future dynamical system modeling. As such it was a research tool. But the model was also designed to evaluate the relative role of specified nodes in the ecosystem; as such it provides contextual and strategic management advice.

EMAX used two energy budget software packages: Econetwrk (Ulanowicz, 2004) and Ecopath (Christensen and Pauly, 1992). There were five main elements critical to the construction of each node for the four NEUS regional networks. Biomass, production, consumption, respiration, and diet composition are estimated for all nodes. Additionally, for some nodes, other sources of removals namely fisheries - are also estimated. The positives of this approach are its inclusion of a wide range of biota and associated processes and its ability to holistically examine an ecosystem to ascertain the relative importance of simultaneous processes. Also positive is the ability to examine tradeoffs in biology and fishing in an integrated fashion. Negatives include the data intensiveness for this many nodes, the lack clarity on detrital dynamics, and the complexity of possible dynamics given the myriad of pathways in the full system. Yet the data intensiveness is the same or less than for many MSVPA and multispecies models; the challenge is that for many of the lower trophic level nodes the information is underdetermined. 


\section{Dynamic Whole Ecosystem Models}

\section{ATLANTIS}

Management Strategy Evaluation (MSE) (Smith et al., 1999) involves assessing the consequences of a range of management strategies (or options) and presenting the results so it is clear what the tradeoffs in performance are across a range of management objectives and under a range of possible conditions. This approach does not seek to proscribe an optimal strategy or decision; rather it seeks to provide the decision maker with the information with which to make rational decisions, given their own objectives, preferences, and attitudes to risk. The MSE approach typically uses simulations, which model each part of the adaptive management cycle. ATLANTIS is a deterministic biogeochemical whole of ecosystem model built specifically around this approach, including modules for each of the major steps in the adaptive management cycle (Plaganyi, 2007). It is arguably the best model worldwide to support MSE. It includes the full trophic spectrum. It has a more simplified representation of physiological processes than most other ecosystem models, using a detailed sensitivity analysis to determine the importance of including various processes (Fulton, 2001). Vertebrates such as fish are modeled using age-structured formulations. Lower trophic level groups are represented better than in most whole ecosystem models, in that it allows some age structuring at the juvenile-adult level for potentially important invertebrates such as cephalopods and large crustaceans), whereas the upper trophic level groups are represented better than in other biogeochemical models. The model is spatially resolved. Multiple vertical layers can be considered. The modular structure allows the substitution of a wide range of different sub-models for various components. The nutrient-pool formulation allows testing of effects such as nutrient inputs from point sources. There is detailed coupling between physical and biological processes. Finally, multiple representations of some of the processes are included, thereby allowing the user to choose the preferred option for their modeled system. It also includes a range of possible predator - prey functional forms, the sensitivity to which can be explored.

There are a considerable number of assumptions associated with any single application of ATLANTIS, the exact nature of which is dependent on which of the options available in it are chosen. While the model includes representation of many sub-grid scale processes, its deterministic form means it still contains many mass action simplifications for the finest resolutions it resolves. To date, the range of models developed (17 with 3 more proposed) have ranged from simple nutrient and plankton models through to a whole of ecosystem model (including 60 ecological groups and 33 fleets) with social and economic drivers of effort allocation. The inclusion of the latter is rare in ecosystem models.

ATLANTIS is not the simplest or easiest model to use - it has no GUI interface and has long calibration and run times. Steps are being taken to remedy this (e.g. development of more user friendly GUI, supporting software is accumulating and documentation is accreting), but this model will never be rated as easy to use. While many users will find an existing model relatively easy to play with, development of new models is always a substantial effort. This difficulty, along with only a crude handling of biodiversity and only simple handling of uncertainty are the greatest weaknesses of ATLANTIS. In contrast, its greatest strengths are its flexibility, the explicit handling of space and biophysical and environment factors, inclusion of critical processes (even if at sub-grid scale) and the coupled MSE structure. Like all ecosystem models it requires careful use if it is to be used well. Plaganyi (2007) argues that in a data rich situation, ATLANTIS may be well suited to a user's needs, whereas in a data poor situation, the framework is still quite useful for asking "what-if" questions.

\section{ERSEM}

The European Regional Seas Ecosystem Model (ERSEM) was developed to simulate the annual cycles of carbon, nitrogen, phosphorus and silicon in the pelagic and benthic components of the North Sea (Baretta-Bekker and Baretta, 1997). The model requires detailed data inputs and focuses on the phytoplankton and zooplankton groups, with detailed representation of microbial, detrital and nutrient regeneration dynamics. A wide range of forcing factors including irradiance and temperature data, atmospheric inputs of nitrogen, suspended matter concentration, hydrodynamic information to describe advective and diffusive transport processes and inorganic and organic river load data drive the model. The spatial scope of the model encompasses the entire North Sea. 
The detailed representation of transport processes within ERSEM have allowed simulation of important North Sea herring juvenile growth processes such as year-specific dispersal and timing of larval recruitment. The model was useful in demonstrating the extent to which hydrographic and planktonic conditions are responsible for short-term year-to-year variability in growth but the model failed to explain longer-term underlying trends thought to be due primarily to density-dependence.

While it could be adapted to other regions, given that the focus of ERSEM is on the lower trophic levels, it is unlikely to be able to contribute to practical fisheries management but is nonetheless a good tool for understanding environmental drivers and bottom-up processes impacting fish populations.

\section{SEAPODYM}

Previously SEPODYM, SEAPODYM (Lehodey et al., 2003) is a two dimensional coupled physicalbiological interaction model at the ocean basin scale, developed for tropical tunas in the Pacific Ocean. The model includes an age-structured population model of tuna species, together with a movement model which is based on a diffusion-advection equation such that swimming behavior is modeled as a function of habitat quality. The inclusion of spatial structure was essential given the need to account for fishing effort distribution, the widely ranging swimming behavior of tuna and environmental variations. The latter are simulated using input data in the form of sea surface temperature (SST), oceanic currents and primary production, predicted either from coupled physical-biogeochemical models such as OGCM (Ocean General Circulation Model) or satellite-derived data.

SEAPODYM has thus far only been run in the Pacific Ocean and the first multispecies simulation including three tuna species (skipjack Katsuwonus pelamis, yellowfin Thunnus albacares and bigeye $T$. obesus) has only recently been completed. However, there are plans to develop additional modules for other oceanic predators. The model structure differs from the other models in the Dynamic Systems Model category in terms of representing only a small subset of the species in the ecosystem but it is linked to a physical model and hence allows investigation of, for example, the relationship between climate variability and recruitment and biomass fluctuations.

\section{OSMOSE}

OSMOSE (Shin and Cury, 2001) is a spatial Individual-Based Model (IBM) that uses simple individual predation rules to model trophic interactions. Individual-Based Models follow the fate of individuals through their life cycle, under the assumption that individual behavior has an appreciable effect on a population's dynamics. They are thus useful in situations in which an understanding is needed of how individual behavior might affect the dynamics of a system. These models are sometimes referred to as "agent-based" models with the "individual/agent" being represented by either individual animals and plants, or composite units such as fish schools or fishing fleets. They have typically been applied to investigate the dynamics of a single population within the marine environment, but a number of applications extend these analyses to consider multi-species dynamics.

OSMOSE is thus an excellent framework to explore the hypothesis that predation is a size-based opportunistic process, depending only on size suitability and spatial co-occurrence between predators and their prey. OSMOSE has a potentially important role to play as an alternative modeling approach that can help to identify consistent patterns in attempting to understand the ecosystem effects of fisheries.

OSMOSE assumes opportunistic predation based on spatial co-occurrence and size adequacy between a predator and its prey (size-based opportunistic predation). It represents fish individuals grouped in schools, which are characterized by their size, weight, age, taxonomy and geographical location (2D model), and which undergo different processes of fish life cycle (growth, explicit predation, natural and starvation mortalities, reproduction and migration) and a fishing mortality distinct for each species. OSMOSE was first applied to the Benguela upwelling ecosystem for which 12 fish species have been specified, from small pelagic fish to large demersal species. The model requires basic parameters that are often available for a wide range of species, and which can be found in FishBase for instance (www.fishbase.org): growth (von Bertalanffy model) and reproduction parameters. It also needs to be forced by spatial distribution maps for each species (by stage and by season). It has been used to 
explore MPA designs and given its flexibility, can handle low species abundances and therefore may be applicable to species at risk questions. It may also be applicable to habitat questions, invasive species, and impacts of aquaculture. It can't yet be used to support harvest control rule development for fisheries. On the downside, it has no pre-packaged user interface and no standardized outputs.

\section{INVITRO}

Traditionally two main types of ecological models have been developed: Aggregate Ecosystem Models, such as EwE and Individual-based Models, such as OSMOSE. Formal separation of these model types is not always easy. For instance, within the latter form of model, the individuals may represent schools, patches of homogeneous ground cover, flocks, patches of reef, or some other subset of a population that could be treated as equivalent to an entity. Aggregate Ecosystem Models can thus be seen as a special case of an individual (or more properly agent) state model. Consequently, we can treat Aggregate Ecosystem Models as agents within an Agent-Based Model (ABM) system. This is the approach that has been taken in INVITRO (Gray et al., 2006), which is currently used as the basis for MSE-based studies focusing on the multiple-use ecosystem-level management questions within the coastal waters of Australia.

While the array of agent types is fairly comprehensive (and allows for immense flexibility), the computational costs of constructing an ecosystem in this way mean that in practice an MRM approach is taken to model structure, with only a subset of the ecosystem that incorporates the dominant system components included explicitly in the model. To date, this has meant that only the commercially valuable fish and crustaceans, top predators, species of special interest (e.g. vulnerable species such as turtles), benthic communities (or forage communities if in the pelagic system) and primary producers have been included in INVITRO models. Ongoing work will see a wider set of "supporting" species included, but it is unlikely that the complete coverage offered by EwE or ATLANTIS will ever be possible. ABMs are faced with all the same complexity, uncertainty and interpretation issues as the other forms of ecosystem models.

\section{MIMES}

Multi-scale Integrated Models of Ecosystem Services (MIMES) was begun as a result of the Millennium Assessment Synthesis report on "Ecosystems and Human Well-being: General Synthesis". The development of MIMES involved many individuals from universities, government, NGOs, and software development (namely Simulistics and STELLA) and is supported by the Gund Institute for Ecological Economics and the University of Vermont.

MIMES is an interactive and dynamic interface developed for the spatial representation of various models describing an ecosystem or ecosystems. These models specifically address environmental resources and are geared towards ecosystem services. The premise is to represent an ecosystem via the true value of services provided for human welfare, and how various management scenarios might alter these services' function and value. By focusing on ecosystems in terms of services, MIMES aims to make clear the value of these ecosystems to human well-being to decision makers, stakeholders, and scientists. It is theorized that these groups can then comprehend and compare the worth and interdependencies of complex systems more clearly to make better, more informed decisions about resource management and sustainability.

MIMES builds on the GUMBO model (Boumans et al., 2002; Costanza et al., 2006), and can be described as a suite of models, but these are determined and modified by the users themselves based on available information and knowledge. MIMES is therefore the interface which brings together information and connects various ecosystem aspects via models and data. Further, it is aimed at encouraging collaboration and the participation of many individuals and decision-makers. To achieve this end, it was designed to be very transparent and easy to use and modify. It is also an open model accessible via the web that can potentially be altered by any one, although permission to become a user must be granted on an individual basis.

Initially, MIMES focused on understanding and quantifying the effects of land use change and resulting variation in environmental conditions, through the lens of ecosystem services. It is currently organized 
into five interrelated spheres: Atmosphere, Lithosphere, Hydrosphere, Biosphere and Anthrosphere. MIMES uses input data to describe relationships between spheres and to demonstrate how changes in human use can affect natural, human and built capital. At this time, the MIMES model is a general structure, designed to be flexible to accommodate various data and scales, from global to local systems. It can be used as a spatially explicit model to represent multiple locations and the flow of species, environmental changes, water, air, and human movement and influence (Boumans and Costanza, 2007). The general representation is similar to a concept map - objects are connected by flows describing the elements and relationships of a system. These objects and flows are defined by the mathematical submodels and data available. Although currently MIMES is predominantly focused on terrestrial systems, one case study under way addresses Pacific salmon and the online technical documents do provide initial data requirements for translation to marine systems.

MIMES appears to be a fairly intuitive and straightforward way to represent systems, models, and data visually. Initial development of MIMES requires an "interaction matrix" to link inputs and outputs among the models involved (Boumans and Costanza, 2007). It is a dynamic approach, allowing various modelers to interact and provide and ask for model output, input, and modification (Boumans and Costanza, 2007). Use of the system presumably follows a steep learning curve, but the interface is user-friendly and meant to promote use by many different people. It also provides case studies and encourages users to "play" with other models to learn the software and how to best apply it. Further, multiple users can access and modify it via the internet, making collaboration easy. However, while it does not seem particularly difficult to use, MIMES may require much data and time to understand and develop. The information needed to get it started could be extensive and time-consuming to find and include in the software, in addition to the need for translating it to address the GOM marine ecosystem. Finally, the spatial representation of such complex systems does result in complex visual maps of elements and flows. These could be confusing and difficult to explain to new users.

\section{SystMod}

"SystMod" is a dynamic multi-species system model for the Barents and Norwegian Seas region. It was first published by J. Hamre and E. Hatlebakk in 1998, and was developed in cooperation between the Institute of Marine Research (IMR) in Bergen, Norway, and Norsk Regnesentral (Norwegian Computing Center). It is temperature dependent and addresses the stock interactions and exploitation of three key species, Atlantic herring (Clupea harengus), capelin (Mallotus villosus), and Artic cod (Gadhum morhua). The focus on these three species is because interactions between them dominate the current system. There is a clear environmental influence, namely the inflow of Atlantic water, determining the distribution, recruitment, and growth of these species, hence the use of temperature in the model.

SystMod is length-based, and addresses changes in biomass and the influence of fishing pressure. Biomass over time is determined by growth, temperature, recruitment, and survival, in addition to predator-prey relationships between the three species, natural mortality, and fishing mortality. These various aspects are interrelated using a hierarchy of models from fishery science and those developed specifically for SystMod to describe specific species interactions. Parameterization is specific to the ecosystem and is based on ecological knowledge and model runs. The main goal of SystMod is to analyze the impact of various management strategies on biomass, but specifically including ecosystem interactions and the impact of environmental influences (in this case, temperature). Currently, the model does not include the economics of fishing or the interaction economics of all three fisheries simultaneously.

For this model, necessary data includes information on growth, length, age, predation, temperature, stock biomass, recruitment, consumption rates, and an understanding of basic ecosystem structure, including the impact of temperature, instances of cannibalism, and species interactions (namely predation and effects of other species on recruitment success and survival). The model itself is based on mathematical equations that are straightforward, yet the hierarchy and occasional complexity of their use may increase time for computation. It is not known if software has been designed to make this easier to use.

Current work being done by IMR and the Research Council of Norway is focusing on further evaluation of the original SystMod model, including increased ability to capture uncertainty, a dynamic description of 
environmental variation, and a description of assessment error, in addition to further parameterization, adapting it to accommodate historical catch and population data, and the inclusion of economic information.. The resulting model will be used to develop optimal yet simple quota strategies that explicitly take into account biology, economics, and uncertainty, but for a trophically simple system. Further goals include a model to determine if precautionary policies and management strategies are needed to avoid overexploitation of the species involved.

SystMod is by definition a model tied to a specific ecosystem. It can be adapted to other communities, but equations and parameters would need to be altered. In addition, obtaining the data that a predator-prey model like SystMod requires can be a very difficult enterprise, especially with a more complicated or less

understood ecosystem. SystMod is currently a tool for looking at water resources in Europe. It would need to be reworked to address marine systems. The main objective is important for fisheries management, however, as it works to include all stakeholders to address and environmental problem, address impacts, trade-offs, and make informed decisions. It is aimed at transparent management of resources at all levels of the process.

\section{Association between Models and Issues relevant to the State of MA and the Partnership}

It was noted above that it is important for the Partnership to articulate the issues that it hopes to address using the ecosystem models discussed in this review. A sense of these issues is presented elsewhere in this report. These are structured according to the dimensions of sustainable development environmental, economic, social and institutional, in this case management. Within the environmental dimension, issues are further considered according to biodiversity, productivity and habitat. The first two relate to the structure and function of an ecosystem while the third relates to the milieu in which the ecosystem lives.

It is useful to consider how the ecosystem models discussed in this report might inform or not the issues of interest to the Partnership. While it is not possible to be definitive, with many models being able to inform a number of different issues, it is possible to in general state which models would likely best inform which issues (Table 3).

Table 3. Relationship between Massachusetts Oceans Act issues and Ecosystem Models considered in this report. 


\begin{tabular}{|c|c|c|c|c|c|c|c|c|}
\hline \multirow{3}{*}{ Class of Issues } & \multicolumn{8}{|c|}{ Minimally Realistic Models } \\
\hline & \multicolumn{6}{|c|}{ Non Spatial } & \multicolumn{2}{|c|}{ Spatial } \\
\hline & ESAM & MRM & MSVPA & MSVPA-X & MS-PROD & MSM & GADGET & CCAMLR \\
\hline \multicolumn{9}{|l|}{ Community biodiversity } \\
\hline \multicolumn{9}{|l|}{ Species biodiversity } \\
\hline \multicolumn{9}{|l|}{ Population biodiversity } \\
\hline \multicolumn{9}{|l|}{ Base of Food Chain } \\
\hline \multicolumn{9}{|l|}{ Population Productivity } \\
\hline \multicolumn{9}{|l|}{ Food Chain Processes } \\
\hline \multicolumn{9}{|l|}{ Water Column } \\
\hline \multicolumn{9}{|l|}{ Bottom Habitat } \\
\hline \multicolumn{9}{|l|}{ Water Quality } \\
\hline \multicolumn{9}{|l|}{ Biota Quality } \\
\hline \multicolumn{9}{|l|}{ Economic } \\
\hline Social \& Cultural & & & & & & & & \\
\hline
\end{tabular}

Table 4 (continued). Relationship between Massachusetts Oceans Act issues and Ecosystem Models considered in this report.

\begin{tabular}{|c|c|c|c|c|c|c|c|c|c|c|c|}
\hline \multirow{3}{*}{ Class of Issues } & \multicolumn{11}{|c|}{ Whole Ecosystem Models } \\
\hline & \multicolumn{4}{|c|}{ Aggregate System Models } & \multicolumn{7}{|c|}{ Dynamic System Models } \\
\hline & EwE & SSEM & Agg-PROD & EMAX & ATLANTIS & ERSEM & SEAPODYM & OSMOSE & INVITRO & MIMES & SystMOD* \\
\hline \multicolumn{12}{|l|}{ Community biodiversity } \\
\hline \multicolumn{12}{|l|}{ Species biodiversity } \\
\hline \multicolumn{12}{|l|}{ Population biodiversity } \\
\hline \multicolumn{12}{|l|}{ Base of Food Chain } \\
\hline \multicolumn{12}{|l|}{ Population Productivity } \\
\hline \multicolumn{12}{|l|}{ Food Chain Processes } \\
\hline \multicolumn{12}{|l|}{ Water Column } \\
\hline \multicolumn{12}{|l|}{ Bottom Habitat } \\
\hline \multicolumn{12}{|l|}{ Water Quality } \\
\hline \multicolumn{12}{|l|}{ Biota Quality } \\
\hline \multicolumn{12}{|l|}{ Economic } \\
\hline Social \& Cultural & & & & & & & & & & & \\
\hline
\end{tabular}

As a class, MRMs are best at informing issues related to species biodiversity (e.g. fisheries bycatch) and population productivity. All in some manner have been used to inform management although for all model, both MRMs and WEMs, this has been limited. Of the MRMs, those of CCAMLR have considered more than just population productivity with incorporation of plankton productivity, food chain and water column processes. Likely the most flexible of the MRMs to address a number of issues is however GADGET.

Regarding WEMs, MIMES, ATLANTIS and INVITRO have the greatest potential to address a wide array of issues. MIMES and ATLANTIS have by far the greatest flexibility to consider biodiversity, productivity and habitat issues. Given that INVITRO is an IBM, it is more limited in its potential application to ecosystem-wide issues although it would be a valuable adjunct in exploring ecosystem processes that may be emergent from the dynamics of individual ecosystem components. OSMOSE and SEAPODYM have the capacity to address a relatively wide array of issues although one (OSMOSE) is an IBM and has the same limitations in this regard as INVITRO and the other (SEAPODYM) is highly configured towards high seas fisheries issues. In contrast, EwE, and EMAX, while limited in its capacity to inform habitat issues, has a great deal to offer in regards to biodiversity and productivity. The last two models, SSEM and ERSEM, will be of limited utility to the Partnership. 
While it is essential to understand which issues the ecosystem models are likely most suited to inform, it is important to consider other features of these models which will influence their utility in the Partnership initiative.

\section{Desirable Features of Models}

Ecosystem model will provide the State and Partnership with some of the tools required for ocean planning; there are additional features of the ecosystem in question that should be taken into consideration. These relate to both the model's capacity to describe the ecosystem in question as well as inform management decisions.

\section{Capacity to Describe Ecosystem}

- Linkage to existing initiatives in New England Area

- Undertaking the construction of ecosystem models is not for the novice and requires both an understanding of the ecosystem in question and as well as expertise on model development. Typically, ecosystem model development requires a team approach with different members bringing divergent and complementary skills to the table. It is thus advisable to build upon complementary modeling efforts in the New England area rather than starting from scratch

- Expandability

- Many ecosystem models were created to address a specific issue. While in principle they may be expandable to the issues being considered by the Partnership (any model would have this feature), the effort to do this in some models would be significant

- Flexibility in prey selection functions

- A key component of ecosystem models is describing energy flow between predators and prey. This is an active field of research with a number of relationships possible (e.g. ATLANTIS allows six). It is important for ecosystem models to allow exploration of the sensitivity of their outputs to predator - prey assumptions.

- Capacity to provide indicators of Ecosystem Health

- Ultimately, an ecosystem model should be able to provide a comprehensive suite of indicators that monitors the health of the ecosystem in question. While this might be possible through use of a number of models working in tandem, having one model that can perform this task has advantages

- Flexibility in Age/Size Structuring

- Many processes within ecosystems are related to the age and / or size of the ecosystem components in question. While modeling is considerably complicated in incorporating these processes, it does allow for consideration of a broader suite of issues than would otherwise be the case.

- Access to Program Code

- This relates to the model's capacity for expansion and modification. The software for some models, being specific to the case in hand, is not well documented. This would hinder efforts to apply it in other situations e.g. New England.

- Capacity to be Tailored to Desired Spatial and Temporal Resolution

- The incorporation of ecosystem processes over both time and space, while adding considerable complexity to model development, allows a much wider array of issues to be addressed than would otherwise be the case

- Capacity to Reflect Major Uncertainties

- Some models have been designed that do not allow exploration of the full scope of uncertainty that may be present in the knowledge of an ecosystem. It is important that an ecosystem model allow exploration of the consequences of these uncertainties on model outputs

Capacity to Inform Decisions

- Accessibility and Transparency to Managers and Stakeholders 
- Ultimately, an ecosystem model is going to be used to communicate with managers and stakeholders on the health of an ecosystem and its components and the need to mitigate human impacts. How accessible and transparent a model is to managers and stakeholders is a function of both its relation to simpler models that this community already is aware of and output products available from the model in question

- Use in Management Scenario Development

- If a model is to be used to assist in decisions on choices between mitigation options, then it must be configured to allow both development of these options and exploration of these to determine those most robust to achievement of desired objectives.

Table 5 provides a synopsis of how well the ecosystem models considered in this report rate against the above desired features. It is based upon the judgment of the authors and is open to interpretation. Notwithstanding this, it provides a general guide to the broader utility of these ecosystem models to the Partnership initiative.

Table 5. Desirable Features of Ecosystem Models considered in this report.

\begin{tabular}{|c|c|c|c|c|c|c|c|c|}
\hline \multirow{3}{*}{ Features of Ecosystem Model } & \multicolumn{8}{|c|}{ Minimally Realistic Models } \\
\hline & \multicolumn{6}{|c|}{ Non Spatial } & \multicolumn{2}{|c|}{ Spatial } \\
\hline & ESAM & MRM & MSVPA & MSVPA-X & MS-PROD & MSM & GADGET & CCAMLR \\
\hline \multicolumn{9}{|c|}{ Capacity to Describe Ecosystem } \\
\hline \multicolumn{9}{|l|}{$\begin{array}{l}\text { Linkage to existing initiatives in New } \\
\text { England Area }\end{array}$} \\
\hline \multicolumn{9}{|l|}{ Expandibility } \\
\hline \multicolumn{9}{|l|}{ Flexibility in prey selection functions } \\
\hline \multicolumn{9}{|l|}{$\begin{array}{l}\text { Capacity to provide indicators of } \\
\text { ecosystem health }\end{array}$} \\
\hline \multicolumn{9}{|l|}{ Flexibility in age/size structuring } \\
\hline \multicolumn{9}{|l|}{ Accessibility of program code } \\
\hline \multicolumn{9}{|l|}{$\begin{array}{l}\text { Capacity to be tailored to desired } \\
\text { spatial \& temporal resolution }\end{array}$} \\
\hline \multicolumn{9}{|l|}{$\begin{array}{l}\text { Capacity to reflect major } \\
\text { uncertainities }\end{array}$} \\
\hline \multicolumn{9}{|c|}{ Capacity to Inform Decisions } \\
\hline \multicolumn{9}{|l|}{$\begin{array}{l}\text { Accessibility \& transparency to } \\
\text { managers \& stakeholders }\end{array}$} \\
\hline $\begin{array}{l}\text { Use in management scenario } \\
\text { development }\end{array}$ & & & & & & & & \\
\hline
\end{tabular}


Table 4 (continued). Desirable Features of Ecosystem Models considered in this report.

\begin{tabular}{|c|c|c|c|c|c|c|c|c|c|c|c|}
\hline \multirow{3}{*}{ Features of Ecosystem Model } & \multicolumn{11}{|c|}{ Whole Ecosystem Models } \\
\hline & \multicolumn{4}{|c|}{ Aggregate System Models } & \multicolumn{7}{|c|}{ Dynamic System Models } \\
\hline & EwE & SSEM & Agg-PROD & EMAX & ATLANTIS & ERSEM & SEAPODYM & OSMOSE & INVITRO & MIMES & SystMOD \\
\hline \multicolumn{12}{|c|}{ Capacity to Describe Ecosystem } \\
\hline \multicolumn{12}{|l|}{$\begin{array}{l}\text { Linkage to existing initiatives in New } \\
\text { England Area }\end{array}$} \\
\hline \multicolumn{12}{|l|}{ Expandibility } \\
\hline \multicolumn{12}{|l|}{ Flexibility in prey selection functions } \\
\hline \multicolumn{12}{|l|}{$\begin{array}{l}\text { Capacity to provide indicators of } \\
\text { ecosystem health }\end{array}$} \\
\hline \multicolumn{12}{|l|}{ Flexibility in age/size structuring } \\
\hline \multicolumn{12}{|l|}{ Accessibility of program code } \\
\hline \multicolumn{12}{|l|}{$\begin{array}{l}\text { Capacity to be tailored to desired } \\
\text { spatial \& temporal resolution }\end{array}$} \\
\hline \multicolumn{12}{|l|}{$\begin{array}{l}\text { Capacity to reflect major } \\
\text { uncertainities }\end{array}$} \\
\hline \multicolumn{12}{|c|}{ Capacity to Inform Decisions } \\
\hline $\begin{array}{l}\text { Accessibility \& transparency to } \\
\text { managers \& stakeholders }\end{array}$ & & & & & & & & & & & \\
\hline $\begin{array}{l}\text { Use in management scenario } \\
\text { development }\end{array}$ & & & & & & & & & & & \\
\hline
\end{tabular}

In relation to the MRMs, both MSVPA (specifically MSVPA $-X$ ) and GADGET have a number of the desirable features. Specifically, MSVPA-X has already been used in the New England area while GADGET has a large user base in the Northeast Atlantic. GADGET appears to be relatively more expandable than MSVPA-X and allows a broader range of prey selection functions. Both incorporate age processes and have relatively accessible code. GADGET has the feature of allowing incorporation of spatial processes. Both allow exploration of uncertainties relating to the ecosystem components being modeled. Being that both are extensions of single - species modeling approaches (e.g. VPA), both should be accessible to managers and stakeholders. Finally, both allow management scenario development.

In relation to the WEMs, EwE, MIMES and ATLANTIS have most of the desired features of an ecosystem model. EwE has a large user base worldwide and a number of projects are already underway in the New England area. For instance, the recent EMAX exercise undertaken in GARM III involved ECOPATH. EwE is relatively expandable and its flexibility has in fact been noted as almost being too much so. EwE6 is certainly is well documented and relatively user - friendly package. While EwE itself does not allow the examination of spatial processes, the related ECOSPACE model does. Considerable effort has been made in the development of EwE to make it accessible and transparent to the oceans community as well as useful to decision making. Indeed this is one of the reasons why EwE6 was developed.

ATLANTIS is by far the most complex model being considered in this review. An ATLANTIS project is presently underway by NMFS in Woods Hole. ATLANTIS is expandable, incorporates age/size processes, can be tailored to different spatial and temporal scales and was designed to allow examination of uncertainties. It was explicitly configured for use in management scenario development which also implies that outputs have been developed to be understandable to managers and stakeholders. On the downside, while the software is accessible, this is definitely only for experts knowledgeable in the field of ecosystem modeling.

The MIMES approach can build upon both EwE and ATLANTIS efforts and has some additional features that may address the needs of ocean planning. MIMES is potentially simpler and more transparent than ATLANTIS but can still simulated a very wide range of ecosystem components. In addition MIMES explicitly has an economic component and allows exploration of management scenarios. Since it is based on the concept of ecosystem services, MIMES is directly applicable to an ecosystem based approach to management. 
This review of a range of potential ecosystem models that are available to the Partnership. Plaganyi (2007) emphasizes that it is important not to rely on any one modeling approach and to gradually build understanding of the ecosystem in question. Thus the process of model development should be seen as important, if not more so, that the final product.

\section{Model Development Process}

The first steps in developing a modeling approach are the same as those in the multi-step EAM process mentioned at the beginning of this report. These include the definition of the boundaries of the ecosystem in question, identification of the issues to address, articulation of the conceptual objectives, threats analysis and Ecological Risk Analysis. All these steps are scoping the scale of the modeling exercise. They could be informed by development of a conceptual model of the ecosystem in question, which could be a relatively straightforward box - style representation of the key ecosystem components and their interactions. This description is analogous to that being developed through the NMFS Ecosystem Overview Report exercise.

Having defined which issues need to be addressed, then the Partnership can then consider which specific modeling approaches to support. In the near term, it appears the immediate needs of planning can best be served by employing some of the decision support tools described in Appendix B while coordinating with the groups developing ecosystem models that can be used to evaluate management options through time. Given ongoing development work on the comprehensive MIMES, Atlantis models already under development in New England; it would be prudent for the Partnership to consider how it could dovetail efforts in the coastal area with those underway offshore. As EwE and Emax can be developed over a shorter time period, it would be useful to undertake an EwE modeling exercise to both inform the larger initiative as well as provide interim products at an ecosystem scale to the oceans community. While these activities are underway, it would be prudent for the Partnership to pursue development of MRMs to address specific issues such as fisheries using approaches such as MSVPA-X or GADGET 


\section{References}

Andersen, K., and E. Ursin. 1977. A multispecies extension to the Beverton and Holt theory of fishing, with accounts of phosphorus circulation and primary production. Meddelelser fra Danmarks Fiskeriog Havundersogelser. 7: $319-435$.

Baretta-Bekker, J.C., and J.W. Baretta (eds). 1997. Special Issue: European Regional Seas Ecosystem Model II. J. Sea Research. 38: 169-436.

Begley, J., and D. Howell. 2004. An overview of GADGET, the Globally Applicable Area- Disaggregated General Ecosystem Toolbox. ICES CM 2004/FF:13: 15 pp.

Bogstad, B., K.H. Hauge, and O. Ulltang, O. 1997. MULTSPEC: a multi-species model for fish and marine mammals in the Barents Sea. J. N. Atl. Fish. Sci., 22: 317-341.

Boumans, R.M.J., R. Costanza, J. Farley, M.A. Wilson, J. Rotmans, F. Villa, R. Portela, and M. Grasso. 2002. Modeling the dynamics of the integrated earth system and the value of global ecosystem services using the GUMBO model. Special issue: the dynamics and value of ecosystem services: integrating economic and ecological perspectives. Ecological Economics, 41(3): 529-560.

Boumans, R., and R. Costanza. 2007. The Multiscale Integrated Earth Systems Model (MIMES): The dynamics, modeling and valuation of ecosystem services. In: Van Bers, C.; Petry, D.; Pahl-Wostl, C. eds. Global Assessments: Bridging Scales and Linking to Policy. Report on the joint TIASGWSP workshop held at the University of Maryland University College, Adelphi, USA, 10 and 11 May 2007. Available online at: http://www.gwsp.org/products.html (accessed 10 November 2008).

Bundy, A., G. Chouinard, D. Duplisea, G. Jamieson, M. Koen-Alonso, M. Koops, J. Rice, and L. Richards. 2008. National Workshop on Modelling Tools for Ecosystem Approaches to Management. Canadian Science Advisory Secretariat. Proceedings Series 2008/007.

Chouinard, G.A., D.P. Swain, M.O. Hammill, and G.A. Poirier. 2005. Co-variation between grey seal (Halichoerus grypus) abundance and natural mortality of cod (Gadus morhua) in the southern Gulf of St. Lawrence. Can. J. Fish. Aquat. Sci., 62: 1991-2000.

Christensen, V., and D. Pauly. 1992. ECOPATH II: a software for balancing steady-state models and calculating network characteristics. Ecol. Model. 61: $169-185$.

Christensen, V., and D. Pauly. 1992. On steady-state modeling of ecosystems. In: Trophic models of aquatic ecosystems. V. Christensen and D. Pauly (eds.). ICLARM, Manilla. ICLARM Conf. Proc., 26: 14-19.

Collie J.S., and A.K. DeLong. 1999. Multispecies interactions in the Georges Bank fish community. Ecosystem Approaches for Fisheries Management pp. 187-210 Alaska Sea Grant College Program, AK-SG-99-01.

Constable, A.J. 2005. Implementing plausible ecosystem models for the Southern Ocean: an ecosystem, productivity, ocean, climate (EPOC) model. Workshop document presented to WG-EMM subgroup of CCAMLR (Commission for the Conservation of Antarctic Marine Living Resources), WG-EMM-05/33. (20 pp).

Costanza, R., R. Leemans, R.M.J. Boumans, and E. Gaddis. 2006. Integrated global models. In Sustainability or collapse? An integrated history and future of people on earth, ed. R. Constanza, L.J. Graumlich \& W. Steffen. Cambridge, USA, MIT Press. 517 pp.

DFO. 2008. National Workshop on Modelling Tools for Ecosystem Approaches to Management; 22-25 October 2007. DFO Can. Sci. Advis. Sec. Proceed. Ser. 2008/007.

Feás, J., C. Giupponi, and P. Rosato. 2004. "Water Management, Public Participation and Decision Support Systems: the MULINO Approach." Proceedings of the iEMS 2004 Conference: Complexity and Integrated Resource Management (University of Osnabruck, Germany) Online at: http://www.iemss.org/iemss2004/sessions/../pdf/ dss2/ jacowate.pdf (30 October 2008).

Fulton, E.A. 2001. The Effects of Model Structure and Complexity on the Behaviour and Performance of Marine Ecosystem Models. Ph.D. thesis, School of Zoology, University of Tasmania, Hobart. 429 pp.

Fulton, E.A., A.D.M. Smith, and A.E. Punt. 2004. Ecological indicators of the ecosystem effects of fishing: Final Report. Report No. R99/1546, Australian Fisheries Management Authority, Canberra. 
Garrison, L., and J. Link. 2004. An expanded multispecies virtual population analysis approach (MSVPA$X)$ to evaluate predator-prey interactions in exploited fish ecosystems. Version 1.1, Users Manual and Model Description. Atlantic States Marine Fisheries Commission. April 17, 2004. 90 pp.

Gislason, H., and T. Helgason. 1985. Species Interaction in assessment of fish stocks with special application to the North Sea. Dana. 4: $1-44$.

Gray, R., E.A. Fulton, L.R. Little, and R. Scott. 2006. Ecosystem Model Specification Within an Agent Based Framework. North West Shelf Joint Environmental Management Study Technical Report Vol 16

Gulland, J.A. 1965. Estimation of mortality rates Annex to Rep. Arc. Fish. Working Group. Int. Counc. Expolr. Sea C. M. 1965 (3), 9.

Hamre, J., and E. Hatlebakk. 1998. "System model (SystMod) for the Norwegian Sea and the Barents Sea." In: T. Rodseth ed. Models for Multispecies management. Physica-Verlag, Heidelberg, New York. Pp 93- 115.

Hamre, J. 2003. Capelin and herring as key species for the yield of north-east Arctic cod. Results from multispecies runs. Scientia Marina 67 (Suppl. 1): 315-323.

Helstad, K. 2000. Management of herring, capelin and cod in the Greater Barents Sea - economic optimal management from a Norwegian point of view." IIFET 200 Proceedings. Oregon State University. Online: http://oregonstate.edu/dept/IIFET/ 2000/papers/helstad.pdf. (28 October, 2008).

Hollowed, A.B., J.N. lanelli, and P.A. Livingston. 2000. Including predation mortality in stock assessments: a case study for Gulf of Alaska walleye Pollock. ICES J. Mar. Sci. 57: 279-293.

Hollowed, A.B., N. Bax, R. Beamish, J. Collie, M. Fogarty, P. Livingston, J. Pope, and J.C. Rice. 2000. Are multi-species models an improvement on single - species models for measuring fishing impacts on marine ecosystems? ICES J. Marine Science. 57: 707 - 719.

Horbowy, J. 2005. The dynamics of Baltic fish stocks based on a multi-species stock production model. J. Appl. Ichthyology, 21: 198-204.

Jurado-Molina, J., P.A. Livingston, and J.N. Ianelli. 2005. Incorporating predation interactions to a statistical catch-at-age model for a predator-prey system in the eastern Bering Sea. Can. J. Fish. Aquat. Sci., 62(8): 1865-1873.

Lehedey, P., E. Chai, and J. Hampton. 2003. Modeling climate-related variability of tuna populations from a coupled ocean-biogeochemical-populations dynamics model. Fisheries Oceanography. 12: 483 $-494$.

Link, J.S. 2003. A Model of Aggregate Biomass Tradeoffs. ICES Annual Science Conference. Theme Session on Reference Point Approaches to Management within the Precautionary Approach. ICES CM 2003/Y08 28 pp.

Link, J.S., C.A. Griswold, E.M. Methratta, and J. Gunnard (eds). 2006. Documentation for the Energy Modeling and Analysis eXercise (EMAX). Northeast Fisheries Science Center Reference Document, 06-15, 166 p. http://www.nefsc.noaa.gov/nefsc/publications/crd/crd0615/crd0615.pdf

Livingston, P.A., and R.D. Methot. 1998. Incorporation of predation into a population assessment model of eastern Bering Sea walleye pollock. Fishery Stock Assessment Models, Alaska Sea Grant College Program, AK-SG-98-01.

Moustahfid H., W. Overholtz, J.S. Link, and M.C. Tyrrell. 2008. The advantage of incorporating explicitly predation mortality in age stock assessment: an application for Northwest Atlantic Mackerel (Scomber scombrus). (In review, ICES J. Mar. Sci.).

Mueter, F.J., and B.A. Megrey. 2006. Using multi-species surplus production models to estimate ecosystem-level maximum sustainable yields. Fish. Res. 81:189-201.

Multiscale Integrated Models of Ecosystem Services (MIMES). Online at: http://www.uvm.edu/giee/mimes/ (accessed 10 November 2008).

Mysiak, K., C. Guipponi,and A. Fassio. 2002. Decision support for water resource management: An application example of the MULINO DSS. In: A. R. Rizzoli and A. J. Jakeman eds. (2002) Integrated Assessment and Decision Support. Proceedings of the 1st Biennial Meeting of the iEMSs. Online at: http://www.iemss.org/iemss2002/ proceedings/pdf/volume\%20uno/16_mysiak.pdf (30 October 2008).

Northeast Fisheries Science Center. 2006. Report of the 42th Northeast Regional Stock Assessment Workshop. Stock Assessment Review Committee (SARC) consensus summary of assessments. B. Atlantic mackerel. Northeast Fish. Sci. Cent. Ref. 
Northeast Fisheries Science Center. 2008. Assessment of 19 Northeast Groundfish Stocks through 2007: Report of the 3rd Groundfish Assessment Review Meeting (GARM III), Northeast Fisheries Science Center, Woods Hole, Massachusetts, August 4-8, 2008. US Dep Commer, NOAA FIsheries, Northeast Fish Sci Cent Ref Doc. 08-15; 884 p + xvii. http://www.nefsc.noaa.gov/nefsc/publications/crd/crd0815/

NMFS. 2006. Stock Assessment Report. Part B: Expanded Multispecies Virtual Population Analysis (MSVPA - X) Stock Assessment Model. 42nd Northeast Regional Stock Assessment Workshop. 308pp.

O'Boyle, R., M. Sinclair, P. Keizer, K. Lee, D. Ricard, and P. Yeats, P. 2004. An integrated management framework for the eastern Scotian Shelf. DFO Canadian Science Advisory Secretariat Research Document Series, 2004/076.

O'Boyle, R., M. Sinclair, P. Keizer, K. Lee, D. Ricard, and P. Yeats. 2005. Indicators for ecosystem-based management on the Scotian Shelf: bridging the gap between theory and practice. ICES Journal of Marine Science. 62: $598-605$.

O'Boyle, R., and G. Jamieson. 2006. Observations on the implementation of ecosystem-based management: Experiences on Canada's east and west coasts. Fisheries Research. 79: 1 - 12

Overholtz, W.J., L.D. Jacobson, and J.S. Link. 2008. An ecosystem approach for assessment advice and biological reference points for the Gulf of Maine -Georges Bank herring complex. N. Amer. J. Fish. Manage.28:247-257, 2008.

Plagányi, É.E. 2007. Models for an Ecosystem Approach to Fisheries. FAO Fisheries Technical Paper No. 477. Rome, FAO. 2007. 108p. http://www.fao.org/docrep/010/a1149e/a1149e00.htm

Plagányi, É.E., and Butterworth, D.S. 2006. A spatial multi-species operating model (SMOM) of krillpredator interactions in small-scale management units in the Scotia Sea. Workshop document presented to WG-EMM subgroup of CCAMLR, WG-EMM- 06/12. $28 \mathrm{pp}$.

Punt, A.E., and D.S. Butterworth. 1995. The effects of future consumption by the Cape fur seal on catches and catch rates of the Cape hakes. 4. Modelling the biological interaction between Cape fur seals (Arctocephales pusillus pusillus) and Cape hakes (Merluccius capensis and M. paradoxus). South African Journal of Marine Fisheries. 16: $255-285$.

Rosenberg, A., M. L. Mooney-Seus, I. Kiessling, C.B. Morgensen, R. O'Boyle, and J.Peacey. 2007. Lessons from National-Level Implementation in North America and Beyond in. McLeod, K. and $\mathrm{H}$. Leslie [Eds.]. Managing for resilience: New directions for marine ecosystem - based management. Island Press. US (submitted).

Schaefer, M.B. 1954. Some aspects of the dynamics of populations important to the management of commercial marine fisheries. Bull. Inter-Am. Trop. Tuna Comm. 1:27-56.

Sekine, M., H. Nakanishi, and M. Ukita. 1991. A shallow - sea ecological model using an object-oriented programming language. Ecol. Model. 57: 221 -236.

Shertzer, K.W., M.H. Prager, D.S. Vaughan, and E.H. Williams. 2008. “Fishery Models." In: S. E. Jorgensen and B. D. Fath eds. Encyclopedia of Ecology: Vol. 2, Population Dynamics. Oxford: Elsevier: 1582-1593.

Shin Y.-J., and P. Cury. 2001. Exploring fish community dynamics through size dependent trophic interactions using a spatialized individual-based model. Aquatic Living Resources, 14(2): 65-80.

Sinclair, A.F., and Crawford, W.R. 2005. Incorporating an environmental stock-recruitment relationship in the assessment of Pacific cod (Gadus macrocephalus). Fish. Ocean. 41: 138-150.

Smith, A.D.M., K.J. Sainsbury, and R.A. Stevens. 1999. Implementing effective fisheries management systems: management strategy evaluation and the Australian partnership approach. ICES J. Mar. Sci., 56: 967-979.

Sparre, P. 1991. Introduction to multispecies virtual population analysis. ICES mar. Sci. Symp. 193:12-21.

Stefansson, G., and O.K. Palsson. 1998. The framework for multi-species modelling of Arcto-boreal systems. Rev. Fish Biol. Fish., 8: 101-104.

Sullivan, K.J., N. Daan, and M.P. Sissenwine. 1991. The estimation of parameters of the multispecies production model. Multispecies models relevant to management of living resources pp. 185-193 ICES Marine Science Symposium, 193.

Tjelmeland, S., and U. Lindstrom. 2005. An ecosystem element added to the assessment of Norwegian spring spawning herring; implementing predation by minke whales. ICES Journal of Marine Science. 62: $285-294$. 
Townsend, H.M., J.S. Link, K.E. Osgood, T. Gedamke, G.M. Watters, J.J. Polvina, P.S. Levin, N. Cyr, and K. Y. Aydin. 2008. Report of the National Ecosystem Modeling Workshop (NEMoW). NOAA Technical Memorandum NMFS - F / SPO - 87. 93 pp.

Tyrrell M.C., J.S. Link, and H. Moustahfid. 2008. Evaluating the effect of predation mortality on forage species population dynamics in the Northeast US continental shelf ecosystem using multispecies virtual population analysis.(accepted, ICES Journal).

Ulanowicz, R.E. 2004. Quantitative methods for ecological network analysis. Comput. Biol. Chem., 28: 321-339.

Walters, C., and S.J.D. Martell. 2004. Fisheries ecology and management. Princeton University Press, Princeton. $399 \mathrm{pp}$.

Walters, C., V. Christensen, and D. Pauly. 1997. Structuring dynamic models of exploited ecosystems from trophic mass-balance assessments. Rev. Fish. Biol. Fish. 7: 139-172.

Walters, C.J., D. Pauly, and V. Christensen. 1999. ECOSPACE: predictions of mesoscale spatial patterns in trophic relationships of exploited ecosystems, with emphasis on the impacts of marine protected areas. Ecosystems. 2: $539-554$.

Watters, G.M., J.T. Hinke, K. Reid, and S. Hill,. 2005. A krill-predator-fishery model for evaluating candidate management procedures. CCAMLR WG-EMM-05/13.

Yodzis, P. 1998. Local trophodynamics and the interactions of marine mammals and fisheries in the Benguela ecosystem. J. Animal Ecology. 67: $635-515$.

Yodzis, P. 2000. Diffuse effects in food webs. Ecology. 81: $261-266$. 


\section{Appendix B: Decision Support Tools}

Decision support tools are just that: tools that support people in the process of making choices. They cannot substitute for the deliberative, analytical, human task of choosing option "A" over option "B" and grappling with the trade-offs-and objections-that may entail. Moreover, the tools applied to a decision will be only as effective as the overarching decision framework of goals, objectives, issue spotting, collection of information, process rules, integration of conflict resolution mechanisms, and measurable outcomes that can be evaluated.

The challenge facing planners of marine management areas is the evaluation and ultimate choice among alternative ocean zones or management structures during the planning process, and providing a transparent rationale for that choice. Different management measures will have varying benefits for the marine environment and different consequences for managers and user groups. There are a number of issues, some process-based and some technical, that make this evaluation process inherently difficult and uncertain, and decidedly political. Models, systems and approaches for assessing risk and ranking priorities make it possible to outline steps in a generic procedure for alternatives analysis and decisionmaking, but there is no single procedure or algorithm suitable for all circumstances, and no system will ever substitute for the tough job of analyzing, deliberating, and choosing.

This appendix includes information on decision tools from the literature, practitioners, and lessons learned projects. Examples of decision processes and how they might apply in Massachusetts follow, and several specific decision tools are discussed briefly.

\section{Decision-making theory and practice in the ecosystem context}

Different management approaches are better suited to achieve different categories of objectives. While objectives are not completely independent (for example, some minimal level of biodiversity is required to support recreation and tourism while some loss of habitat may be required to support dredging for shipping safety), there is no common or single a priori set of objectives that can be identified based on scientific or technical factors. Instead, decisions about which objective, or combination of objectives, to focus on in any particular circumstance is a policy choice to be made by the involved stakeholders. Such choices are most frequently values-based and reflect the inherent social, economic, political, and cultural concerns and perspectives of stakeholder communities.

There are a number of approaches available for identifying potential objectives, eliciting the underlying values affecting stakeholder preferences, and developing agreement on a set of common objectives in a given situation. They range from more subjective visioning exercises to more structured scenario planning and gaming processes. In particular, multi-attribute analysis is a widely used tool for eliciting values and the hierarchy of preferences that stem from them. The ultimate choice of objectives should be influenced by the relative degree of risk and uncertainty associated with each.

Layered on the overriding influence of area-specific preferences is a second source of complexity that stems from our limited ability to quantitatively predict the outcomes of specific management proposals. This uncertainty reflects substantial knowledge gaps about the distribution of marine habitats and populations, the life histories and population biology of key species, and the timing and influence of shifts in the marine environment on a wide range of space and time scales. These make the use of quantitative planning and decision tools such as cost-benefit analysis a challenge.

These efforts have in common a basic, iterative, two-step structure. The first step involves projecting expected outcomes in as much detail as possible, along with realistic estimates of their associated uncertainty. The second step entails assessing the projected outcomes, and the time scales over which they are expected to occur, against the stakeholders' hierarchy of objectives. Depending on the level of information available and the maturity of the planning process, such assessments can be either qualitative or as quantitative as possible. Decision analysis is a useful tool for structuring assessments, since it can utilize qualitative information and includes uncertainty as an integral part of the analysis. 
However, such efforts become rapidly more complex and difficult the greater the number of objectives involved.

In every report summarizing various approaches to ecosystem-based decision- making and alternatives analysis, the importance of clear objectives is paramount. There is nowhere that becomes more important than in the process of analyzing alternatives.

If possible, it is useful to illuminate how each of the options for management measures compares with the others, and how effectively they address the objectives of the plan. Following that comparison, a section describing the comparative economic effects of the proposed measure will assist decision makers in their analysis and choices. The important task for planners is not to make the choice, but highlight all the considerations for the decision maker who must eventually not only select the trade-offs but be able to explain why he or she made them.

The creation of a management plan for the waters of Massachusetts takes place within a statutory context. The Ocean Act clearly anticipates both a scientific and a public process. The statute creates an ocean advisory commission, an ocean science advisory council, and provides for significant public outreach and engagement. It also calls for coordination among various authorities and jurisdictions. The Ocean Act defers management measures and decision-making about land-based activity to the office of coastal zone management, and any decisions about fisheries to the division of marine fisheries. The underlying statutes for those authorities must be taken into account as well.

All of this guidance requires that managers have available decision tools that perform a variety of functions:

- Organizing and clarifying scientific information

- Predicting possible outcomes of various management options

- Displaying overlapping or integrated jurisdictional areas

- Integrating scientific, social, economic and political information

- Providing mechanisms to set priorities

- Structuring and displaying hierarchies of values

- Creating a framework to analyze and compare alternatives

- Providing a transparent rationale for choices

Decisions by Massachusetts state officials that affect the environment also must comply with the Massachusetts Environmental Policy Act (MEPA, Ch. 30, Sec. 61; 301 CMR 11.00), which calls for analysis of alternatives and comparison of potential consequences of proposed actions.

Alternatives analysis also is at the heart of the National Environmental Policy Act (NEPA (42 U.S.C. 4321 et seq.)). NEPA establishes environmental policy for the nation, provides an interdisciplinary framework for federal agencies to consider the environmental consequences of their actions, and contains actionforcing procedures to ensure that agency decision-makers take the environment into account. Although NEPA applies to federal actions and decisions, it offers a history of examples of alternatives analysis, cumulative impacts analysis, and current best practice on how presentation of alternatives must include sufficient detail to provide decision-makers a means to evaluate comparative merits.

\section{Lessons from other marine area management plans}

An assessment of the California MLPA process found that contentious points in the alternatives development process were resolving conflicting scientific approaches to marine life protection (ecological versus fishery management); acquisition and incorporation of sufficient information on socio-economic impacts, and providing for evaluation of potential "hot spots" or conflicts in specific areas and reflecting how specific management choices reflect that evaluation.

In an examination of six MPA designations in the U.S., Kessler (2003) and Bernstein and others (2004) report that decision-making can occur at several levels and be exercised using different management styles. Within the general decision rules and underlying purposes of the applicable statutes, the choices 
among alternatives were influenced variously by a combination of science and user group allocation politics; science and stakeholder consensus; science and enforcement considerations; local politics.

Choices among alternatives may purport to be based upon scientific principles or ecological objectives, but are at heart political decisions. One observer of such processes notes that decision-makers sometimes choose sets of goals and objectives post hoc to match desired economic and environmental outcomes, rather than matching alternatives with objectives that were defined at the front end (ludicello et al., 2005).

There are important economic, cultural, and institutional elements that influence management choices, how they will function, and, ultimately how successful they will be in achieving their objectives. A course to avoid is to have scientists and resource managers draw boundaries or propose managers before consideration of human activities and economic effects (Bernstein et al., 2004).

The reported ecological and economic benefits of ecosystem management notwithstanding, the planning and management of areas restricting some or all prior human uses becomes a progressively more political and economic activity (rather than a strictly scientific one) as planning proceeds, and as such requires an understanding of human behavior and institutions.

Another example where decision makers were able to analyze various options for spatial management was the designation of Essential Fish Habitat in the Gulf of Mexico. The identification of EFH, required by the Sustainable Fisheries Act, was accompanied by preparation of a Draft Environmental Impact Statement (GMFMC, 2003) that used a variety of matrix and systems tables to aid decision makers in understanding likely consequences of a variety of alternative actions. The choices the council had to make were identifying areas as essential fish habitat, identifying threats to essential fish habitat, and then choosing methods to reduce those threats. Each analysis had a set of steps that helped the decision maker set priorities and choose among alternatives based on biological, geographic and socio-economic information. Ecological risk assessment, Ecoregional assessments, the OCEAN framework, MARXAN, DPSIR, MULINO, multi-criteria decision-making, cumulative impact assessment, social impact assessment, QUEST, conservation assessment and prioritization system, and InVEST are discussed in detail below.

\section{References}

Bass, R.E., and A.I. Herson. 1993. Mastering NEPA: A step-by-step approach. Solano Press Books. Point Arena, California. 233 p.

Bernstein, B.B., S. ludicello, and C. Stringer. 2004. Lessons Learned from Recent Marine Protected Area Designations in the United States. A Report to: The National Marine Protected Areas Center NOAA. Available online at http://www.mpa.gov

Gulf of Mexico Fishery Management Council (GMFMC). 2003. Draft Environmental Impact Statement for the Generic Essential Fish Habitat Amendment to the following fishery management plans of the Gulf of Mexico (GOM): Shrimp Fishery of the Gulf of Mexico, Red Drum Fishery of the Gulf of Mexico, Reef Fish Fishery of the Gulf of Mexico Stone Crab Fishery of the Gulf of Mexico, Coral and Coral Reef Fishery of the Gulf of Mexico, Spiny Lobster Fishery of the Gulf of Mexico and South Atlantic, Coastal Migratory Pelagic Resources of the Gulf of Mexico and South Atlantic. Volume 1: Text. July 2003. 654 p. Available online at http://www.gulfcouncil.org

ludicello, S., B. Bernstein, I. Tetrault, M. Keene, and M. Shoemaker. 2005. Report to California MLPA Task Force summarizing literature reviews on approaches to design of marine protected areas and evaluation of MPAs and MPA networks.

Kessler B. 2003. An evaluation of marine protected area designation processes in the United States: Understanding the role of stakeholder involvement. [Masters Thesis]. Charleston (SC): College of Charleston.

National Marine Fisheries Service (NMFS). 2004. Programmatic Supplemental Environmental Impact Statement for the Alaska Groundfish Fisheries Implemented Under the Authority of the Fishery Management Plans for the Groundfish Fishery of the Gulf of Alaska and the Groundfish of the Bering Sea and Aleutian Islands Area June 2004. USDC National Oceanic and Atmospheric 
Administration, National Marine Fisheries Service, Alaska Region, Juneau, Alaska, and Seattle, Washington. Available online at: http://www.fakr.noaa.gov/sustainablefisheries/seis/intro.htm

\section{Ecological Risk Assessment}

Scientists at the Australian CSIRO have developed an ecological risk management (ERM) framework designed to assess and address the impacts that fisheries activities have on five aspects of the marine ecosystem, including: target species; bycatch; threatened, endangered and protected (TEP) species; habitats; and communities. The risk assessments, briefly described here, are the foundation of the ERM framework and are designed to assist with prioritizing research, data collection, monitoring and future management decisions. Their approach was designed to facilitate and ecosystem approach to management and identify gaps in information and allocation of resources. While the approach has been catered for impacts from fishing, the underlying process is a valuable exercise to evaluate ecosystem and community vulnerability to alternative impacts as well.

The Ecological Risk Assessment for the Effects of Fishing (ERAEF) framework begins with identification of the unit of analysis, whether species, habitat or community, potentially impacted by fishery activities. Assessors select the objectives of the assessment, which need to be clearly defined and requires stakeholder involvement; and subsequently, select relevant activities (hazards) that will build off of an expanded list and through stakeholder consultation involving expert and anecdotal evidence. The ERAEF framework, as with conventional risk assessments presents opportunities to maintain stakeholder engagement throughout the process; stakeholders possess expert judgment, fishery-specific and ecological knowledge and process and outcome ownership that will effectively inform the assessment.

The framework involves a hierarchal approach that proceeds from a comprehensive analysis of risk (Level 1) through a more focused semi-quantitative approach (Level 2) to a fully quantitative model-based approach (Level 3). Level 1 uses a scale, intensity, consequence analysis (SICA) method to scope out a detailed description of the fishery and serve as the first filter to screen out low risks efficiently, with the assessment proceeding to Level 2 only if the perceived risk is judged to be below a determined threshold. The SICA analysis evaluates the risk to ecological components resulting from the agreed set of activities. Evaluation of temporal and spatial scale, sub-component, unit of analysis can be undertaken in a workshop or by draft case study.

The level of analysis required to conduct a Level 1 assessment can be limited by taking a "worst case" approach in selection of the unit of analysis identified to be most vulnerable to each activity (with a maximum number of 160 scenarios, 32 activities by five components). In some cases this initial level of assessment is sufficient to identify risks and instigate risk management actions. This step also identifies information available to support assessment at the subsequent levels.

Level 2 assessments are based on a productivity-susceptibility approach (Stobutzki et al., 2001). All units not screened out at Level 1 are assessed through the Level 2 (Productivity-Susceptibility Analysis, PSA). The PSA approach is a method of assessing a unit of analysis based on a comprehensive screening of risk for a set of predetermined measurable attributes. The approach is based on the assumption that the risk to an ecological component will depend on two characteristics of the component units: (1) the productivity of the unit (ability of the unit to recover from impact; $\approx$ resilience); and (2) the susceptibility (exposure of the unit to impact; $\approx$ vulnerability. During the PSA assessment, each unit of analysis is scored for risk with regard to attributes productivity and susceptibility and the output graphed to produce a PSA plot that illustrates the relative vulnerability of the unit of analysis. The PSA analysis essentially measures the relative risk or the vulnerability of the resource to the potential for fishery impacts; this approach is especially useful as it allows for a baseline comparison between many species with varying levels of available information.

Level 3 assessments are fully quantitative assessments and are not traditionally part of an ERA. These assessments are typically target and non-target stock assessments, population viability analysis for TEP species and other community analysis models, such as EwE (described earlier in this report. 
The ERAEF approach is precautionary with its explicit and formal treatment of uncertainty. Level 1 analysis are based on a plausible worst case treatment of impact and Level 2 uses a default scoring that leads to high risk in the absence of information; this also provides an incentive to improve information collection. This framework would serve as a valuable tool in identification and prioritization of policy issues by recognizing impact activities and sensitive habitats and assigning levels of threat and vulnerability to those impacts and habitats. In the capacity an ecological risk assessment should be conducted once priority goals and objectives have been set to assist in the determination of priority activities and their impacts.

While this approach has been designed around fishery issues it can be developed for other activities as well. The framework is general and many of the tools for assessing risk are the same so it should not be considered a fishery specific approach.

\section{References}

Australian Fisheries Management Authority Wesbite, accessed November 5, 2008: http://www.afma.gov.au/environment/eco based/default.htm

Stobutzki, I.C., M.J. Miller, and D.T. Brewer. 2001. Sustainability of fishery bycatch: a process for assessing highly diverse and numerous bycatch. Environmental Conservation, 28: 167-181.

Smith, A.D.M., E.J. Fulton, A.J. Hobday, D.C. Smith, and P. Shoulder. 2007. Scientific tools to support the practical implementation of ecosystem-based fisheries management. ICES Journal of Marine Science, 64: 633-639.

Hobday, A.J., A. Smith, H. Webb, R. Daley, S. Wayte, C. Bulman, J. Dowdney, A. Williams, M. Sporcic, J. Dambacher, M. Fuller, and T. Walker. 2007. Ecological Risk Assessment for the Effects of Fishing: Methodology. Report R04/1072 for the Australian Fisheries Management Authority, Canberra.

\section{TNC Ecoregional Assessments}

The Nature Conservancy (TNC) has been working with the World Wildlife Fund (WWF) in recent years to assess biodiversity using ecoregions. Ecoregions (ecological regions) as defined by TNC are "large, relatively distinct, geographic areas that share similar climate, topography or ocean conditions, and assemblages of species and natural communities" (TNC, 2008b). TNC's Ecoregional Assessments (ERA) are useful in informing the types, places and priorities for actions, and focusing large-scale conservation planning. As part of each assessment, TNC evaluates various decision support tools that managers and decision makers might employ when managing natural resources. The TNC has 14 standards that they follow when performing ERAs (Higgins and Esselman, 2006), including (inter alia) assembling an assessment team, engaging stakeholders, developing work plans, goals and targets, gathering data and setting long term priorities.

TNC is confident that these ERAs will be complementary to ongoing efforts as they are displaying and organizing existing data in an EBM context. The assessments bring together data from numerous state and federal agencies in a centralized database and the assessments use innovative methods and product results that are both transparent and reproducible.

Currently, TNC is nearing the end of Phase 1 of a Northwest Atlantic Marine Ecoregional Assessment (ranging from the US-Canada border to North Carolina's Outer Banks) that could provide invaluable support to MOP and the State's development of an ocean management plan. Phase 1 includes engagement of stakeholders, gathering of data and design of a decision support and mapping database. A Phase 1 summary report will describe the methodology used and conditions and trends in all the marine habitats, target species and human uses included in the analysis. Phase 2, which will begin soon, will use the information and resources from Phase 1 to identify significant areas, species and ecological processes requiring conservation to protect biological diversity. A summary report will discuss prioritization, strategies and recommendations for conservation. The basic goals of the Northwest Atlantic Marine ERA are to:

- Provide a comprehensive set of data and decision support tools 
- Identify areas of especially high biological significance and regional marine conservation strategies

- Identify keystone species and/or species assemblages and develop alternative strategies to complement "place-based" approaches

- Offer a venue for research and development (adapted from TNC, 2008a)

The Norwest Atlantic Marine ERA will utilize data on marine ecosystems, habitats, species and human uses. Human use data may include locations of shoreline hardening, shipping lanes, port facilities, wind, hydrokinetic energy, oil and gas resources, fishing effort, power plants, dredge sites and toxic hotspots, among others. As habitats and boundaries change over time, advanced geospatial analysis will aid in mapping activities. TNC will also perform analyses of sea level rise and polluted runoff, inter alia, and examine the effects of human activity on identified items of concern, such as migratory patterns and spawning.

\section{References}

Higgins, J., and R. Esselman (eds.). 2006. Ecoregional Assessment Toolbox. The Nature Conservancy, Arlington, VA. Online: http://conservationgateway.org/era.

The Nature Conservancy. 2007. Northwest Atlantic Marine Ecoregional Assessment Fact Sheet. November 6, 2007.

The Nature Conservancy. 2008a. Northwest Atlantic Marine Ecoregional Assessment Core Team Charter.

The Nature Conservancy. 2008b. Northwest Atlantic Marine Ecoregional Assessment Frequently Asked Questions.

The Nature Conservancy and World Wildlife Fund. 2006. Standards for Ecoregional Assessments and Biodiversity Visions. January 26, 2006. The Nature Conservancy, Arlington, VA.

\section{The OCEAN Framework}

OCEAN, the Ocean Communities 3E Analysis (the three "Es" stand for economy, ecology and equity), is a suite of tools developed by Ecotrust. Ecotrust developed OCEAN out of a need for spatial analysis and interpretation of ecological and socioeconomic data. This need arose from a long-standing general disregard for multi-species and ecological linkages in traditional ocean and coastal management. Included in the OCEAN framework's suite of tools are GIS databases, analyses, and decision support systems allowing for integrated and systematic ecological and socioeconomic assessments of fishery policy and marine conservation and their effects on coastal communities.

Currently, Ecotrust has designed the OCEAN toolkit to aid in the designation of Marine Protected Areas (MPAs). In advancing this goal, the toolkit performs four main functions. The first is data collection. For this activity, OCEAN provides for portside interviews or a web-based interface which allows for extensive stakeholder consultation. OCEAN uses a program called Open OceanMap (an easy-to-use open source tool) which allows community stakeholders to place value on specific areas of the ocean (e.g., fishing grounds), and create a value-laden map of the area in question. This exercise supports decision making and also helps to minimize the socio-economic effect of MPAs on communities. The data collection step is invaluable, as it promotes interaction among stakeholders and creates transparency in the process. An online QA/QC companion tool to Open OceanMap is also included in the OCEAN toolkit. This tool allows stakeholders to individually verify the information they provided during the data collection process and provide comments. It is the hope of Ecotrust that OCEAN will be able to support other types of decision making and ocean zoning activities, such as placement of windmills or building of marinas.

The second function of the OCEAN toolkit is spatial design. The OCEAN program takes input and constraints from decision makers (derived from stakeholder consultation in the data collection phase) and runs a numerical analysis to produce various MPA scenarios. The third function of the toolkit is that of decision support. Stakeholder consultation is again very important in this phase. This is when they will have their opportunity to rank and express their opinions about the various MPA scenarios. The OCEAN program then uses a multi-criteria assessment (described above) to choose the best scenario, with 
minimal negative effect on communities. Finally, the OCEAN toolkit is used for monitoring. In relation to MPAs, OCEAN utilizes fish population data to illustrate benefits or drawbacks of the chosen MPA designation.

Numerous projects around the United States have utilized the OCEAN framework, mainly in regard to fisheries and MPA designation, but there is no reason why the tool could not be easily adapted to suit the needs of MOP and the State. One relevant example of a project using OCEAN is the California Marine Life Protection Act Initiative. The State of California is using the OCEAN framework to help in their design and implementation of a network of MPAs running along the entire coastline of California (over 1,000 miles). Another west coast project conducted by Ecotrust is the Joint Management Plan Review. The management plans for three National Marine Sanctuaries in California (Cordell Bank, Gulf of Farallones and Monterey Bay) are being reviewed and Ecotrust will collect, compile and analyze socioeconomic information pertaining to commercial and recreational fisheries using aspects of the OCEAN framework. Other projects are the Aleutian Islands Bering Sea Rockfish Bycatch Analysis, West Coast Groundfish Fleet Restructuring and Incentive-based Conservation of Marine Ecosystems in the Gulf of Mexico.

\section{References \\ Ecosystem-Based Management Tools Network Database. 2007. http://www.smartgrowthtools.org/ebmtools/index.php \\ Ecotrust. 2008. Gathering local knowledge, building transparency. http://www.ecotrust.org/ocean/ocean poster.pdf. \\ Ecotrust. 2007. OCEAN Website: http://www.ecotrust.org/ocean/}

\section{MARXAN}

MARXAN is conservation planning software developed by lan Ball and Hugh Possingham, University of Queensland. MARXAN is a stand alone decision support tool aimed to assist planners with site selection and has been used extensively in marine and coastal planning and used to support multiple-use zoning plans that balance the varied interests of stakeholders. MARXAN allows a user to define targets and incorporate a wide variety of spatial data on marine ecosystems, habitats and species, as well as threats to and human uses of them. The analysis identifies tradeoffs between conservation and socio-economic objectives. MARXAN uses a heuristic algorithm that has proved valuable in the designation of marine protected areas and for monitoring activities. MARXAN was developed as a modified version of SPEXAN to meet the needs of the Great Barrier Reef Marine Planning Authority (GBRMPA) in their rezoning plans; and is extensively used in marine and coastal planning applications worldwide, including in the US coast of the Gulf of Mexico, the Florida Keys, the Galapagos Islands, British Columbia, Canada, the Gulf of California, the marine park in the Great Barrier Reef, in the evaluation of reserve systems in southern Australia, and as a tool in the assessment and analysis of the protected areas system in Belize.

Through the use of MARXAN, conservation planners can identify an efficient system of conservation sites that include a suite of biodiversity targets at a minimal cost. The optimization algorithm in MARXAN attempts to find the most efficient solution to site selection using 'simulated annealing'. The model will then provide a "cost" for each solution and attempt to minimize this cost, while generating a near optimal solution. Users identify targets for a range of biodiversity features and input reasonably uniform data on those biodiversity features and divide the project area into "planning units". The designated size of the units is important and must match the scale of the data input. Small planning units yield detailed results but require a longer run time for the analysis, and small planning units may be irrelevant when relatively few data are available. In the absence of data for particular zones that may lie outside the planning area but are of importance (e.g. the exclusive economic zone), MARXAN has problems deciding where the optimum planning units are to be placed; additionally in marine zones data are not as clearly defined and easy to map as data for terrestrial ecosystems.

A valuable variable in the model analysis is the "boundary modifier". This determines the clumping of conservation targets, such that a tight clumping will result in fewer larger selected areas giving a reduced boundary effect and a loose clumping will result in more selected areas that are not necessarily linked. The MARXAN output will indentify multiple solutions for easy comparison by policy makers and 
stakeholders. The models approach allows users to define ecological and economic goals, with higher specificity yielding more usable results. The user identifies threats to those goals and MARXAN creates reserve scenarios and allows for comparison between those scenarios on the basis of economic cost and biodiversity benefit; this allows managers and stakeholders to assess the real "cost" of site designations. Different analysis options provide multiple ways to interpret results. One useful output provides summed irreplaceability of planning units (the "seeded" output); this shows how often each planning unit is in one of the good systems, and units that are selected more than $50 \%$ of the time can be thought as essential for efficiently meeting biodiversity goals. This analysis tries to place conservation features inside existing protected areas but will place them elsewhere if there are better options available, thus identifying the best placement of conservation features and those areas that are less critical for conservation. Alternatively, MARXAN can present a "best or locked" result that gives one optimum outcome of the analysis. The former option is more diffuse but allows planners openness with interpretation of results; while the latter serves as a surrogate gap analysis by identifying conservations features that could not be placed inside existing protected areas and those areas cannot be reassigned.

The basis for the MARXAN analysis is the conservation feature ("species" in the MARXAN terminology, though can be a species, feature or an ecosystem); and MARXAN includes or excludes planning units in a conservation network based on information about the distribution of conservation features across the designated planning region. Data representing conservation features must be uniform for the project area; only geo-referenced data of nationally researched features can be used; non-geo referenced data or data restricted to a geographical area are useless. This restricts the amount and type of data that can be used for the analysis. Additionally, MARXAN does not consider uncertainty in the data so the quality of data input is reflected in the results generated. Before initiating the use of MARXAN or any similar tool, the planners and other involved participants must have already considered which elements of reserve design are most critical to addressing priority issues for a given site. Caution must be applied, as with use of any model. Targets and desired outcomes must be clearly defined and correlated to the scale of data available for input.

The value of MARXAN are in its ability to run and compare hundreds of scenarios and allow comparisons for planners to evaluate suite of outcomes and spatial patterns to determine the most critical areas for conservation. In previous studies, stakeholders were able to review the input parameters and visualize the output. Therefore they have largely received the results are impartial and based on the best scientific information and outputs were viewed to truly address the defined criteria. This elucidates the costs and benefits of alternative decisions, leading to more informed decision making. With multiple solutions to choose from, a high level of stakeholder involvement can be maintained throughout the process, as is particularly pertinent to the development of the MA Ocean Plan.

\section{References}

Ball, I. R., and H. P. Possingham. 2000. MARXAN (V1.8.2): Marine Reserve Design Using Spatially Explicit Annealing, a Manual pdf (267KB)

Ecosystem Based Management Tools Network Website. Accessed October 2008. http://www.ebmtools.org/introduction-marxan.html

Global Marine Initiative: Advancing Ecosystem-Based Management Website. Accessed October 2008. http://www.marineebm.org/22.htm

Meerman, J., and R.J. Wilson. 2005 The Belize National Protected Areas System Plan. Taskforce on Belize's Protected Areas Policy and Systems Plan. November 2005. http://www.biologicaldiversity.info/Downloads/NPAPSP/NPAPSP 2005.pdf; http://biologicaldiversity.info/Downloads/NPAPSP/MARXANanalysis.pdf

NatureServe. 2004. Tools for Coastal-Marine Ecosystem-Based Management: A Survey and Evaluation Of Utility, Sustainability, and Opportunities for Further Development. Final Report by NatureServe for the David and Lucile Packard Foundation. Program Officer Scott Rehmus. September 15, 2004. 59 pp. www.natureserve.org/prodServices/ebm/pdf/NatureServe EBM Tools Survey.pdf

Pattison, D.D. dosReis, and H. Smillie. 2004. An Inventory of GIS-Based Decision-Support Tools for MPAs. Prepared by the National Marine Protected Areas Center in cooperation with the

National Oceanic and Atmospheric Administration Coastal Services Center. November 2004. www.mpa.gov/pdf/publications/FINAL Decision\%20Sup\%20Rpt.pdf 
Possingham, H.P., I.R. Ball, and S. Andelman.2000. Mathematical methods for identifying representative reserve networks. In: S. Ferson and M. Burgman (eds) Quantitative methods for conservation biology. Springer-Verlag, New York, pp. 291-305. pdf (223KB)

University of Queensland, MARXAN website. Accessed October 2008. http://www.uq.edu.au/marxan/

\section{DPSIR}

DPSIR is a common framework used to structure indicators of relationships within and between human and environmental systems. These indicators address interactions between people and their environment, and can simplify complex relationships for both decision-makers and other stakeholder groups tackling an environmental problem. The conceptual framework that results from a DPSIR approach can aid in identifying alternatives for solving the target problem. Decision making processes generally include 1) the identification of various alternative solutions to a problem, 2) the selection of evaluation criteria to address the solutions, 3) evaluation of alternatives based on the criteria, 4) selection of aggregation procedures for the evaluation results and determining relative importance of evaluation criteria for the final decision. In DSPIR, the public and additional stakeholder groups are integrally involved in this process, providing information and value judgment for various steps. Public participation may also increase the level of acceptance of final decisions.

DPSIR provides insights into the true complexity of EBM by relating large-scale human drivers of forces (e.g., increases in population density and land use patterns in coastal drainage basins) to pressures (e.g., extraction of living resources, nutrient loading and contaminant loading of coastal marine ecosystems), changes in state (harmful algal dynamics, eutrophication) of coastal ecosystems, their consequences or impacts (loss of commercial fishing value, public health costs), and management responses to them (e.g., fishery management, management of land-use activities, sewage treatment). Initially, decision makers must acquire and consolidate all existing information, which is then formalized into a DPSIR conceptual framework. The framework describes Driving Forces as directly impacting the behavior of the system and Pressures as expressing the rates of various processes. The State variables are outputs describing system change over time, as affected by the Forces and Pressures. Impacts are problems resulting from changes in the State variables, described in terms of economic value, environmental function, and social role.

The DPSIR framework is designed to ensure that management consider not only the state of environmental systems but the various sources of environmental change as well as the socio-economic costs of environmental degradation and social benefits that emerge from improvements in environmental conditions. Reasoned and effective management decisions need consider all these attributes in order to ensure success. In the context of coastal ecosystem functions, R. Kerry Turner and colleagues (Turner, et al., 2000) have argued that the DPSIR is useful for the scoping of biodiversity management issues and problems. It can make tractable the complexity of causes of habitat/species degradation or loss and the links to socio-economic activities, across the relevant spatial and temporal scales. It also provides the important conceptual connection between ecosystem change and the effects of that change (impacts) on people's economic and social well-being. Relevant indicators of environmental change can be derived and the loss of ecosystem function provision in terms of goods and services (direct and indirectly received) can be translated into human welfare loss and quantified in monetary and/or other more qualitative ways.

\section{References}

Bowen, Robert E., Jin-Seok Kim, and Jack Wiggin. 2008. Linking Socio-Economics and Coastal Environmental Change: Outcome Indicators to Assess Coastal Management Success (English).pp. 242-290. In J.-Y. Choi, H.J. Choi, J.D. Kim, J.H. Jeong, and C.O. Shin, Development of Coastal Indicators and Survey Guideline (in Korean). Seoul, Republic of Korea, Korea Maritime Institute, $348 \mathrm{ppg}$.

Turner, R.K., R. Brouwer, S. Georgiou, and I.J. Batement. 2000. Ecosystem Functions and Services: An Integrated Framework and Case Study for Environmental Evaluation. The Centre for Social and Economic Research on the Global Environment (CSERGE). ISSN 0967-8875. 


\section{MULINO}

The model discussed here directly addresses the decision making process regarding environment resources and was developed during the European project, MULINO. This project involved many stakeholder groups in water resource management (Feás et al. 2004), including the public. The project was launched in 2001 and completed in 2003, developing a tool for modeling the hydrological system affecting water resources in specific catchments, and a user interface that provided a step-by-step guide to evaluating various water use options. In general, the framework is to facilitate and structure productive discussion between decision-makers and stakeholder groups regarding environmental problems. The methodology combines a DPSIR (Driving Force - Pressure - State - Impact - Response) approach with multi-criteria analysis methods using a decision support system (DSS) called mDSS. This involves the combination of Integrated Assessment Modeling (IAM) and Multi-Criteria Analysis (MCA) methods for analysis and assessment within the DPSIR framework.

Developing Responses is the main goal of the MULINO model and should be related to the magnitude of the Impacts. Models describe these various aspects and different levels and in varying ways, varying from one-to-one flows to multi-sector integrated models. Possible Responses are determined via sets of indicator values derived from simulation runs that parameterize the various models to represent possible outcomes.

The model is currently designed as software to address water resource decisions in a specific locale (Feás et al., 2004). It is aimed at allowing end-user involvement in the early development of the system model, described via models and flows in the software, and the DPSIR conceptual framework. By involving many users in this process, the software designed to be used in group decision making. The software itself was designed to be user-friendly and to guide users through the process in a step-by-step fashion. It therefore not only provides for early involvement, but also improves awareness and understanding of process and relationships within the system and the overlying decision making method. Ultimately, all user groups and decision makers devise various possible Responses and make final decisions with similar understanding of the system as a whole.

The MULINO model is currently site-specific, but could be used in other areas and for other environmental problems. The underlying framework is useful for and flexible to accommodate various conflicts in resource management, including fisheries. As a user-friendly software that accommodates group decision making and the inclusion of various stakeholder groups, it would work well in developing policy for fisheries, especially using an ecosystem-based perspective. However, the model requires a wide variety of information and knowledge about a system and the human interactions involved. Converting it for use in other systems would appear to be very time- and labor- intensive. Once converted, it may also require a considerable commitment of time and effort among a variety of individuals and decision makers, despite its purported ease of use.

\section{References}

Feás, J., C. Giupponi, and P. Rosato (2004). "Water Management, Public Participation and Decision Support Systems: the MULINO Approach." Proceedings of the iEMS 2004 Conference: Complexity and Integrated Resource Management (University of Osnabruck, Germany) Online at: http://www.iemss.org/iemss2004/sessions/../pdf/ dss2/ jacowate.pdf (30 October 2008).

Mysiak, K., C. Guipponi, and A. Fassio. (2002). "Decision support for water resource management: An application example of the MULINO DSS." In: A. R. Rizzoli and A. J. Jakeman eds. (2002) Integrated Assessment and Decision Support. Proceedings of the $1^{\text {st }}$ Biennial Meeting of the iEMSs. Online at: http://www.iemss.org/iemss2002/

proceedings/pdf/volume\%20uno/16_mysiak.pdf (30 October 2008). 


\section{Decision Analysis and Multi-Criteria Decision Making}

Decision Analysis (DA) is the term given to a class of analytical tools historical emerging from both Game Theory and Operations Research. While specific DA-based techniques differ in important ways in how they address critical steps in overall DA process they are all effectively designed to follow the same multistep process and address the same general policy needs. In general, Decision Analysis was originally developed as a systematic approach to complex decision questions wherein (i) multistakeholders/decision makers are involved, (ii) the policy decision requires a common structured approach to assess competing policy choices, (iii) essential information is either unavailable or too challenging to develop using a common metric (e.g., monetary variables), (iv) professional judgment can be used to diminish the impact of highly uncertain data, and, ( $v$ ) the various attributes needed to make a decision are not of equal value in the overall decision calculus. Within the last several years two DAbased tools have been successfully used in environmental and resource management policy; notably Multi-Criteria Assessment and Analytic Hierarchy Process.

Multi-Criteria Assessment Models, or Multi-Criteria Decision Making methods (MCDM), are tools that assist decision makers in choosing a solution when multiple alternatives or courses of action are possible. It is a quantitative way to evaluate often complex problems containing both quantitative and qualitative data, and the solutions are transparent and easy to understand. These models can also assess the performance of alternatives against a defined standard.

Prior to undertaking MCDM, the decision maker must explicitly define the overall goal or objective of the problem at hand. In using these models, the decision maker chooses a set of criteria and rates the individual alternatives against them. The criteria must be weighted based upon importance, and are typically normalized so they add up to one. There is a degree of subjectivity when setting and weighting criteria, and the ethics of the decision maker may influence the accuracy and fairness of the results. For Massachusetts, the criteria setting and weighting step of the process should involve significant stakeholder involvement, to ensure that all viewpoints obtain fair consideration. The data required as input for these models depends wholly on the criteria defined for assessment. There are many different approaches to MCDM, and the type used depends on the problem and the users comfort level with the different approaches. One expert in MCDM (Karasakal, 2001) groups various approaches or techniques into three categories depending on when the decision maker inputs his or her preferences into the model (at the start of the solution process, iteratively throughout the process, or at the end of the process).

One of the most well-known types of MCDM methods is the Analytic Hierarchy Process, or AHP. It is applicable in a wide variety of fields, such as government, business, industry, healthcare, and education. The AHP allows researchers to make decisions utilizing experience and intuition along with measurable data in order to select the best alternative from a group or to prioritize all of the alternatives within a group. In this process, complex decisions are broken down into smaller parts (goal, criteria, sub-criteria, and alternatives) which the researcher organizes in a hierarchical manner. Uncertainties and other influencing factors can also be included. The researcher then conducts pair-wise comparisons and each results in a numerical value that allows consistent comparison of elements which may not have been previously comparable.

There are numerous examples of AHP implementation around the world, and certification bodies (CBs) for the Marine Stewardship Council (MSC) perform one of the most prominent marine-focused applications of AHP. As part of the MSC fisheries certification process, CBs must determine sub-criteria and performance indicators for measuring the performance of each individual fishery relative to the MSC standard, and weight the Criteria, all levels of Sub-criteria and Performance Indicators (each level of the assessment tree lower than Principle) using the pair wise comparison approach. These weights will reflect the certification body's assessment of the importance of the criteria for the fishery and developed and justified by the experts on the assessment team. The result of this process is subject to stakeholder vetting and consultation. The assessment team will then assess the fishery against each of the performance indicators to produce scores for the operational sub-criteria and combine the scores with the criteria weights to produce overall weighted scores at the MSC criterion and MSC principle level. Another relevant example of decision-making using issue prioritization and weighting is that explored by Fletcher 
(2005) in his article examining the effectiveness of a qualitative risk assessment process for prioritizing issues across the seven most valuable Western Australian commercial fisheries. The Australians did not use AHP explicitly, but the basic principles of identifying issues and developing and weighting criteria while incorporating stakeholder and expert input to assess the risk associated with each issue is virtually identical.

\section{References}

Karasakal, E.K. 2001. Annex 4. Multi-criteria decision making: An overview of techniques relevant to fishery management planning and some comments on traffic light approach. From: Proceedings of the Fisheries Management Studies Working Group, 25-29 June 2001. Bedford Institute of Oceanography, Dartmouth, NS. Prepared by RG Halliday and R O'Boyle, Chairman, August 2001.

Fletcher, W.J. 2005. The application of qualitative risk assessment methodology to prioritize issues for fisheries management. ICES Journal of Marine Science, 62: 1576-1587.

Forman, E., and M.A. Selly. 2000. Chapter 4: The Analytic Hierarchy Process and Expert Choice. From: Decision by Objectives (How to convince others that you are right). [Online] http://www.expertchoice.com/assets/dbo/chapter4.pdf.

Keeney, R.L. 1982. Decision Analysis: An Overview. Operations Research, 30(1982): 803-838.

Keefer, D.L., C.W. Kirkwood, and J.L. Corner. 2004. Perspective on Decision Analysis Applications, 1990-2001", Decision Analysis; March 2004.

Williams, S. 2005. Using the AHP and Expert Choice to support the MSC fisheries certification process, Version 2. Prepared by Hartley McMaster, Ltd. for the Marine Stewardship Council, September, 2005.

\section{Cumulative Impact Assessment (Halpern et al.)}

Implementing ecosystem-based management requires tools for 1) quantitatively assessing the interaction of multiple human uses of and stressors on the oceans, and 2) measuring the effects of multiple uses at a whole ecosystem level. Ben Halpern and colleagues at the University of California, Santa Barbara, have developed a model to estimate and illustrate human impacts on the global marine environment. The cumulative impact model produces a map built from comprehensive, high resolution spatial data on the distributions of both habitat and human activities and stressors in a focal region. The map and its contributing datasets can aid in determining priority management goals and in making spatial comparisons within a management region that integrate across many diverse types of information. The maps can be used to 1) identify pairs and suites of threats that often co-occur and might be key targets of cross-sector coordination, 2) identify highly sensitive zones where small shifts in the location of activities might lead to large decreases in impact, 3) identify areas of very low human use to be set aside for future preservation, 4) set baselines for monitoring changes in cumulative impact or individual stressors on a management region, and 5) aid in permitting decisions for new uses. New uses can be rapidly evaluated with the expert survey and inserted into the cumulative impact model. Halpern et al. are developing a user-friendly interactive mapping website to enable this type of scenario analysis in real time.

The cumulative impact model follows a four step process (Figure 1) that can be implemented at any spatial scale and data resolution. First, assemble data for each anthropogenic driver (often called a 'threat') and each ecosystem within a given system. Second, transform and rescale between 0-1 each driver layer to put them on a single, unitless scale that allows direct comparison. In other words, this allows one to 'compare apples and oranges'. Third, for each $1 \mathrm{~km}^{2}$ cell of ocean, multiply each driver layer with each ecosystem layer to create driver-by-ecosystem combinations, and then multiply these combinations by an appropriate weighting variable. These weighting variables come from an expert survey that is designed to assess the vulnerability of each ecosystem to each driver on the basis of the exposure and sensitivity of ecosystems to threats. The expert judgment is used in a fully transparent, repeatable, and quantitative manner. The weighting values represent the relative impact of an anthropogenic driver on an ecosystem within a given cell when both exist in that cell. The sum of these weighted driver-by-ecosystem combinations then represents the relative cumulative impact of human activities on all ecosystems in a particular map cell. Finally, when possible, use empirical data on the condition of ecosystems to groundtruth the scores, to provide ecological meaning to these relative 
cumulative impact scores. Many of these steps can be streamlined by leveraging the existing spatial data that were gathered and processed for the global scale analysis (Halpern et al., 2008, Science v.319, p.948).

Their approach provides a framework for quantifying tradeoffs among human uses of ecosystem services and strategies to minimize ecological impact and promote sustainable use. This framework has value and applicability at local and regional scale planning and can accommodate the input of a finer scale of data to potentially identify hotspots for conservation priority, of both high diversity and high cumulative human impact. Their process and resulting maps provide a useful tool for decision making regarding the allocations of conservation resources, ecosystem-based management and to inform marine spatial planning, education and data needs.

Through this approach, managers would identify regions requiring increased management of human activities, assess whether or how human activities can be spatially managed to reduce impacts, and identify gaps in information and data needs (this may include shifting of fishing zones, rerouting navigation lanes to protect sensitive habitats, etc.). This model evaluates the impact of various anthropogenic drivers, and the degree to which these drivers impact marine ecosystems, which would be valuable in decisions on balancing trade-offs in coastal MA. This approach can also elucidate gaps in data, particularly given that the model utilizes some of the most basic information for habitat types and whether and how different anthropogenic drivers interact. As with many of the tools described herein, the results and their interpretation directly depend on the quality and scale of data available. Given that the MA Ocean Act Planning area is a relatively discrete area of the ocean, fine scale data will be required for adequate evaluations of human impact on the zones within the planning area.

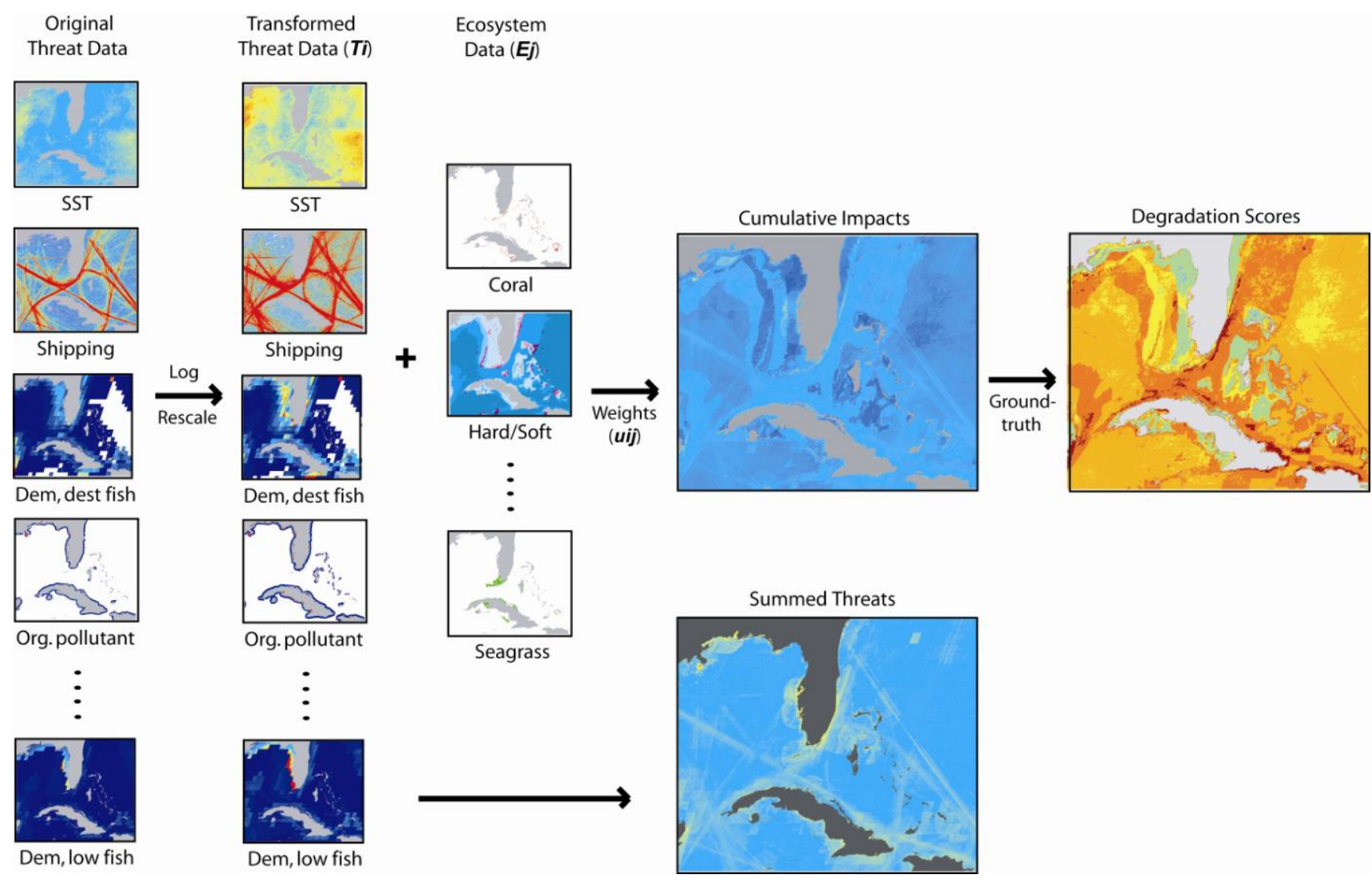

Figure 1: The four step process of the Cumulative Impact Model. 


\section{References}

Halpern, B.S., K.A. Selkoe, F. Micheli, and C.V. Kappel. 2007. Evaluating and Ranking the Vulnerability of Global Marine Ecosystems to Anthropogenic Threats. Conservation Biology, Oct 2007, Vol. 21 Issue 5, p1301-1315.

Halpern, B.S., A. Walbridge, K.A. Selkoe, C.V. Kappel, F. Micheli, C. D'Agrosa, J.F. Bruno, K.S. Casey, C. Ebert, H.E. Fox, R. Fujita, D. Heinemann, H.S. Lenihan, E.M.P. Madin, M.T. Perry, E.R. Selig, M. Spalding, R. Steneck, and R. Watson. 2008. A Global Map of Human Impact on Marine Ecosystems. Science, 319, 948-952. http://www.sciencemag.org/cgi/content/abstract/sci;319/5865/948

A Global Map of Human Impacts to Marine Ecosystems, UCSB website: http://www.nceas.ucsb.edu/GlobalMarine

Pandolfi, J.M., R.H. Bradbury, E. Sala, T.P. Hughes, K.A. Bjorndal, R.G. Cooke, D. McArdle, L. McClenachan, M.J.H. Newman, G. Paredes, R.R. Warner, and J.B.C. Jackson. 2003. Global Trajectories of the Long-Term Decline of Coral Reef Ecosystems. Science 15 August 2003: Vol. 301. no. 5635, pp. $955-958$. http://www.sciencemag.org/cgi/content/abstract/sci;301/5635/955

\section{Social Impact Assessment}

Social Impact Assessment (SIA) is a sub-field of the social sciences that provides a systematic appraisal in advance of impacts on the day-to-day quality of life of persons and communities whose environment is affected by a proposed plan, program, project, or policy change. The SIA methodology is designed to review the social effects of development and management decisions before they are implemented. It has been incorporated into formal planning and approval processes in various countries as a means to assess how major developments may affect groups and populations. SIA is often conducted in concert with Environmental Impact Assessments (EIA), but is not yet as widely adopted as EIAs.

Social impacts refer to changes to individuals and communities due to a proposed action that alters the way in which people live, work, play, relate to one another, organize to meet their needs and generally cope as members of society. A social assessment is the analysis of the capacity of a group of individuals, a community or a region to deal with social changes resulting from a plan, program, project or policy change.

SIA overlaps with the monitoring and evaluation that occurs after the implementation of a plan and is essential to gauge the effectiveness of any management decisions at meeting the designated goals. SIA could effectively be conducted at various steps in a planning framework and would serve to inform that decisions are effective and do not disadvantage local people or generate negative social and environmental impacts. The use of SIA allows for the participation of all stakeholders in the design and implementation of policy decisions, which is a primary goal of the MA Oceans Act.

Social Impact Assessments are conducted to understand how a proposed action will change life of communities and regions; a SIA provides empirical indicators of likely social impacts, suggest alternatives to those impacts, develops a blueprint for mitigation, monitoring and evaluation and identifies benefits from change that development may bring. SIAs incorporate multiple phases (design, implementation and analysis) intended to unveil the network of issues that affect people directly or indirectly.

The process of SIA incorporates a number of variables defined by assessors, these include: population impacts, community/institutional arrangements, communities in transition, individual and family level impacts and community infrastructure needs. By addressing the appropriate variables, SIA can serve as an overarching evaluation of all impacts on humans and on all the ways in which people and communities interact with their socio-cultural, economic and environmental surroundings.

\section{References}

Social impact assessment defined on Wikipedia. Accessed 2008. http://en.wikipedia.org/wiki/Social_impact_assessment 
International Association for Impact Assessment (IAIA). 2003. Social Impact Assessment International Principles. Special Publication Series No. 2. May 2003.

http://www.iaia.org/Members/Publications/Guidelines Principles/SP2.pdf

Verna DeLauer (personnel communications)

\section{QUEST}

The QUEST Program, Quantifying and Understanding the Earth System, is an interdisciplinary program created by the Natural Environment Research Council (NERC). The program centers on the fact that humans, as part of the global ecosystem, are changing and transforming the environment in ways that we cannot begin to comprehend. However, even though we don't understand everything that is happening, we are starting to see physical changes in the environment as a result of ongoing climate change and human use. The QUEST Program aims to provide "step-change improvements" in our understanding of global environmental change and large-scale processes, and inform decision making at all levels. The Program focuses on three research themes with different temporal perspectives:

- $\quad$ Theme 1: How important are biotic feedbacks for 21 st century climate change? (or The contemporary carbon cycle and its interactions with climate and atmospheric chemistry)

- Theme 2: How are climate and atmospheric composition regulated on time scales up to a million years? (or The natural regulation of atmospheric composition on glacial-interglacial and longer time scales)

- $\quad$ Theme 3: How much climate change is a) dangerous? b) avoidable by managing the biosphere? (or The implications of global environmental changes for the sustainable use of resources)

Key to QUEST's success is integration. One of the guiding principles is based on the fact that sustained interdisciplinary research and cooperation leads to earlier and more advances in our understanding of the Earth's systems. QUEST invests in multi-institution consortiums that tackle the interactions between science themes (land, atmospheric and marine domains; modeling and observations; natural and human sciences). Massachusetts may be interested in pursuing future funding from QUEST, if interests align.

The QUEST Program has two strategic activities that could be of great use to MOP and Massachusetts. The first is Earth System Modeling. These Earth System models include ocean and land biosphere processes and their physical and chemical interactions with the ocean and atmosphere, building on Theme 1 projects. Interfacing with socio-economic models and research from Theme 3 projects will also be possible. The second activity is development of an Earth System Atlas. This Atlas is, in essence, a virtual warehouse for numerous, peer-reviewed, global data sets including paleo-environmental observations and socio-economic variables as well as variables of general importance relating to physiography, ecosystems, and climate, inter alia.

\section{References}

QUEST. 2004. Quantifying and Understanding the Earth System (QUEST): Science Plan. Published, 22 June 2004. http://quest.bris.ac.uk/about/policies/scienceplan.pdf.

QUEST. 2004. Quantifying and Understanding the Earth System (QUEST): Implementation Plan. Published, 22 June 2004. http://quest.bris.ac.uk/about/policies/impplan.pdf.

QUEST. 2007. QUEST: Quantifying and Understanding the Earth System, http://quest.bris.ac.uk/index.html.

\section{Conservation Assessment and Prioritization System (CAPS)}

The Conservation Assessment and Prioritization System (CAPS) is a computer software program designed by the University of Massachusetts at Amherst (UMass). It is a decision support tool for conservation and restoration site selection. UMass uses this tool to assess the ecological integrity and biodiversity value of lands and waters, and they base their assessments on natural community-specific models. UMass defines ecological integrity as "the ability of an area to support biodiversity and the 
ecosystem processes necessary to sustain biodiversity over the long term". The main premise of the system is that by conserving intact, ecologically-defined communities of high integrity, conservation of most species and ecosystems is also possible.

To begin the process, researchers map the communities using three community levels defined by the Natural Heritage and Endangered Species Program's Natural Community Classification scheme. The primary community level is at the finest scale and tertiary is at the broadest scale. For example, the primary community of "High-gradient Headwater" would fall into the secondary community of "Riverine" and the tertiary community of "Wetlands and Aquatic Communities". Once mapping of the communities in finished, filters or landscape metrics are applied that account for the size of a community patch, its proximity to streams and rivers, the diversity of soil units in the patch, or the intensity of roads in the vicinity, inter alia. After all the filters are applied, CAPS calculates the Index of Ecological Integrity (IEI) for each point in the landscape (15m blocks). This IEI is, in essence, the value placed on the habitat and biodiversity of that point in the landscape. Even though an IEI can be assigned to individual points in the landscape, it is important to realize that the overall approach focuses on a valuation of the entire landscape by combining numerous spatial relationships which drive ecological processes.

Using the results of the assessments, researchers and decision makers prioritize land areas for conservation action based on their assessed ecological value. UMass piloted the CAPS effort in the Housatonic watershed and the Highlands Communities region of Massachusetts. They performed a second CAPS assessment for the proposed Route 11 extension in southeastern Connecticut. It is easy to see how Massachusetts could use such a program to assign value to ocean and coastal areas, incorporating stakeholder feedback, and then use those valuations to prioritize sites for development, zoning or conservation.

To date, the CAPS software has been used mainly for terrestrial systems, but could be adapted for tidal and marine systems. It should be noted that the CAPS software is intended for the public domain, although it is still under development and not yet available to the public. However, UMass Boston and the State (Mass EEA funded the program) may be able to gain access to the system for use in creating an Ocean Management Framework, should they wish to do so.

\section{References}

Ecosystem-Based Management Tools Network Database. 2007. http://www.smartgrowthtools.org/ebmtools/index.php

University of Massachusetts at Amherst. 2007. CAPS: Conservation Assessment and Prioritization System. http://www.umass.edu/landeco/research/caps/caps.html, http://www.umass.edu/landeco/research/caps/data/caps data.html,http://www.umass.edu/landec o/research/caps/reports/caps reports.html

University of Massachusetts at Amherst. 2001. Biodiversity Filters, Created March 14, 2001. http://www.umass.edu/landeco/research/caps/documentation/caps documentation.html

University of Massachusetts at Amherst. 2006. UMass CAPS Project (PowerPoint slideshow). http://www.umass.edu/landeco/research/caps/presentations/summary/index.html. Last updated, September 28, 2006.

\section{InVEST}

InVEST, the Integrated Valuation of Ecosystem Services and Tradeoffs tool, was developed by the Natural Capital Project (www.naturalcapitalproject.org) to model and map the delivery, distribution, and economic value of ecosystem services, or natural capital, something that Massachusetts has not achieved to date. A few examples of ecosystem services are the buffering capacity provided by wetlands, energy provided by wind, waves and tides, and recreation opportunities such as fishing, whale watching, visiting the beach or kayaking. InVEST can also determine benefits or drawbacks for individual social groups, largely dependent on access. InVEST's development arose partly out of the fear that decision makers would ignore ecosystem services not easily described or measured in economic terms. It assigns value and tangible benefits to ecosystem services and helps identify tradeoffs and compatibilities between environmental, economic, and social benefits. According to Tallis and Polasaky (in press), 
"InVEST has several key features that make this a flexible yet scientifically grounded tool. InVEST is a set of computer based models that:

- clearly reveals relationships among multiple services,

- focuses on ecosystem services rather than biophysical processes,

- is spatially explicit,

- provides output in both biophysical and economic terms,

- is scenario driven,

- has a tiered approach to deal with data availability and the state of system knowledge."

There are three tiers available for use in the InVEST program, the first of which examines biophysical consequences of decision making. This tier does not require extensive input data, and provides a sense of the level of services provided in the ecosystem in question. With the amount of data available to Massachusetts, and time input required, using InVEST at the first level only could be a good initial option for the Commonwealth. The second and third tiers examine high resolution biophysical and economic consequences of management decisions. InVEST has been applied in decision-making processes at several sites, a brief description of two such sites, the Amazon Basin (South America) and the Willamette Basin (Oregon, USA), is given below.

In the Amazon Basin, InVEST predicted the physical structure of the basin after 20 years of development (mainly road) and deforestation. The models showed that the most heavily populated areas would lose the most overall forest product provision. Indigenous populations in Montane forest, savanna and varzea ecosystems, however, would have the greatest loss in both marketed and subsistence products.

In the Willamette Basin, mandates required the protection of the spotted owl and salmon populations while addressing economic and social concerns. The Willamette Basin had a wealth of available data, which made it an ideal candidate for InVEST. Modeling occurred under three scenarios (plan trend, development, and conservation) for a 60-year period from 1990-2050. The InVEST models tracked changes in water quality, storm peak mitigation, erosion control, carbon sequestration, biodiversity conservation and market returns for agriculture, timber and housing development. The results showed that if ecosystem services were enhanced, biodiversity conservation would be enhanced as well. If, however, landowners could pursue unrestricted social and economic gains from ecosystem service use, ecosystem services and biodiversity conservation would suffer. One tradeoff that resulted from the models was that of paying for ecosystem services. If $\$ 43$ per ton of carbon was paid by the service user, carbon sequestration could be negated and made the conservation scenario the most valuable outcome.

The data inputs for the Willamette basin informed a subset of simple InVEST models (Water Service Models, Soil Conservation, Carbon Sequestration, Biodiversity Conservation and Commodity Production Value). The inputs used were: discharge of dissolved phosphorus into the local watershed, volume and timing of water flow from an area to its catchment's outlet, average annual rate of soil erosion, carbon stored in above and below ground biomass, soil, and harvested wood products, species-area relationship for 24 vertebrate species to determine capacity and market value of commodities provided by an area. Inputs can be on any spatial scale, but the finer scale the more informative the model.

\section{References}

Nelson, E., J. Mendoza, J. Regetz, S. Polasky, H. Tallis, D.R. Cameron, K.M.A. Chan, G.C. Daily, J. Goldstein, P. Kareiva, E. Lonsdorf, R. Naidoo, T.H. Ricketts, and M.R. Shaw. In press. Modeling multiple ecosystem services, biodiversity, commodity production and tradeoffs at landscape scales. Frontiers in Ecology and the Environment.

Tallis, H., and S. Polasky. In press. Mapping and valuing ecosystem services as an approach for conservation and natural resource management. Chapter for the New York Academy of Sciences Year in Conservation, $25 \mathrm{pp}$.

Natural Capital Project Website: http://www.naturalcapitalproject.org/lnVEST.html 


\section{Appendix C: Suggested MOP Indicators within the DPSIR Framework}

\begin{tabular}{|c|c|c|c|c|c|c|c|}
\hline \multirow[t]{2}{*}{ Indicator Class } & \multirow[t]{2}{*}{ Organizing Theme } & \multirow[t]{2}{*}{ Indicator } & \multicolumn{5}{|c|}{ Type/Focus } \\
\hline & & & D & $\mathbf{P}$ & $\mathrm{S}$ & I & $\mathbf{R}$ \\
\hline \multirow{9}{*}{$\begin{array}{l}\text { Environmental } \\
\text { Indicators }^{1}\end{array}$} & Diversity & $\begin{array}{ll}- & \text { Diversity of communities } \\
- & \text { Diversity of populations } \\
- & \text { Diversity of species } \\
- & \text { Genetic diversity } \\
- & \text { Invasive species/pests }\end{array}$ & & & $\mathbf{\square}$ & $\mathbf{\square}$ & \\
\hline & Distribution & $\begin{array}{ll}\text { - } & \text { Horizontal distribution (patchiness, aggregation) } \\
\text { - } & \text { Vertical distribution (food web/trophic structure) } \\
\end{array}$ & & & $\mathbf{\square}$ & $\mathbf{\square}$ & \\
\hline & Abundance & $\begin{array}{ll}- & \text { Biomass (key populations) } \\
- & \text { Number of individuals (marine mammals) } \\
- & \text { Density (plants, benthic organisms) } \\
\end{array}$ & & & $\mathbf{\square}$ & $\mathbf{\square}$ & \\
\hline & Production and reproduction & $\begin{array}{ll}- & \text { Complexity of food web } \\
- & \text { Key predator/prey interactions } \\
- & \text { Keystone species } \\
- & \text { Size spectra } \\
\end{array}$ & & & $\mathbf{\square}$ & $\mathbf{\square}$ & \\
\hline & Trophic interactions & $\begin{array}{ll}- & \text { Complexity of food web } \\
- & \text { Key predator/prey interactions } \\
- & \text { Keystone species } \\
- & \text { Size spectra }\end{array}$ & & & $\mathbf{\square}$ & $\mathbf{\square}$ & \\
\hline & Mortality & $\begin{array}{ll}- & \text { Fishing mortality } \\
- & \text { Incidental mortalities (by-catch) } \\
- & \text { Natural mortality (predation) } \\
\end{array}$ & & $\mathbf{\square}$ & $\mathbf{\square}$ & $\mathbf{\square}$ & \\
\hline & Species health & $\begin{array}{ll}- & \text { Species at-risk of extinction } \\
- & \text { (Bio)accumulation of toxic compounds } \\
- & \text { Diseases and abnormalities } \\
\end{array}$ & & $\mathbf{\square}$ & $\mathbf{\square}$ & $\mathbf{\square}$ & \\
\hline & Water quality & $\begin{array}{ll}- & \text { Water column properties } \\
\text { - } & \text { Oceanographic processes \& variability (\& regime shifts) } \\
\text { - } & \text { Sedimentation (e.g. transport of suspended sediments) } \\
- & \text { Eutrophication parameters }\end{array}$ & $\square$ & & $\mathbf{\square}$ & & \\
\hline & Contaminant Introduction & $\begin{array}{ll}- & \text { Industrial Inputs of Persistent Organic Pollutants (POPS)/Metals } \\
- & \text { Fertilizer Use in Coastal Watershed } \\
\end{array}$ & & $\mathbf{\square}$ & & $\mathbf{\square}$ & \\
\hline
\end{tabular}




\begin{tabular}{|c|c|c|c|c|c|c|c|}
\hline \multirow[t]{2}{*}{ Indicator Class } & \multirow[t]{2}{*}{ Organizing Theme } & \multirow[t]{2}{*}{ Indicator } & \multicolumn{5}{|c|}{ Type/Focus } \\
\hline & & & D & $\mathbf{P}$ & $\mathrm{S}$ & I & $\mathbf{R}$ \\
\hline & & $\begin{array}{ll}- & \text { Pesticide Use in Coastal Watershed } \\
- & \text { Non-Agricultural Nutrient Inputs } \\
\text { - } & \text { Non-Industrial Inputs of POPs/Metals } \\
- & \text { Vessel Introduction of Nutrients, POPs, Metals } \\
- & \text { Oil Entering Environment from All Sources } \\
\end{array}$ & & & & & \\
\hline & Habitat quality & $\begin{array}{ll}- & \text { Habitat types } \\
- & \text { Habitat alteration } \\
- & \text { Sea level change } \\
- & \text { Landscape and bottomscape integrity } \\
- & \text { Sediment quality (nature/properties of sediments) }\end{array}$ & $\mathbf{a}$ & & $\mathbf{\square}$ & & \\
\hline
\end{tabular}

\begin{tabular}{|c|c|c|c|c|c|c|c|}
\hline Indicator Class & Organizing Theme & Indicator & \multicolumn{5}{|c|}{ Type/Focus } \\
\hline & & & D & $\mathbf{P}$ & $\mathrm{S}$ & I & $\mathbf{R}$ \\
\hline \multirow{4}{*}{$\begin{array}{l}\text { Socio- } \\
\text { Economic } \\
\text { Indicators }^{2}\end{array}$} & Population Dynamics & $\begin{array}{ll}\text { - } & \text { Resident Population within MA Ocean Planning Area } \\
- & \text { Peak seasonal population } \\
\text { - } & \text { Population in Coastal High Hazard Areas } \\
- & \text { Age Demographics } \\
\text { - } & \text { Urban/Rural Population } \\
\text { - } & \text { Population density }\end{array}$ & $\square$ & $\square$ & & $\mathbf{\square}$ & \\
\hline & Coastal Zone Extent & $\begin{array}{ll}- & \text { Land Use/Land Cover Patterns in Coastal Zone } \\
\text { - } & \text { Coastal Zoning Patterns (Including Offshore Use Zones) }\end{array}$ & 口 & $\mathbf{\square}$ & & & \\
\hline & Economic Conditions & $\begin{array}{ll}- & \text { Gross Domestic Product (GDP)- Mass. } \\
\text { - } & \text { Environmentally Adjusted Net Domestic Product-Mass. } \\
\text { - } & \text { Per capita Income } \\
\text { - } & \text { Patterns of Income Distribution } \\
\text { - } & \text { Employment Patterns and Trends } \\
\text { - } & \text { Patterns and Trends in Industrial Production } \\
- & \text { Economic Value of and Employment in Coastal Industry Sectors } \\
- & \text { Property values } \\
- & \text { Income/ wealth distribution }\end{array}$ & $\square$ & $\mathbf{\square}$ & & & \\
\hline & $\begin{array}{l}\text { Social Conditions and Cultural } \\
\text { Traditions }\end{array}$ & $\begin{array}{ll}- & \% \text { of Population with Access to Public Water and Wastewater } \\
& \text { Systems } \\
\text { - } & \text { Educational Attainment } \\
\text { - } & \% \text { of Population with Internet Access (High-Speed) }\end{array}$ & $\square$ & $\mathbf{\square}$ & & & \\
\hline
\end{tabular}




\begin{tabular}{|c|c|c|c|c|c|c|c|}
\hline \multirow[t]{2}{*}{ Indicator Class } & \multirow[t]{2}{*}{ Organizing Theme } & \multirow[t]{2}{*}{ Indicator } & \multicolumn{5}{|c|}{ Type/Focus } \\
\hline & & & D & $P$ & $\mathbf{S}$ & I & $\mathbf{R}$ \\
\hline & Development/Capital Construction & $\begin{array}{ll}- & \% \text { or Miles of Artificial Coast (jetties, seawalls, groins, } \\
\text { breakwaters)- change per KM of coast } \\
\text { - } & \text { \# of Coastal Building Permits } \\
\text { - } & \text { \% of Impermeable Surfaces in Coastal Zone } \\
\text { - } & \text { Functioning/Age of Wastewater Facilities } \\
\text { - } & \text { Public Dredging (Location/Cost/Volume) } \\
- & \text { Coastal Fill acres/year } \\
- & \text { Freshwater Dams - Location, capacity } \\
- & \% \text { water-dependent use industry / coastal industry } \\
\end{array}$ & & $\mathbf{\square}$ & & & \\
\hline & Habitat Change/Ecological Value & $\begin{array}{ll}\text { - } & \text { Value of Manufactured Products from Coastal Habitats } \\
\text { - } & \text { Value of Pharmaceutical and Biotechnology from Coastal Habitats } \\
\text { - } & \text { Non-Use Values of Coastal Habitat (Bequest/Existence/Option) } \\
\text { - } & \text { Marine Protected Areas - Location, Size, Type } \\
\text { - } & \% \text { Public Ownership of Coastal Watershed }\end{array}$ & & $\mathbf{\square}$ & & $\mathbf{\square}$ & \\
\hline & Resource Extraction Activities & $\begin{array}{ll}- & \text { Coastal Renewable Energy - Location, Production Capacity } \\
- & \text { Marine Mining Permits and Extracted Amounts } \\
\text { - } & \text { Tar balls } \\
\text { - } & \text { Level/Value of Commercial Landings by Harvest Area } \\
\text { - } & \text { Commercial Catch/Unit Effort } \\
- & \text { Structure of Commercial Fleet- \% Within MA Registration } \\
- & \text { Levels of Commercial By-Catch } \\
- & \text { Level of government financial support (Subsidy, loans guarantees, } \\
\text { - } & \text { tax credits) } \\
- & \text { Numbanal Fishing Effort } \\
- & \text { Total Seafood Consumption } \\
- & \text { Seafood Consumption Demographics } \\
- & \text { Seafood Import/Export Quantity, Value by Species } \\
- & \text { Change in value of Coastal Ornamentals }\end{array}$ & $\square$ & $\mathbf{\square}$ & & $\mathbf{\square}$ & \\
\hline & Human Uses/Activities & $\begin{array}{ll}- & \text { Coastal Watershed Aquaculture (Number, Location, Species } \\
& \text { Annual Yield) } \\
\text { - } & \text { International Coastal Tourist Arrivals } \\
\text { - } & \text { Value of Tourism and Employment in Coastal Tourism Sector } \\
\text { - } & \text { Proportion of Coastal Ecotourism/Coastal Tourism }\end{array}$ & & $\mathbf{\square}$ & & $\mathbf{\square}$ & \\
\hline
\end{tabular}




\begin{tabular}{|c|c|c|c|c|c|c|c|}
\hline \multirow{2}{*}{ Indicator Class } & \multirow{2}{*}{ Organizing Theme } & \multirow{2}{*}{ Indicator } & \multicolumn{5}{|c|}{ Type/Focus } \\
\hline & & & D & $\mathbf{P}$ & $\mathbf{S}$ & I & $\mathbf{R}$ \\
\hline & & $\begin{array}{ll}- & \text { Number/Attendance Recreational Bathing Beaches } \\
- & \text { Number of Recreational Boats/Boaters in Coastal Zone } \\
- & \text { Number/Size of Recreational Marinas/Commercial Ports and } \\
\text { - } & \text { Harbors } \\
\text { - } & \text { Numacity of Commercial Ports and Harbors } \\
\text { Number of Shipping Vessels Entering/Transiting Coastal Waters }\end{array}$ & & & & & \\
\hline & $\begin{array}{l}\text { Infrastructure Development } \\
\text { Pressure/Capital Construction }\end{array}$ & $\begin{array}{ll}\text { - } & \text { Cost of Coastal Flooding and Coastal Hazards/Savings Provided } \\
\text { by Coastal Habitat } \\
\text { - } \\
\text { Infrastructure Costs Associated w/ Development Driven Coastal } \\
\text { Erosion } \\
\text { - Dredging Costs/Savings Driven by Sediment } \\
\text { Contamination/Mitigation } \\
\text { - } \quad \text { Coastal Clean-up Costs other than Dredging Costs } \\
\text { Beach Replenishment Costs }\end{array}$ & & $\square$ & & $\mathbf{\square}$ & \\
\hline & Habitat Change/Ecological Value & $\begin{array}{ll}- & \text { Social Costs of Invasive Species } \\
\text { - } & \text { Changes to Non-Use Values of Coastal Habitats } \\
\text { (Bequest/Existence/Option) } \\
\text { - } \quad \text { Service Value changes from Habitat Alteration }\end{array}$ & & $\mathbf{\square}$ & & $\mathbf{\square}$ & \\
\hline & Resource Extraction Activities & $\begin{array}{ll} & \text { \% Coastal Harvesting Areas Under Environmental Restrictions } \\
\text { - } & \text { Value changes to Seafood Due to Chemical Contamination } \\
\text { - } & \text { Value changes to Seafood Lost Due to Pathogenic/ Toxic } \\
\text { - } & \text { Contamination } \\
& \text { Value changes to Seafood Lost to Factors other than } \\
& \text { Overexploitation (habitat loss) }\end{array}$ & & $\mathbf{\square}$ & & $\mathbf{\square}$ & \\
\hline & Human Uses/Activities & $\begin{array}{ll} & \text { Marine-vectored Disease (Cases/Outbreaks/ Disability Adjusted } \\
- & \text { Life Years) } \\
- & \text { Number of Beach Closings/Beach Closing Days } \\
- & \text { Value of Coastal Recreation Days } \\
- & \text { Changes to Coastal Property Values } \\
- & \text { Change in cultural traditions resulting in social dislocation/ Change } \\
\text { - } & \text { in livelihood } \\
& \text { Level of user conflict }\end{array}$ & & $\mathbf{\square}$ & & $\mathbf{\square}$ & \\
\hline
\end{tabular}


Notes:

1. The general structure for this table is drawn from working drafts developed by Belfiore and Bowen. The "Environmental Indicators" section of this table draws heavily from a version of that work as published in:

Belfiore, Stafano, Julianne Barbiere, Robert E. Bowen, Biliana Cicin-Sain, Charles Ehler, Camille Mageau, Dan McDougal and Robert Simon. 2006. "A Handbook for Measuring the Progress and Outcomes of Integrated Coastal Management, UNESCO Intergovernmental Oceanographic Commission (IOC) Manuals and Guidelines, 46; ICAM Dossier, 2. Paris. 217 ppg. See, in particular, ppg. 78-80.

2. The "Socio-Economic Indicators", while using a consistent format, draws primary influence from both:

Intergovernmental Oceanographic Commission (IOC), ICAM Programme. 2003. A Reference Guide on the Use of Indicators for Integrated Coastal Management. Paris. ICAM Dossier No. 1, 2003.

Bowen, Robert E., Jin-Seok Kim and Jack Wiggin. 2008. Linking Socio-Economics and Coastal Environmental Change: Outcome Indicators to Assess Coastal Management Success (English): pp. 242-290 In J.-Y. Choi, H.J. Choi, J.D. Kim, J.H. Jeong, and C.O. Shin, Development of Coastal Indicators and Survey Guideline (in Korean). Seoul, Republic of Korea, Korea Maritime Institute, 348 pp. 


\section{Appendix D: Economic Methodologies}

In this Appendix, we review briefly a number of economic methodologies potentially useful for ocean planning. More detail on these methodologies can be found in the references located at the end of the appendix.

\section{Benefit-Cost Analysis}

Benefit-cost analysis (BCA) comprises studies that compare the economic benefits and economic costs of the potential implementation of a policy to modify the allocation of resources. Economic benefits are measured in terms of consumer and producer surpluses; these surpluses may be observed in market settings or they may arise outside of markets, in the case of public goods or failed markets. Economic costs are opportunity costs, which are the potential surpluses that could obtain under alternative resource allocations. BCA involves identifying and estimating total economic value, comprising market values as well as non-market values, such as use and nonuse (existence, bequest, option) values. Often it may be costly to compile and analyze data to estimate total economic value comprehensively.

BCA may be static or dynamic; the latter is concerned with the pattern of benefits and costs over time as they are affected by the distribution of investments, ecological changes (e.g., growth of fish stocks), or changing human preferences. Where policy adjustment can be incremental, BCA may be utilized to characterize the economically optimal level of activity. Most federal and state planning frameworks, including the conduct of environmental assessments, do not require the application of strict BCA methods in the analysis of policy actions. Nevertheless, there is a large literature on the application of BCA to specific cases of coastal and ocean resource management.

\section{Bioeconomic modeling}

Bioeconomic analysis was pioneered by Gordon (1954) and Schaefer (1957). The most important conclusion of earlier studies is that common-property resources will become over-exploited, since the fishing effort under open access is greater than what is considered socially optimal (Gordon, 1954). A typical fisheries economic model would include two major components which captures fish market (demand and supply, or benefit (revenue) and cost) and fish stock dynamics, respectively.

Fish stock dynamics in a bioeconomic model captures two effects. First, fishery resource is renewable and subject to laws of natural growth that define a biological constraint on the activities of a fishing industry. Also, the resource and the activity of production from it form a stock-flow relationship. The new growth in the fish stock depends on the harvest rate relative to natural recruitment to the stock. If the harvest rate exceeds the recruitment rate, the stock declines, and vice versa (Smith, 1969).

One of the most important topics in bioeconomic studies is to examine fishermen's behavior under open access (common-property resources) (Clark, 1976; 1985) and compare that with what is considered socially optimal exploitation (Plourde, 1970; Clark and Munro, 1975). In these studies, individual fishermen are modeled to maximize profit, defined as revenue from fish sales minus cost associated with fishing operations. To explore the socially optimal solution, these studies view the fish stock as a type of capital asset that should be managed so as to maximize its value to society. In this case, a social planner's objective is to maximize the net social benefit, defined as the social benefit (e.g. the area under the demand curve for fish) minus the total cost of the fishery. The total cost includes not only the fishing cost incurred to fishermen but also the associated external cost (e.g. effects on fish stock and the ecosystem).

The bioeconomic approach has been used widely to examine fisheries management problems since the mid-1970s (Clark, 1976). Its strengths lie in revealing economically optimal levels of yield and the net benefits of the implementation of alternative management measures (cf., Edwards and Murawski, 1993). In some circumstances, the bioeconomic approach also can be used to determine the optimal dynamic path to a steady state. Because it often involves the use of nonlinear dynamic models of production and 
species growth and interactions, the bioeconomic approach is difficult to apply to a large number of species or markets.

Although most multispecies bioeconomic models incorporate only two species, they can involve complex biological and technological inter-relationships (Beddington and Cooke, 1982). Other extensions of the classical bioeconomic analysis include spatially explicit and multispecies models. Sanchirico and Wilen (2001) develop a spatial dynamic framework of renewable resource exploitation to investigate the effects of marine reserve creation. Their framework combines a metapopulation model incorporating resource patch heterogeneity and dispersal with a behaviorally based, spatially explicit harvesting model. The combined spatial bioeconomic model is used to simulate the effects of reserve creation under various ecological structures. Finnoff and Tschirhart (2003) examine the impacts of fish harvesting on an eightspecies ecosystem. Holland and Schnier (2006) formulate a dynamic and spatial fishery and habitat model to explore the cost-effectiveness of achieve habitat conservation targets with an individual habitat quota (IHQ) system.

\section{Non-market valuation}

Non-market valuation is utilized to identify and estimate the net benefits (economic surpluses) of goods and services that are not traded in established markets. Consequently, non-market valuation may be an important aspect of estimating total economic value for use in benefit-cost analysis. Holland et al. (2007) provide an excellent recent overview of non-market valuation with specific examples relevant to Massachusetts. As emphasized by these authors, it is especially important to assess non-market values where they are likely to be displaced or lost due to development activities, the values of which are more easily estimated in established markets. Historically, non-market resources have been degraded or lost essentially because they do not command a market price, i.e., they have been either ignored or assumptions were made that their value was close to zero.

Coastal and marine examples of non-market values include the benefits of marine habitat, ecological processes and state, beach access and visitation, residential waterfront, recreational fishing, yachting, ecotourism, including whale-watching, water quality, seascapes, coastal and marine conservation areas, among many others. Specific non-market valuation studies that have been conducted in Massachusetts and region have been compiled in Appendix $\mathrm{E}$. These studies have also been plotted on a web-based map $^{1}$, and they will be discussed in more detail in Appendix E.

There are a number of different methodologies employed to estimate non-market values. These methodologies are summarized in

Table 1(Holland et al., 2007). Importantly, many of the methodologies that are employed to estimate nonmarket values may capture only a portion of the value. In practice, it is critical to consider the nature of the values (e.g., use v. nonuse) in order to identify the most relevant methodology.

Problems arise where there is a lack of interest on the part of resource management agencies in undertaking non-market valuation. This lack of interest may arise as a consequence of lack of expertise, lack of data, insufficient budgets, among other reasons. Where ecological states, linkages, or processes affect a non-market resource (e.g., wetlands habitat), inadequate scientific understanding of the ecosystem imposes an enormous constraint on non-market valuation. The reason for this constraint is that human preferences are conditioned on their understanding of relevant goods and services; where non-market goods and services are poorly understood, there will be significant uncertainty in assessing value.

1

http://maps.google.com/maps/ms?ie=UTF8\&hl=en\&msa=0\&msid=114476102882294796535.00045c0de 04db901 ef396\&t=h\&z=7 
Holland et al. (2007) identify four options for decision-makers who are considering non-market valuation. These four options include: (1) do nothing (the most common case); (2) undertake a benefit transfer; (3) undertake original non-market valuation of some non-market goods and services; (4) undertake original non-market valuation of all non-market goods and services. In practice, due to the significant financial cost of undertaking credible non-market valuations, option 4 is rarely possible. Option 2, benefits transfer, involves the use of non-market valuation results from studies conducted at other times or in other locations. Benefits transfer holds great promise for the future, although there is often substantial error in its application. Option 3, or some combination of options 2 and 3 , are the most likely choices. When considering carrying out non-market valuation studies, it is crucial to characterize the specific nature of the problem at hand and to identify the types of non-market resources that are at risk. This kind of problem definition can improve greatly the effectiveness of non-market valuation.

\section{Adaptive management}

Adaptive management is a structured, iterative process of updating management decisions based on changes in observed outcomes or in factors that may be expected to change future outcomes. It is a useful approach for managing renewable resources, such as commercial fish stocks, that change in response to the combination of human exploitation/management and other exogenous factors, such as climate conditions. Adaptive management can also be a practical alternative to an outright ban on an economic activity that produces an uncertain risk of significant but reversible harm to marine resources. Under adaptive management, such an activity might be allowed to proceed at a limited scale, under guidelines that ensure monitoring and research to detect adverse effects early, and with provisions for the adjustment and revision of the activity in light of new information about its effects. Adaptive management may not be appropriate in situations where harmful effects are likely to be irreversible and may be difficult to detect in time to allow for useful adjustment (see "decision-making under uncertainty").

Key features of an adaptive management approach are the establishment of appropriate time intervals for the review and possible revision of management measures, and provisions for the monitoring and research necessary to detect effects and changes that might trigger a change in management measures. The practice of reviewing and revising fisheries management regulations at regular intervals to take into account new information about stock conditions is an example of adaptive management.

\section{Decision-making under uncertainty/value of information}

Uncertainty about future effects is a common feature of management decisions about activities that affect natural resources. Decisions under uncertainty can be made systematically by trading off the expected benefits of the managed activity against the expected costs, including the risk of adverse consequences on natural resources and on other activities and uses. This requires an assessment of the potential risks (see "risk assessment and mitigation"), and a framework for trading off risks and benefits.

A key feature of the risk/benefit tradeoff framework is the tolerance for risk of the group(s) on whose behalf the decision is made, e.g. how heavily should the decision process weight the risk of a severe negative outcome, such as the extinction of a species? A risk-neutral decision process attaches no additional significance to extreme outcomes and makes the decision based on the "average" expected outcome. A risk adverse decision maker - technically, one who is inclined to prefer a bargain that is likely to lead to limited gains over a more uncertain bargain that could result in larger gains or losses - will attach a greater significance to (the avoidance of) extreme losses.

\section{Risk Aversion and the Precautionary Principle}

One prominent expression of risk aversion is the "precautionary principle". This principle evolved in the 1960s, in the context of environmental policy, from the German Vorsorgeprinzip, and has been used, in various forms in international agreements over the past 15 years. The precautionary principle calls on decision makers to consider potential risks even when no harm has as yet been demonstrated. In its limited ("weak") versions, the precautionary principle suggests that a lack of decisive evidence of harm should not be grounds for refusing to respond; see for example the 1992 Rio Declaration's principles for sustainable development (Sunstein, 2008). Stronger versions of the principle suggest that activities that 
may entail severe or irreversible harm to an environmental resource should not be permitted, regardless of potential benefits, see for example the 1994 "Seas at Risk" conference (Raffensberger and Tickner, 1999). A precautionary approach may be particularly relevant in decisions affecting ecological resources, such as marine mammals (Thompson et al., 2000); where actual harm is difficult to observe until it is too late to avoid a severe negative outcome, such as extinction.

The precautionary principle itself is not well defined or encased in US law; and it is controversial in part because a strict application would prohibit most modern economic activity, much of which has some potential for contributing to severe environmental harm (Sunstein, 2008). A more practical approach in the face of potential but uncertain risk of significant (and reversible) harm may be to allow the activity to proceed at a limited scale, under guidelines that ensure monitoring and research to detect adverse effects early, and with provisions for the adjustment and revision of the permitted activity in light of new information about its effects (see "adaptive management").

\section{Value of Information}

When decisions are made under conditions of uncertainty, it is often possible to improve the expected outcome of the decisions by improving the information available to the decision maker. For example, the expected outcome of fisheries management measures might be reflected by the annual value of landed catch and the condition of the fish stocks being exploited. If management measures are implemented with limited information about the initial condition of these stocks, there is a greater likelihood of either allowing too much fishing and reducing the stock below its optimum level, or restricting fishing unnecessarily and reducing landings below sustainable levels. Better information about the initial state of the fish stocks would enable a superior management decision. There is an established framework for evaluating the economic value of information in this sort of context.

\section{Risk assessment and mitigation}

Risk is usually defined as the combination (product) of negative consequences and the probability that they will in fact arise. The assessment of risks associated with an activity to be managed therefore requires a description of the range of possible outcomes (e.g., nature and severity of future ecological damage, including the degree to which the damage may be reversible, and its ecological and economic significance or cost), and the probability that each of these outcomes may occur.

Determining the probabilities is often particularly difficult. Some probabilities, such as the likelihood of unusually high levels of precipitation or human visitors on Cape Cod's beaches next year, can be estimated with some confidence from historical data and trends. Other probabilities, such as the likelihood of a certain level of ecological harm from a new kind of marine aquaculture, often cannot be derived from historical data alone; they must be estimated using a process of expert judgment informed by science. In these situations, it may be appropriate to invest in research to better understand probabilities and risks to ensure sound management (see "value of information").

Once risks are understood, it is often possible to manage or mitigate them in some way. For example, the risks of possible negative effects from a proposed activity on certain spawning grounds of a commercially valuable fish species can be reduced by ensuring the protection of another spawning area.

\section{Green accounting}

It has been widely recognized that conventional measures, such as GDP and GNP, are incomplete in gauging an economy's contribution to the well-being of a country's population. A major problem is that these measures do not take into account the environmental degradation and resource depletion associated with the economic production processes. As a result, policies based on these measures cannot ensure sustainability, particularly in countries largely dependent on natural resources, due to the confusion between increases in national income and decline in national wealth (Repetto, 2007). For two decades, efforts have been made by scholars and government agencies around the world to develop and implement green accounting, a system accounts for changes in natural resource stocks and environmental pollution. 
The theory behind green accounting is the same as that of the Net National Product (NNP). The NNP adjusts GDP for the depreciation of fixed capital assets. Weitzman (1976) has shown that NNP is the maximum welfare attainable along a competitive trajectory for an economy. Weitzman's treatment of NNP has been extended by Solow (1986) to include exhaustible resources, and by Hartwick (1990) and Maler (1991) who consider renewable resources and pollution. The Hartwick-Maler-Solow-Weitzman framework forms the theoretical foundation for natural resource and environmental accounting (Hrubovcak et al., 2000).

Solow (1993) suggests that when the NNP framework is applied to nonrenewable resources and environmental assets such as clean air and water, green accounting should provide a proper measurement of stocks and flows in a linked economic and natural system so that policies (i.e., productive investment) may be developed to preserve productive capacity for the indefinite future.

The implementation of green accounting involves two primary tasks. The first is to measure, in physical units, the changes in environmental quality, natural resource stocks, and other ecosystem services (de Groot et al., 2002). Next, shadow prices for environmental quality, resource stocks, and ecosystem services must be estimated. With both the quantity and price estimated, the green account framework can properly charge the economy for the consumption of its resource endowment (e.g., depletion of exhaustible resources) and depreciate its environmental quality stock.

Considerable progress has been made in many parts of the world in documenting the stocks and flows in marine pollution discharges and resource deletion in recent decades (Repetto, 2007). In contrast, environmental and resource valuation has been more challenging and controversial. This is because (1) many of these environmental and ecological services are not traded in markets; (2) shadow values (rents) of natural resources are functions of resource conditions that are affected by management institutions (Freeman, 1991); (3) ecosystems are very complex with multiple links and feedbacks.

Efforts in developing green accounting in many countries around the world have shown that it is possible at reasonable cost and time to construct meaningful accounts that capture important resource trends. Information from these accounts is quantitatively important for resource management and economic policy decisions (Repetto, 2007). Examples of green accounting studies in marine industries and for coastal regions include fisheries resource accounts for Malaysia (Tai et al., 2000) and for Iceland (Danielsson, 2005); and a comprehensive resource accounts for Costa Rica (Solorzano et al., 1991).

\section{Economic Impact Analysis}

Economic impact analysis comprises positive studies of changes in an economy, through factors affecting either supply or demand in established markets. Economic impacts typically are analyzed through the use of models that link sectors of the economy in patterns of trade (viz., Donohue Institute, 2006). These linkages can be used to understand how changes in one industry sector may ripple through other sectors, affecting not only trade patterns but also employment and consumer spending. The more sophisticated models can be used to understand how changes in consumer demand, development in an industry sector, or government policies can affect sales, employment, tax receipts, and other indicators of economic performance. While these measures often are closely monitored by policymakers, economic impact analysis should not be used to make normative decisions about the most efficient or rational policies (Propst and Gavrilis ,1987). The further development of economic impact analysis to incorporate changes in economic surpluses holds the promise of its use in normative decisions.

\section{Input-Output modeling}

The input-output model of economics was developed by Wassily Leontief. A model of this type can be represented as a system of linear equations, and the principles of linear algebra can be used to solve for the values of interest. The major advantage of the input-output model is its explicit inclusion of all the links across a large number of industrial sectors. For example, suppose a fisheries management option requires a reduction in the number of fishing vessels in a fleet. To capture the full effect of this reduction, we need to quantify the economic importance of the industry to the economy of a region. Fisheries 
contribute to employment and to household incomes. Port buildings and equipment also provide a basis for tax revenues that support local and state government programs. In addition, as purchasers of inputs, the fishing industry supports a number of other industries such as boat-building and repair. When all the links within the economy are considered, income and employment generated by the fishing industry have ripple effects on the overall income and employment of the region.

An input-output model answers the following question: given a specified shift in the level of final demands for economic goods and services, how do the levels of output from each of the industrial sectors of the economy change? The model is useful because it provides a map of the links between industrial sectors. The scale of these links can be summarized by one or more of a family of measures known as "multipliers."

Input-output analysis is theoretically consistent with the kind of welfare analysis represented by a neoclassical growth model. This is because the coefficients of an input-output model are derived from complete income and product accounts for an economy, which include net national product (NNP) (Millar and Blair 1985). Notwithstanding this consistency with macroeconomic welfare theory, it is clearly understood among economists that the input-output model is not designed to guide resource allocations, since the framework does not fully capture consumer surplus gains or losses.

Since the late 1960s, input-output models have been extended to incorporate links to environmental or natural resource sectors. Most of them have been concerned with the effects of pollution from one or more industrial sectors on the output of other sectors (e.g., Ayres and Kneese, 1969; Leontief, 1970; Førsund and Strøm, 1976; Lee, 1981; Perrings, 1987). Xie (2000) describe the concept and application of an environmentally extended social accounting matrix for environmental policy analysis. Typically, resource inputs and pollutants are included in policy models in physical units.

Input-output models have been widely used in regional economic impact analyses (Loomis, 1993). A small number of studies have examined the economic impact of fisheries and marine-related activities in New England (Briggs et al., 1982; Grigalunas and Ascari, 1982; Andrews and Rossi, 1986; Steinback, 1999). Another use of the input-output model is to assess ocean's contribution to national or regional economies, a research subject pioneered by Pontecorvo et al. (1980). Examples of these studies include an analysis of marine economic activities associated with the Northeastern Shelf Large Marine Ecosystems (Hoagland et al., 2005) and an assessment of the coastal marine economies of Massachusetts (Donahue Institute, 2006).

\section{Computable General Equilibrium (CGE) modeling}

Computable general equilibrium (CGE) models use empirical data to estimate how an economy might react to changes in policy, technology or other external factors. Like the input-output model, a CGE model includes multiple sections in an economy. However, it is significantly different from the input-output model in that the CGE framework explicitly models factor and product markets in the economy by including supply and demand functions for relevant factors and products. Thus, the welfare effects (changes in surpluses) of changing prices associated with changing production quantities may be assessed in a CGE model. A CGE model can be used to examine economic efficiency. The CGE model is useful for normative analysis because it explicitly includes utility maximization by consumers and profit maximization by producers in the economy.

Førsund (1985) presents a framework that captures the major interactions between economic activities and the environment/ecosystem in an economy, including consumption, production, waste generation and treatment, natural decomposition, natural resources, and ecosystem condition. In this type of analysis, natural resource inputs and pollution are not necessarily expressed in monetary terms.

Although CGE models have been widely used for policy analysis in recent years, their potential use in ecosystem valuation in coastal environments has been incompletely explored. Results of a preliminary review of recent resource and environmental CGE models suggest that, although most models have been specified at the national level, there have been efforts to develop models for local or regional decision- 
making at the county (Seung et al., 2000) and even municipal levels (Taylor et al., 1999). In addition, many CGE models include environmental and resource sectors for environmental policy analysis (viz. Abler et al., 1999; Xie et al., 1996). Although many CGE models are static, there have been attempts to develop dynamic models to examine policy effects over time (Seung et al., 2000).

\section{Economic-Ecological modeling}

Increasingly, economists and ecologists have recognized the value to public policy of combining information and results from each discipline into multidisciplinary studies. Bockstael et al. (1995) describe a comprehensive approach for ecological economic modeling and ecosystem valuation for the Patuxent River drainage basin in Maryland. These authors argue that two salient features of ecological models, dynamics and spatial disaggregation, are important for modeling the economy as well. The two types of models often differ, however, in terms of time step, geographic scale, and level of aggregation. In Bockstael et al.'s (1995) analysis, the two types of models are developed in parallel and at their own levels of specificity. The two types of models exchange information on their respective ecological and economic elements. For example, specific environmental and natural resource parameters may be calculated by the ecological model and then used as input parameters for the economic model.

Jin et al. (2003) present a methodological approach that links economic and ecological analyses. Specifically, they develop an economic-ecological model by merging an input-output model of a coastal economy with a linear model of a marine food web (Hannon, 1973). The authors present a numerical example for the New England region using coastal economic and marine ecological data from the region for a restricted set of industry sectors and food web trophic levels. The approach can be extended to incorporate the full range of sectors in the economy and trophic levels in a linked ecosystem.

Finnoff and Tschirhart (2008) develop a framework linking a dynamic economic CGE and a dynamic general equilibrium ecosystem model (GEEM). In their analysis, a CGE model of the Alaska economy is linked to an eight-species marine ecosystem. Two ecosystem services, commercial fishing and marine mammal tourism, are the linkages between the economic and the ecological systems. Variables as output from the CGE model serve as input parameters into GEEM, and vice versa. The study shows that when economic activity draws upon one ecosystem service, it will inevitably affect other ecosystem services. A standard bioeconomic model would not include the impacts of fish harvesting on the tourism industry. A CGE model that included both the fishing and marine mammal tourism but did not include the ecosystem connections between the fish and mammals, would not account for the ecosystem externality that fish harvesting has on tourism. The linked CGE and GEEM capture interactions within the eight-species ecosystem and interactions within the regional economy.

Most classical bioeconomic models involve the dynamic control of nonlinear biosystems. Because of complexity, these models include a small number of variables (e.g., biomass and either fishery yield or fishing effort). The advantage of the approach is that it can be used to conduct both positive and normative analyses. Linear economic models (e.g., input-output models) can handle a large number of variables (industry sectors). However, the input-output approach often is limited to positive (descriptive) studies in a static framework. The input-output models are unable to develop welfare estimates that are relevant for policy analysis.

The challenge is to develop a useful economic sub-model that captures several key economic sectors related to the ecosystem and to examine the normative aspects of the integrated system. The CGE approach moves in the direction of a useful economic model that may be employed for normative analyses. A fundamental tradeoff exists between the number of variables and the nonlinear dynamics. In addition, the information need for a CGE model is considerable. Building a CGE model is labor intensive and requires numerous assumptions (Finnoff and Tschirhart, 2008). As a consequence, we must carefully examine linkages between ecological and economic systems for a specific study region in order to identify the key economic sectors to be modeled explicitly so that the resulting model is useful for management policy analysis. 


\section{References}

Clark, C.W. 1985. Bioeconomic Modeling and Fisheries Management. John Wiley \& Sons. New York.

Clark, C.W., and G.R. Munro. 1975. The economics of fishing and modern capital theory: a simplified approach. Journal of Environmental Economics and Management 2:92-106.

Donahue Institute. 2006. An Assessment of the Coastal Marine Economies of Massachusetts. Massachusetts Office of Coastal Zone Management Report 1. University of Massachusetts, Amherst, MA.

Finnoff, D., and J. Tschirhart, 2003. Harvesting in an eight-species ecosystem. Journal of Environmental Economics and Management 45(3):589-611.

Finnoff, D., and J. Tschirhart, 2008. Linking dynamic economic and ecological general equilibrium models. Resource and Energy Economics 30(2):91-114.

Gordon, H.S. 1954. The economic theory of a common-property resource: the fishery. Journal of Political Economy 62(2):124-142.

Hannon, B. 1973. The structure of ecosystems. Journal of Theoretical Biology 41:535-546.

Holland, D.S., J. Sanchirico, R. Johnston, and D. Joglekar. 2007. An introduction to the use of economic analysis in ecosystem based management for coastal waters: an application to Massachusetts. Portland, ME: Gulf of Maine Research Institute (30 September).

Jin, D., P. Hoagland and T.M. Dalton. 2003. Linking economic and ecological models for a marine ecosystem. Ecological Economics 46(3):367-385.

Plourde, C.G. 1970. A simple model of replenishable natural resource exploitation. American Economic Review 60:518-522.

Pontecorvo, G., M. Wilkinson, R. Anderson, and M. Holdowsky. 1980. Contribution of the Ocean Sector to the United States Economy. Science 208: 1000-1006.

Propst, D.B., and D.G. Gavrilis. 1987. Role of economic impact assessment procedures in recreational fisheries management. Transactions of the American Fisheries Society 116:450-460.

Raffensberger, C., and J. Tickner, eds. 1999. Protecting Public Health and the Environment: Implementing the Precautionary Principle. Island Press, Washington, DC.

Repetto, R. 2007. Comment on environmental accounting. Ecological Economics 61:611-612.

Schaefer, M.B. 1957. Some considerations of population dynamics and economics in relation to the management of marine fisheries. Journal of the Fisheries Research Board of Canada 14:669-81.

Smith, V.L. 1969. On model of commercial fishing. Journal of Political Economy 77:181-198.

Solow R. 1993. An almost practical step toward sustainability. Resources Policy 19(3):162-172.

Sunstein, C.R. 2008. Precaution and nature. Daedalus 137(2): 49-58.

Thompson, P.M., B. Wilson, K. Grellier, and P.S. Hammond. 2000. Combining power analysis and population viability analysis to compare traditional and precautionary approaches to conservation of coastal cetaceans. Conservation Biology 14(5):1253-1263. 
Table 1. Non-market valuation methods (Holland et al., 2007).

\begin{tabular}{|c|c|c|c|}
\hline Type of Method & Method & $\begin{array}{l}\text { Measures } \\
\text { Nonuse } \\
\text { Values? }\end{array}$ & Description \\
\hline \multicolumn{4}{|l|}{ Revealed Prefereoce } \\
\hline & $\begin{array}{l}\text { Recreation Demnd } \\
\text { Models }\end{array}$ & No & 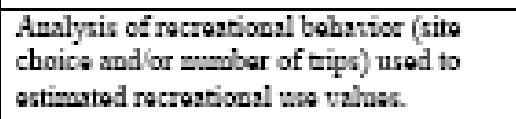 \\
\hline & $\begin{array}{l}\text { Hedonic Property } \\
\text { Value Nethods }\end{array}$ & No & 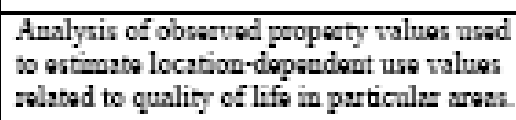 \\
\hline & $\begin{array}{l}\text { Hedonic Wage } \\
\text { Nethods }\end{array}$ & No & 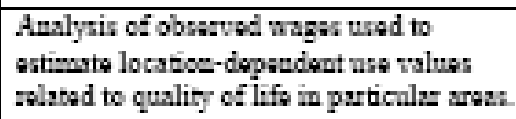 \\
\hline & $\begin{array}{l}\text { Defensive Behavior } \\
\text { Nethods }\end{array}$ & No & 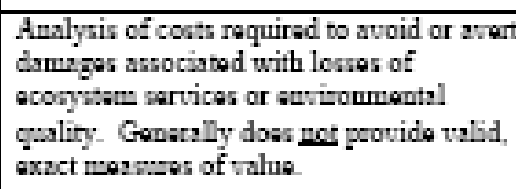 \\
\hline \multicolumn{4}{|l|}{ Stated Preference } \\
\hline & Contingen: Valuation & Yes & $\begin{array}{l}\text { Analysis of open-endad williegzass to puy } \\
\text { wevoy çastione. }\end{array}$ \\
\hline & $\begin{array}{l}\text { Contingent Choice/ } \\
\text { Ranking }\end{array}$ & Yes & 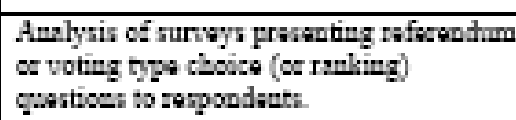 \\
\hline & $\begin{array}{l}\text { Choice Experiments / } \\
\text { Modeling }\end{array}$ & Yes & 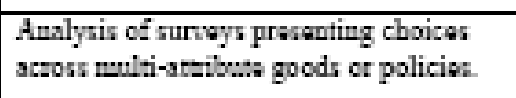 \\
\hline \multicolumn{4}{|l|}{ Other / Hybrid } \\
\hline & $\begin{array}{l}\text { Bcological } \\
\text { Prodactivity Methods }\end{array}$ & Sonetimes & 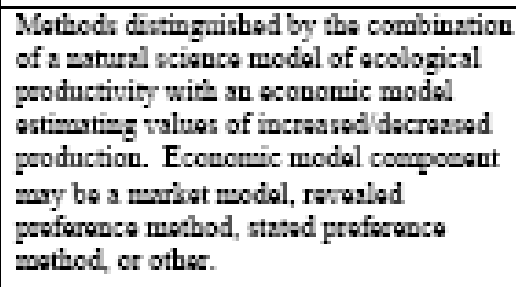 \\
\hline & $\begin{array}{l}\text { Revenled / Stated } \\
\text { Preference Techriques }\end{array}$ & Sonetimes & 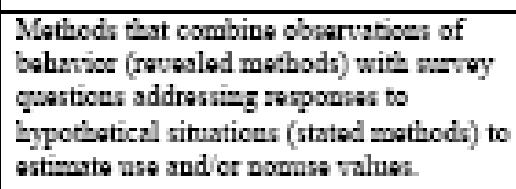 \\
\hline & Bemefit Transfer & Sometimes & 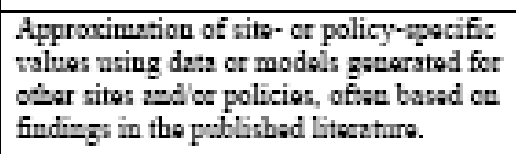 \\
\hline
\end{tabular}

